Southern Methodist University

SMU Scholar

Anthropology Theses and Dissertations

Anthropology

Spring 5-18-2019

\title{
"I Am Not My Illness!": Navigating the Mental Healthcare System in New Orleans
}

Saira Mehmood

Southern Methodist University, smehmood@smu.edu

Follow this and additional works at: https://scholar.smu.edu/hum_sci_anthropology_etds

Part of the Social and Cultural Anthropology Commons, and the Sociology Commons

\section{Recommended Citation}

Mehmood, Saira, "'I Am Not My Illness!": Navigating the Mental Healthcare System in New Orleans" (2019). Anthropology Theses and Dissertations. DOI: https://doi.org/10.25172/td/14474183

https://scholar.smu.edu/hum_sci_anthropology_etds/8

This Dissertation is brought to you for free and open access by the Anthropology at SMU Scholar. It has been accepted for inclusion in Anthropology Theses and Dissertations by an authorized administrator of SMU Scholar. For more information, please visit http://digitalrepository.smu.edu. 
“I AM NOT MY ILLNESS!”: NAVIGATING THE

\section{MENTAL HEALTHCARE SYSTEM}

IN NEW ORLEANS

Approved by:

Prof. Caroline Brettell

Professor of Anthropology

Prof. Anne M. Lovell

Senior Research Scientist (Anthropologist)

Prof. Nia Parson

Associate Professor of Anthropology

Prof. Carolyn Smith-Morris

Associate Professor of Anthropology 
"I AM NOT MY ILLNESS!": NAVIGATING THE

\section{MENTAL HEALTHCARE SYSTEM}

IN NEW ORLEANS

A Dissertation Presented to the Graduate Faculty of the

Dedman College

Southern Methodist University

in

Partial Fulfillment of the Requirements

for the degree of

Doctor of Philosophy

with a

Major in Anthropology

by

Saira A. Mehmood

M.A., Anthropology, Southern Methodist University, Dallas

May 18, 2019 
Copyright (2019)

Saira A. Mehmood

All Rights Reserved 
"I Am Not My Illness!": Navigating the

Mental Healthcare System

in New Orleans

Advisor: Professor Caroline Brettell

Doctor of Philosophy conferred May 18, 2019

Dissertation completed April 25, 2019

This research examines the experiences of individuals diagnosed with chronic mental illnesses and how they navigated the mental healthcare system in New Orleans, Louisiana. To realize the main research objective, I analyzed how individuals with chronic mental illnesses perceive mental illness and stigma; the services individuals use to address their mental health needs and the barriers they face in this process; who individuals disclose their mental illness to and under what contexts; and how individuals diagnosed with mental illness and their caregivers understand and embody recovery. Situated between medical anthropology and urban anthropology, it examines the challenges individuals diagnosed with chronic mental illness and caregivers encounter in utilizing mental health services.

Using critical race theory and studies on whiteness, I analyze the intersectional identities of individuals to understand how various axes of identities such as race, gender, age, and religion affect how people utilize mental health services, conceptualize stigma, how this is related to disclosure, and what recovery means to them. While I use stigma scales to measure various types of stigma, I triangulate this data with observations from participant-observation and interviews to reconceptualize stigma in what Tyler and Slater (2018) argue for approaching the social and 
political dynamics of stigma and acknowledging history. I do this through the use of stigma syndemics. Central to this is the role of mental health professionals and other key stakeholders, and how they interact with individuals utilizing community mental health services. I examine how past experiences such as trauma and incarceration limit access to housing programs, employment, and how this affects recovery.

Lastly, I argue that for effective advocacy on mental health to occur, synergistic activism through coalition building needs to transpire between all the entities that affect individuals who have mental illnesses. 


\section{TABLE OF CONTENTS}

LIST OF FIGURES $\quad$ x

LIST OF TABLES — xi

ACKNOWLEDGMENTS $\quad$ xii

CHAPTER 1: INTRODUCTION 1

Research Objectives and Overview of Theoretical Frameworks 3

$\begin{array}{ll}\text { Research Context } & 11\end{array}$

Diagnostic Controversies: A Note on Terminology 25

$\begin{array}{ll}\text { Overview of Chapters } & 26\end{array}$

CHAPTER 2: RESEARCH METHODOLOGY 28

Fieldwork and Research Sites $\quad 28$

Research Populations $\quad 41$

Research Methods $\quad 46$

Methodological Reflections on Fieldwork $\quad 51$

$\begin{array}{ll}\text { Conclusion } & 57\end{array}$

CHAPTER 3: STIGMA AND DISCLOSURE 58

Belief and Healing $\quad 59$

$\begin{array}{ll}\text { Reconceptualizing Stigma } & 62\end{array}$

$\begin{array}{ll}\text { The Effect of Stigma Perceptions on Disclosure } & 68\end{array}$

Institutionalized Stigma: Obstacles to Finding a Job 70 
$\begin{array}{ll}\text { Stigmatized "Productivity" } & 76\end{array}$

$\begin{array}{ll}\text { Nostalgia } & 78\end{array}$

$\begin{array}{lr}\text { Recovery } & 80\end{array}$

$\begin{array}{lr}\text { Conclusion } & 82\end{array}$

CHAPTER 4: MINORITY MENTAL HEALTH 85

Minority Mental Health Month 85

Trauma-Informed Care? $\quad 89$

Understanding of Illnesses or Medications $\quad 95$

$\begin{array}{ll}\text { The Sojourner Syndrome } & 97\end{array}$

Conceptualizing Mental Health Services $\quad 99$

$\begin{array}{ll}\text { Language Barriers } & 101\end{array}$

$\begin{array}{ll}\text { Conclusion } & 102\end{array}$

CHAPTER 5: MEDICAL PLURALISM: SPIRITUALITY AS MEDICINE 105

$\begin{array}{ll}\text { Support Services in the Community } & 107\end{array}$

$\begin{array}{ll}\text { Church Nurses } & 110\end{array}$

$\begin{array}{ll}\text { Cultural Sensitivity and Education } & 113\end{array}$

$\begin{array}{ll}\text { Spirituality as Medicine } & 114\end{array}$

$\begin{array}{ll}\text { Conclusion } & 115\end{array}$

CHAPTER 6: COUNTING CULTURE: CLINICIAN-PATIENT MATCHING 117

$\begin{array}{ll}\text { Jordan } & 118\end{array}$

$\begin{array}{ll}\text { Jessica } & 122\end{array}$

$\begin{array}{ll}\text { Danish } & 125\end{array}$

$\begin{array}{ll}\text { Clinician-Patient Matching } & 128\end{array}$ 
Recognition

Conclusion

CHAPTER 7: THE CHALLENGES OF CAREGIVING

Grace Martin

Debra Green

Anita Williams

Caregivers and the Therapeutic Process

Conclusion

Quentin Holmes

The Institutional Circuit

Affordable Housing Options in New Orleans

Navigating Housing Programs

Chronically Homeless

Permanent Supportive Housing

Short-Term Housing Options

Changes and Expansion of Medicaid Under the ACA

Conclusion: Fault Lines of Care 
APPENDIX A

APPENDIX B

APPENDIX D

208

BIBLIOGRAPHY

209 


\section{LIST OF FIGURES}

Figure 1: Inpatient Psychiatric Beds Pre- and Post-Katrina 13

Figure 2: Protest Outside of LSU Dentistry School to Save Southeast Hospital 17

Figure 3: Decision Tree Created by Mental Health Professionals 19

Figure 4: Local Governing Entities (LGEs) in Louisiana $\quad 20$

Figure 5: Clinic Locations for Metropolitan Human Services District 22

Figure 6: Jefferson Parish Human Services Authority Locations 23

$\begin{array}{ll}\text { Figure 7: Tina's Time Diary } & 98\end{array}$

Figure 8: Decision Tree for Caregivers 134

Figure 9: Permanent Supportive Housing Model 174 


\section{LIST OF TABLES}

Table 1: Breakdown of Various Field Periods and Methods

Table 2: Ethnicity and Gender of Individuals $\quad 42$

Table 3: Population in New Orleans and Jefferson Parishes 43

Table 4: Ethnicity and Gender of Caregivers 44

Table 5: Ethnicity and Gender of Mental Health Professionals, Legal Advocates, and Housing Advocates

Table 6: Correlation of Stigma Scales $\quad 64$

Table 7: U.S. Department of Labor Disability Identification Form 74

Table 8: Sample Instrument for Evaluating Decisional Capacity 208 


\section{ACKNOWLEDGMENTS}

Alhamdulillah! At times I did not think I would make it to this point, but this dissertation could not have been completed without the support from a community of people. First, I have to thank the staff and members at Vista, who allowed me into their lives and let this research be possible. I cannot name them, but their participation made this work not only feasible, but also enjoyable.

There are a number of professors who helped me make it this far. At Tulane, Dr. Stephen Selka (now at Indiana University Bloomington) and Dr. Trenton Holliday first got me interested in anthropology. Dr. Adeline Masquelier and Dr. Allison Truitt helped spark my interest in medical anthropology. The continued support of the Tulane anthropology department while I was conducting research in New Orleans was invaluable.

My committee members have been patient with my research and writing. Dr. Caroline Brettell helped me finish this project through the end. Dr. Carolyn Smith-Morris provided feedback and sources for me to think about how I was analyzing things. Dr. Nia Parson's Current Anthropological Literature class helped me decide what type of anthropologist I want to be.

Lastly, it was important for me to have a committee member who was familiar with and understood New Orleans. When she asked me which high school I attended in New Orleans at a AAA meeting, I knew Dr. Anne Lovell was the perfect person.

The late Dr. Robert Van Kemper and Dr. Victoria Lockwood helped me during my last semester of coursework during a time when I was unsure about my future. Their humanity has 
taught me how to approach students and to enjoy each day. Dr. Sarah Willen (now at the University of Connecticut) challenged me to think about medical anthropology in different ways. Dr. Diane Hardgrave (now at the College of Southern Nevada) taught me how to shatter stereotypes just by showing up, and I will always be grateful to have the guidance from another woman of color.

Furthermore, I could not have asked for a better cohort and group of friends at SMU including Sydney Yeager, Michaela Wallerstedt, and Dawn Crawford. Laura Jarvis and Carina Heckert constantly checked up on me, made sure I was eating, and made great traveling buddies. Afshan Kamrudin's writing group and weekly check-ins pushed me to make realistic goals and complete them. Nazia Hussain picked my brain and taught me to think about anthropology in different ways. Kerri Brown and her family provided constant support, entertainment, and a place to stay when I needed to make quick trips back to Dallas. Ashvina Patel's questions about AAA pushed me to think about how I could better serve students while I was on the board.

The colleagues I found in Tallahassee during the summer of 2017 still support, guide, and check in on me to this day. Erin Tooher, Judith Williams, Maya Kearney, Lilly Brown, and Ramon Lee keep my interest in anthropology alive and give me hope for the future of the discipline.

This research was made possible by various grants from the SMU Department of Anthropology, including the Robert Kemper Summer Research Fund and the Mary Moore PreDissertation Fund. The writing was possible through the AAA Minority Dissertation Fellowship. In New Orleans, Arnetha Torry, Jacqueline Woodward, and Victoria Roberts were interested in my research from beginning to end and supported me in numerous ways; I will always be grateful for their encouragement, feedback, and constant motivation. My colleagues at 
the Dryades Public Market kept me entertained during the writing process, and my friends at the Dryades YMCA made sure I maintained focus and showed up to practice job talks to help me work on my presentations. I will always be grateful to my activist friends in New Orleans, who helped me realize that I am an activist-scholar. They checked in on me, dropped off food when deadlines were close, and allowed me to think about my research in new ways.

Last but not least, I cannot forget my family. I owe them everything, especially my parents, Bilquis and Mohammad Mehmood. Their support and guidance was crucial during this journey. I am lucky to have two older brothers to learn from, and their children brought me entertainment and joy when I needed a break from research and writing. 


\section{CHAPTER 1 \\ INTRODUCTION}

On January 28, 2008, 24-year-old New Orleans Police Department (NOPD) officer Nicola Cotton approached Bernel Johnson, a man diagnosed with paranoid schizophrenia. Johnson, 44, was homeless, had spent much of his life in and out of institutions since his diagnosis at the age of 19, and had just been released from Southeast Louisiana Hospital in Mandeville a few weeks earlier, a psychiatric hospital famous for having former Louisiana Governor Earl K. Long as a patient in 1959. Nicola Cotton's encounter with Bernel Johnson ended with Johnson overtaking Cotton's gun, and shooting her 15 times, leading to her death. This story made national headlines and exposed the mental health crisis in New Orleans after Hurricane Katrina (Eaton 2008).

A little more than a year later, I interviewed for a fellowship at City Hall in New Orleans. I was finishing up my master's degree in anthropology at Tulane University and was interested in the fellowship program, designed to involve students who had graduated from high schools or universities in New Orleans to become more involved in government. During the interview for this fellowship, which was comprised of a committee of 15 individuals composed of professors from local universities, politicians, and community members, I was asked by one committee member, "How would you fix the mental health problems in the city?" The question caught me off guard because nothing on my application addressed mental illness or mental health services,

but I was aware of the healthcare context in New Orleans. It is easy to see Officer Nicola Cotton 
as the victim in this story. However, it is harder to see Bernel Johnson as a victim, but he is one. The mental healthcare system, one that was supposed to help him with his recovery, failed him. Nicola Cotton lost her life, but Bernel Johnson was declared "irrestorably incompetent" by a judge and will most likely spend the rest of his life in a forensic psychiatric hospital (Filosa 2010).

How do we prevent fates similar to Bernel Johnson? Could Nicola's death have been avoided? I often think of Nicola Cotton and Bernel Johnson when I am asked why I chose my dissertation topic. I ended up getting the fellowship I interviewed for at City Hall, and one of the projects I worked on examined mental health services in the city. However, much of the data I collected came from the perspectives of mental health professionals, whom I interviewed during the time of my fellowship working at City Hall between 2009 and 2010. Most of my time was spent trying to advocate for better mental health services with state legislators. What I was missing was the stories of individuals who were actually living with a mental illness, which is why I decided to go back to graduate school. These are the voices that need to be heard and which I amplify in my research. Mental health is usually not on the radar of politicians or discussed positively in the media; Bernel Johnson and Nicola Cotton's story, like others that involve gun violence, offers a good example. However, the link between gun violence and mental illness perpetuates a stigma that individuals with chronic mental illnesses are dangerous (Mehmood 2018). In fact, many of the people I encountered with mental illnesses, especially black men, were actually victims of gun violence. Epidemiological data show that among individuals with mental illness, they are more likely to be victims of violence "anywhere between 2 and 100 times more common than in the general population" (Bhavsar and Bhugra $2018,811)$. From a legal perspective, there is a significant difference between individuals in 
psychosis and individuals in crisis. Under Louisiana State law (Louisiana State Legislature RS 28:53 n.d.), individuals are in crisis if they: 1) are in psychosis; 2) are gravely disabled to the point where they cannot take care of themselves; and 3) are a danger to themselves or others. Bernel Johnson would have met the criteria of someone in crisis. Yet, he was released from a psychiatric hospital not long before his encounter with Nicola Cotton. Between the time Bernel Johnson was released from Southeast Louisiana Hospital and his encounter with Officer Nicola Cotton, he may have been stable at some point, but it is unlikely he received outpatient treatment to prevent psychosis again.

The "mental health problems" mentioned in my interview for the City Hall fellowship referred to a range of problems within the mental healthcare system in New Orleans. Nicola Cotton and Bernel Johnson's story just highlighted one aspect. In the immediate years after Hurricane Katrina in 2005, the number of inpatient psychiatric beds were reduced, the number of deaths by suicide increased, there was a shortage of mental health providers, and the number of calls for the NOPD crisis unit increased significantly by 2009 (Mehmood 2010). The 2018 Mental Health America report ranked Louisiana 46 out of 51 in the U.S. for access to mental healthcare (Hellebuyck et al. 2018, 13).

\section{Research Objective and Overview of Theoretical Frameworks}

My main research objective was formulated to understand how individuals with chronic mental illnesses navigated the mental healthcare system in the New Orleans metropolitan area. To realize the main research objective, I analyzed how individuals with chronic mental illnesses perceive mental illness and stigma; the services individuals use to address their mental health needs and the barriers they face in this process; who individuals disclose their mental illness to 
and under what contexts; and how individuals diagnosed with mental illness and their caregivers understand and embody recovery.

Race was not an initial inquiry of my study. Using a grounded theory approach (Bernard $2011,435)$, it quickly became clear that race was a prominent theme during fieldwork. The way a black woman who grew up in the housing projects of New Orleans navigated the mental healthcare system was completely different from a white, upper-class woman who grew up in a prominent neighborhood in Uptown New Orleans. In a city where the population is prominently black, but where certain historically working-class neighborhoods are rapidly gentrifying, race is central to how people are stigmatized and access mental healthcare services. Thus, I use critical race theory and studies on whiteness theory as my primary frameworks. However, to these, I add an intersectional approach.

Intersectionality, coined by Kimberlé Crenshaw in discussing black feminism, argued that the experience of being a black woman could not be understood in independent terms of either being black or a woman; instead, it needed to include interactions between the two identities which often reinforce one another and other axes of identity (Crenshaw 1989). The framework of intersectionality "discredits the idea that the single axis of race — whiteness—can capture the multidimensional nature of oppression and experiences" (Chen 2017, 19). In other words, intersectionality emphasizes the simultaneity of how race, gender, and class intersect in people's lives, and can capture more aspects of the oppressed person's experiences than does one single axis of oppression. Coming from critical race theory, Crenshaw's work is based in legal studies. As Burton (2009) and Chen (2017) point out, critical race theory often centers its focus on race/ethnicity, is often conducted by researchers who identify as people of color, with research conducted on people of color, with methodological traditions based on storytelling, 
counter-stories which tell the stories of individuals whose experiences are not often told (Solórzano and Yosso 2002), oral history, ethnography, and participatory action research.

In contrast, studies of whiteness emerged primarily from labor history, and among researchers who generally identify as white, with research conducted on white people, and the methodological tradition is often textual analysis, discourse analysis, and in-depth interviewing (Chen 2017). Whiteness studies grew out of the ambition to purge racism and white privilege (Chen 2017). While whiteness studies often only focus on a single axis of oppression (race/whiteness), scholars of whiteness studies who focus on the experiential approach illustrate the benefits of having white privilege (DiAngelo 2018). While critical race theory and whiteness theory emerged from different disciplines, they also have similarities: both emphasize how white supremacy works and share a common goal to achieve racial equality (Chen 2017).

I use both scholarship from critical race theory and whiteness theory to situate how people navigate and experience mental health services in the New Orleans metropolitan area. While it may seem like critical race theory and whiteness theory are at odds with each other, given the demographics of the area in which I conducted fieldwork, using both of these frameworks allows me to examine intersectionality for the people of color I interviewed but also white privilege simultaneously. For individuals with chronic mental illness who come from lowincome or marginalized communities, race, gender, class, sexuality, religion, and other axes of identity play a significant role in how they seek and perceive mental health services.

Furthermore, to survive as a person of color (and especially a black person) in the U.S., requires some expertise regarding whiteness. This became apparent throughout my fieldwork, notably in how individuals approached or avoided the police, often the first entity people call during times 
of crisis; the disparities by race amongst my interlocuters who were incarcerated were significant.

\section{Anthropological Approaches to Race}

Anthropology has had a long engagement with the concept of "race," but the ideas have changed over time. The foundations of racial ideology began in the $18^{\text {th }}$ century and evolved in the American colonies and later throughout the territories of colonizing countries of Western Europe (Smedley1998, 694). The concept of race emerged as a social classification that reflected the idea of "human separateness and differences," but its real meaning rested in social and political realities (Smedley 1998, 694). Race "developed in the minds of some Europeans as a way to rationalize the conquest and brutal treatment of Native American populations, and especially the retention and perpetuation of slavery for imported Africans" (Smedley 1998, 694).

Europeans justified their attitudes toward human differences by focusing on the physical features of non-European populations: they exaggerated their differences, concluded that Africans and Indians and their descendants were lesser forms of human beings, and believed their inferiority was natural and God-given (Smedley 1998, 694).

Although not professional anthropologists, Samuel Morton, Josiah Nott, and Louis Agassiz were the most influential scholars of anthropology in North America who supported the polygenesis perspective (Baker 1998, 14), which argued that races were separate biological species as the descendants of different Adams, and the races have not changed since creation (Gould 1981, 39). Their studies and publications were repeatedly published and often used by $19^{\text {th }}$ century anthropologists to demonstrate the superiority of white males over all other groups of humanity and perpetuated racist ideology. 
Franz Boas and his students played a role in discussions of race. In his collection of essays in Race, Language, and Culture (1940), Boas argued that the measures polygenists used such as the cephalic index (ratio of head width to head breadth) were not fixed but varied by environment, there was no such things as racial types, and he emphasized the plasticity of human anatomy. Boas' student, Ruth Benedict promoted cultural relativism, while combating ethnocentrism and racism intellectually and politically. To show that the concept of race was scientifically weak and politically destructive, Benedict wrote Race: Science and Politics (1982). Benedict's intent with this book was to reject the claims of superiority offered by racists (Benedict and Mead 1959), and she believed anthropologists had a duty to "expose the travesty of sober anthropological material which racism offers" (Benedict 1942, vii).

Despite these early considerations, Mullings (2005a, 670) has argued more recently that anthropological analysis of race and racism has "failed to become a major current in anthropology." The reasons attributing to the lack of critical studies of race and racism in anthropology, according to Mullings, include the fact that anthropologists still do not agree about the role of race and racism within the discipline or in society, and the focus on ethnicity "rather than analyzing how categories of race emerge and persist" contributes to the under-theorization of racism in anthropology $(2004,670)$. Mullings $(2005 \mathrm{a}, 670)$ states that while many cultural anthropologists have become "race avoidant" altogether to distance themselves from the negative consequences of biological racism, she warns that "race avoidant" anthropologists consequently ignore racism. In addition, Mukhopadhyay and Moses question if anthropology has actually discarded race as a valid scientific concept or if the "no-race policy of the past two decades has actually been a policy of no discussion of race by either physical or cultural anthropologists" (1997, 520-521). Because of the lack of open discussion and failure to introduce conversations 
about race to the public, Mukhopadhyay and Moses (1997) called for anthropologists to reestablish a dialogue on race. The response resulted in a dialogue from anthropologists in all four major subfields and two allied disciplines, published in a special series on race and racism in American Anthropologist (Sussman 1999) to address the possible ways in which the anthropological discourse on race could "become more holistic and amenable to the urgent needs and interests of the public" (Harrison 1999, 609).

According to Harrison, one important concern is "race's interaction with class and gender; race is always lived in class-and gender-specific ways" $(1995,63)$. Much of the work on intersectionality has come out of feminist theory scholarship (Collins 2000; Davis 1981; McCall 2005; Sacks 1989) as a response to the feminist movement's initial focus on "middle-class, White experiences" (Mohanty 1991, 7). By incorporating gender and class into race, anthropologists have illustrated how experiences of race are dynamic. With gender, feminist anthropologists critiqued early work for focusing on the white, middle-class experience (Mohanty 1991). Regarding class, issues in defining it bring challenges just as defining race and ethnicity do. Class in the Marxist perspective generally refers to owners of the means of production and the workers, but this system is not useful in North American analyses; however, the labels "lower class," "middle class," and "upper class" also impose challenges because the "vast majority of Americans think of themselves as "middle class"” (Ortner 1998, 8). Ortner argues that there is always "some sort of tendency to merge race/ethnic and class categories in American cultural thought," but class tends to be the last factor introduced as an explanation of privilege and power or poverty and impotence $(1998,13)$. Furthermore, Leslie McCall states that in the study of intersectionality, which she defines as "the relationships among multiple dimensions and modalities of social relations and subject formations," new methodological 
problems are introduced because there has been little discussion on how to actually study the variables $(2005,1771-1772)$. While studies on race that incorporate gender, class, and other factors provide a dynamic understanding in how complex variables of inequality interact, anthropologists studying race in North America have yet to develop new theoretical frameworks for how these variables actually articulate.

Situating this research most broadly within the fields of medical anthropology and urban anthropology, I examine mental health and the services people received at the intersections of race, class, and gender for several reasons. How do we address health disparities without a focus on race, class, gender, and other axes of identity? As Mullings and Schulz (2006, 3) argue, "Health disparities based on race/racism, class, and gender/sexism are matters of life and death." I examine how race intersects with stigma, disclosure, and how people access and experience the mental healthcare system in New Orleans. My contributions to medical anthropology here come through the framework of examining intersectionality with relation to mental illness. With exceptions such as Jonathan Metzl's book The Protest Psychosis: How Schizophrenia Became a Black Disease (2009) and Emily Martin’s article, “Moods and Representations of Social Inequality" in the Gender, Race, Class, and Health: Intersectional Approaches volume (Schulz and Mullings 2006), few anthropologists have looked closely at the relationship between mental illness, health disparities, and intersectionality. Approaches to Stigma

In his work on stigma, Goffman (1963) distinguishes between stigmata that are "discrediting" and those that are "discreditable." While discrediting attributes are immediately apparent to others, discreditable attributes are not visible or readily apparent (Goffman 1963, 4). Mental illness is often conceptualized as a discreditable attribute that is not readily apparent to 
others; thus, individuals with mental illness, a non-visible stigma, change from "normal" to a "discredited" status if they disclose their condition or if others perceive their behavior as "crazy" (Yang et al. 2007, 1527). Like Goffman, Crocker et al. (1998) define stigma as a characteristic of the individual and describe stigma as a devaluing social identity. However, Crocker et al. (1998) observe that stigma is not located entirely within the stigmatized person, but occurs within a specific social context.

Other literature provides accounts of various forms of stigma and methods to measure them including (1) self-stigma, (2) perceived stigma, and (3) experienced stigma. Corrigan and Watson (2002) use the term public stigma to describe the ways in which the general public stigmatizes individuals with mental illness; they describe self-stigma as the internalization of this public stigma. Self-stigma can also be defined as the product of internalization, blame, hopelessness, guilt, and fear of discrimination associated with mental illness (Corrigan and Watson 2002). In addition, LeBel (2008) and Brohan et al. (2010) state that perceived stigma can include what an individual thinks most people believe about the stigmatized group generally and how the individual thinks society views him/her personally as a member of the stigmatized group. Experienced stigma can be defined as the experience of actual discrimination for the person affected (Van Brakel et al. 2006).

Tyler and Slater (2018) argue that the conceptual understanding of stigma inherited from Goffman, along with the psychological research methods of stigma research, often ignore questions about where stigma is produced, by whom, and for what purposes. Furthermore, Tyler and Slater $(2018,721)$ state that the social and political questions are often missing from studies on stigma such as, "how stigma is used by individuals, communities and the state to produce and reproduce social inequality.", One way to approach the social and political questions is by 
incorporating the use of stigma syndemics, which Singer, Ostrach, and Lerman $(2017$, vii) use to look at how social stigmas are enacted and perpetuated through structural forces which drive “disease-disease and other biological or behavioral interactions that worsen health outcomes and increase suffering." For those incarcerated, usually black men, the combination of previous incarceration and mental illness adds another layer of stigma, often leading to some form of inequity.

\section{Research Context}

A comprehensive research context in New Orleans and Louisiana provides an understanding of the mental healthcare system and challenges residents face. Before Hurricane Katrina, the mental healthcare system in New Orleans was essentially a "two-tier" system, where those with health insurance had access to private community hospitals and clinics, while the "poor and uninsured were cared for mainly through the Medical Center of Louisiana at New Orleans" (MCLNO), which included Charity and University Hospitals, part of the state-wide Charity Hospital system, and clinics associated with Louisiana's Office of Mental Health ${ }^{1}$ through the Metropolitan Human Services District (Calderón-Abbo 2008, 304). Following Hurricane Katrina in August 2005, the State of Louisiana never reopened Charity Hospital, also commonly referred to in New Orleans as "Big Charity." Big Charity was a 270-year-old institution, the safety net hospital for the poor, and one of 10 total acute care hospitals in the State of Louisiana that was part of the public hospital system. The entire third floor of Big Charity was devoted to psychiatry, with 97 beds (Mehmood 2010). With the closure of Big

\footnotetext{
${ }^{1}$ Louisiana's Office of Mental Health was renamed as the Office of Behavioral Health (OBH) by Act 384 during the 2009 Legislative Session. Act 384 directed "the consolidation of the offices of addictive disorders and mental health into the Office of Behavioral Health effective July 1, 2010 in order to streamline services and better address the needs of people with co-occurring mental illness and addictive disorders" (OBH 2018a).
} 
Charity, along with the closure of inpatient psychiatric units at for-profit hospitals such as Tulane Medical Center, the number of psychiatric beds in the New Orleans metropolitan region ${ }^{2}$ had been significantly reduced; child and adolescent beds decreased by $27.6 \%$, adult beds by $54.7 \%$, geriatric beds by $41.6 \%$, and medical detoxification beds had decreased by $2.9 \%$ by 2009 (Mehmood 2010). Each type of psychiatric bed in the metropolitan region decreased significantly after Hurricane Katrina, with the exception of medical detox beds. These reductions in services would be devastating enough to the populations they serve in regular times, let alone during a time of crisis post-Katrina. I focus on inpatient beds here because every time I asked mental health professionals what type of services the city needed, they would always identify the need for more hospital psychiatric beds, and this was just one variable reflecting Katrina's impact on mental healthcare services. Figure 1 illustrates the reduction in inpatient psychiatric beds in New Orleans and the metropolitan area from 2004 (the year before Hurricane Katrina) to five years later in 2009 .

\footnotetext{
${ }^{2}$ I identify the New Orleans metropolitan region as the four parishes that make up Southeast Louisiana: Orleans Parish, Jefferson Parish, St. Bernard Parish, and Plaquemines Parish. Orleans Parish has the same boundaries as the city of New Orleans. Parishes are the equivalent of counties in other states.
} 


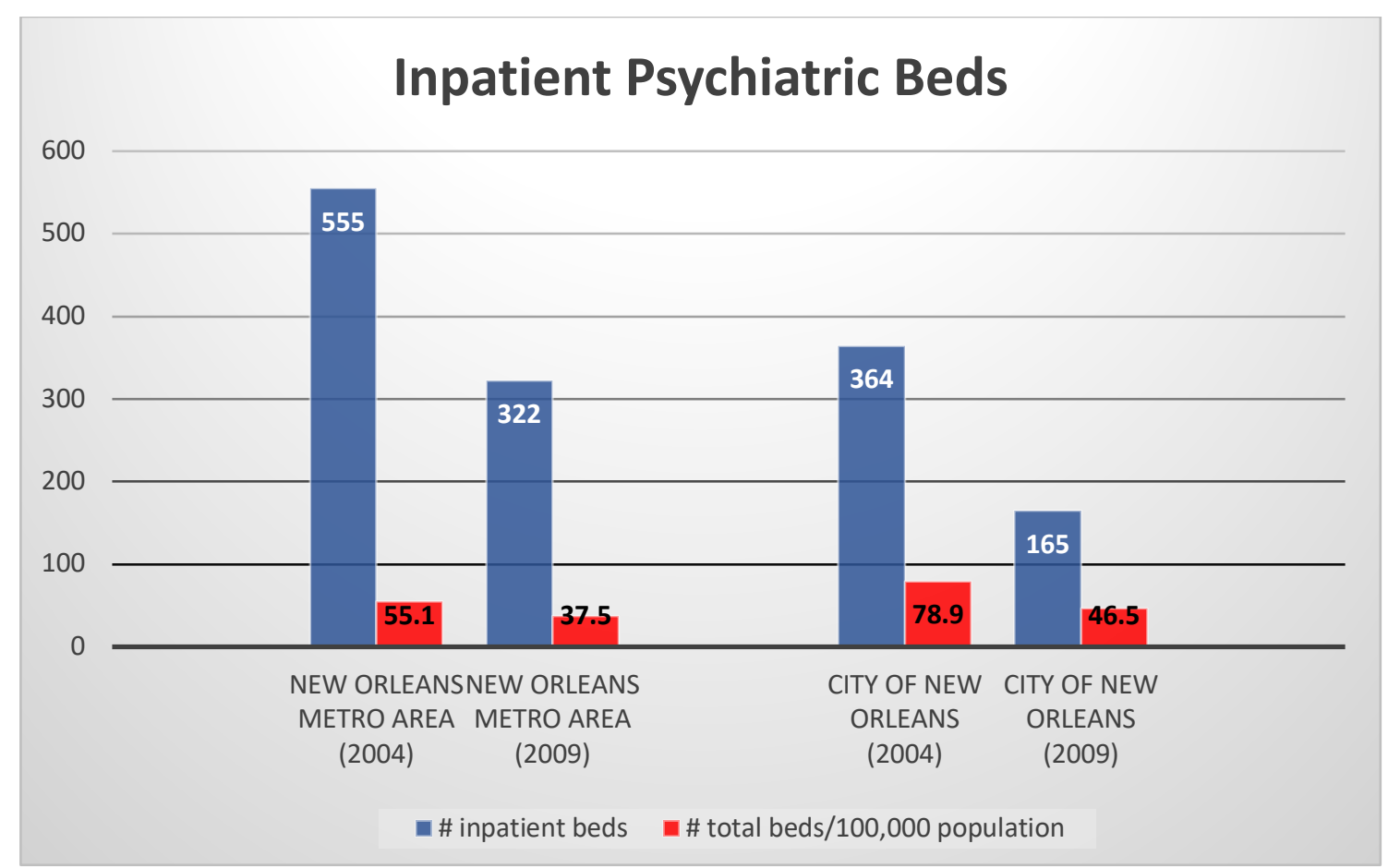

Figure 1: Inpatient Psychiatric Beds Pre- and Post-Katrina

With an ongoing claim with the Federal Emergency Management Agency (FEMA) in the years following Hurricane Katrina, Louisiana State University (LSU), which operated Big Charity, argued that the hospital was damaged by more than fifty percent. The amount of damage determined whether Big Charity would be renovated or if a new hospital would be built and how much money LSU would get from FEMA for the new hospital. The lower floors of Big Charity flooded after the levees breeched, as did the surrounding area in Downtown New Orleans. As Anne Lovell writes $(2011,259)$ :

During the days after evacuation from Charity Hospital, doctors, nurses, other medical personnel, and volunteers worked alongside the 82nd Airborne, Seabees, and the Oklahoma National Guard to drain, clean, and repair enough of the flooded basement and other hospital areas to reopen three floors. Shortly afterward, hospital administrators officially closed the hospital, without going through the state legislature, as required by law. 
Even though surrounding buildings which also flooded next to Big Charity were reopened, including one of LSU's medical school buildings, Big Charity remained closed. Despite evidence that Big Charity was ready to reopen in the weeks after Hurricane Katrina, as shown in the documentary Big Charity: The Death of America's Oldest Hospital (Glustrom 2014), the State of Louisiana pushed for a new hospital and got one. In 2015, with funds from FEMA, a new 1.2billion-dollar hospital, University Medical Center (UMC), opened in Lower Midcity, 10 years after Hurricane Katrina. Psychiatry in UMC has as total of 60 adult beds, with three units: a 30bed Acute Stabilization Unit for patients with diagnoses such as schizophrenia or experiencing psychosis, a 15-bed Mood Disorders Unit for patients with Major Depression or Bipolar Disorder, and a 15-bed Addiction Disorders Unit for patients with addiction and a concurrent psychiatric disorder (UMC 2019).

UMC, operating as a public-private partnership, offers a good example of how mental health services can be impacted by disaster capitalism, which is "the total collapse of infrastructure and social services" produced by what Naomi Klein refers to as the "perfect conditions of 'schock,' -a collapse so severe as to authorize a new government arrangement in which the state contracts with private firms to provide services it previously provided" (Adams, Van Hattum, and English 2009, 616-617). Hurricane Katrina and the flooding which followed it produced a collapse so severe, it helped authorize these new government arrangements. Adams discusses how post-Katrina New Orleans was an example of how "public-sector interests became blurred with private sector opportunities" $(2013,13)$. Disaster capitalism enabled neoliberalism, which Gotham and Greenberg $(2008,1041)$ define as ideology that "rests on the doctrine that open, competitive and deregulated markets are the most efficient mechanism for economic development and social betterment." Gotham and Greenberg $(2008,1041)$ argue that neoliberal 
frameworks "filtered into major policy debates and constrained the formulation and implementation of post-disaster recovery programs." Neoliberalism became prevalent after Hurricane Katrina with the privatization of the other public hospitals in Louisiana. Lallie Kemp Regional Medical Center, in Independence, Louisiana, is the only remaining state-run hospital of the 10 safety-net public hospitals privatized since 2013 under former Governor Bobby Jindal's administration. These 10 public safety-net hospitals, part of the Charity Hospital system, were unique to Louisiana and had no counterpart in the U.S.; when other states were dismantling public hospitals in the 1960s, Louisiana was building more with its populist policies (Lovell 2014).

The closures of state psychiatric hospitals, separate from the Charity Hospital system, led to fewer mental health resources for individuals in Louisiana. In 2009, the state closed the New Orleans Adolescent Hospital (NOAH), a psychiatric hospital for children and adolescents that was located in Uptown New Orleans. The Louisiana Department of Health and Hospitals (DHH), in its plan to transform the public mental health system in the state, shifted services by merging its inpatient mental health beds at NOAH into Southeast Louisiana Hospital in Mandeville, Louisiana as a way to save money (Mehmood 2010). The premise for this change, according to the Louisiana DHH was to move closer to evidence-supported models, reducing the reliance on inpatient services while increasing services in the community setting for families (Mehmood 2010). However, outsourcing pediatric patients to Southeast Louisiana Hospital in Mandeville, about 40 miles from New Orleans on the north shore of Lake Pontchartrain, created other problems for residents in the New Orleans metropolitan area. For example, while pediatric patients were transported to Southeast Louisiana Hospital or to beds in other parts of Louisiana, their parents often did not have the transportation means to accompany their children, let alone to 
visit their hospitalized children, which is important for treatment and family support (Mehmood 2010).

Three years later, in 2012, the State of Louisiana closed down and sold Southeast Louisiana Hospital, which now operates as a private hospital. The state's decision to close Southeast Louisiana Hospital was premised on the idea that psychiatric services under a sustainable model were needed without reliance on large public hospitals and to make more efficient use of taxpayer dollars. However, the closure of Southeast Louisiana Hospital did not come without objection from mental health professionals. I attended a protest on July 31, 2012, largely joined by those affected by the mental healthcare system. Before Southeast Louisiana Hospital closed, the state closed Greenwell Springs earlier in 2012, another state psychiatric hospital in Louisiana, located north of Baton Rouge. While inpatient psychiatric care is not always considered best practice, without links to sufficient community-based outpatient treatment and other resources, the closures of the psychiatric hospitals left a gap in services that mental health professionals reiterated to me during interviews. 


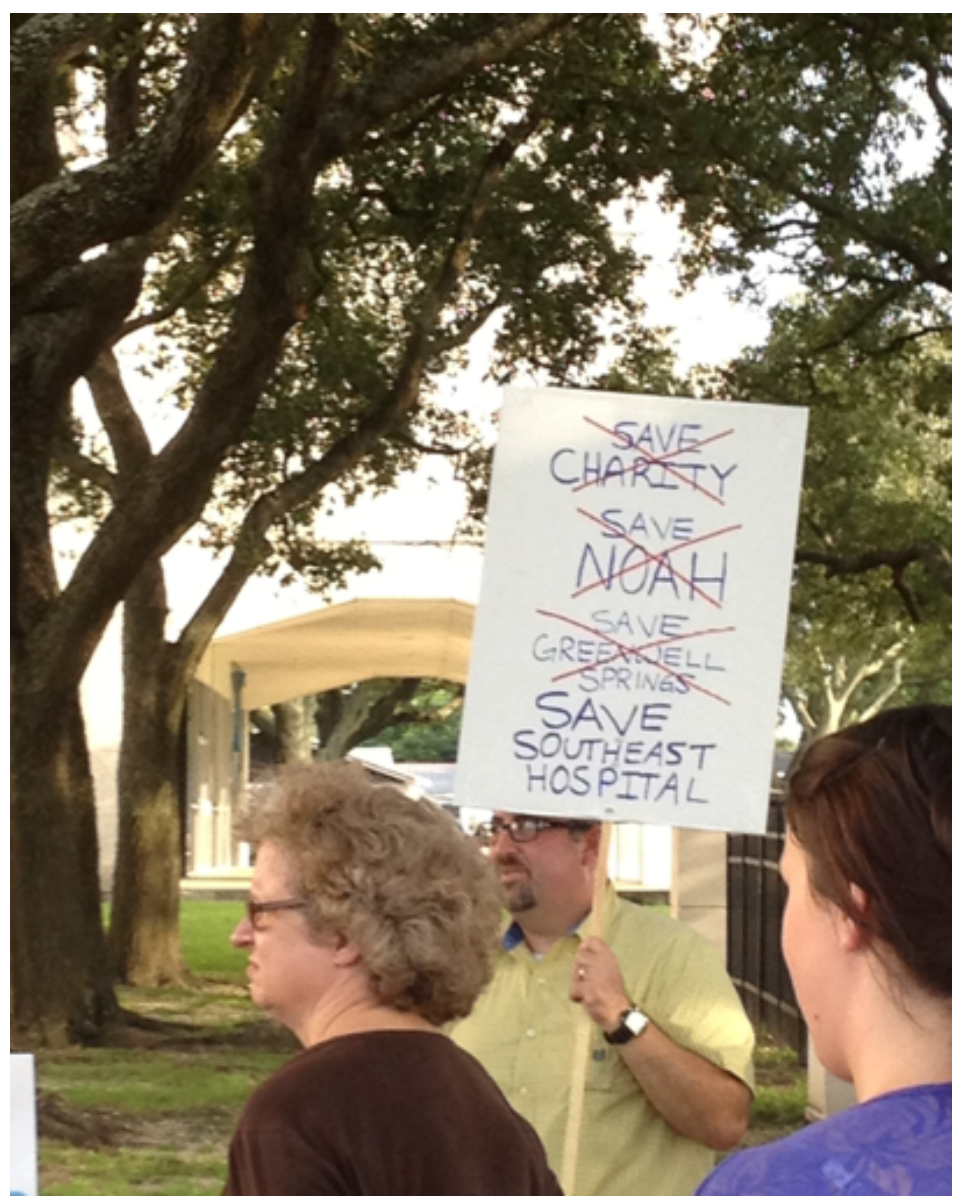

Figure 2: Protest outside of LSU Dentistry School to save Southeast Hospital

During the summer of 2012, I interviewed a psychiatrist who used to work at Southeast, who noted the immediate impact of the closures of these hospitals was the loss of beds and fewer resources as patients were shifted from one hospital to another in the state. The longer-term impact, he noted, would be fewer psychiatrists in the state and in New Orleans. Those receiving training in the psychiatry residency programs of the two medical schools in New Orleans, LSU and Tulane, received much of their training from these hospitals. With the shift to public-private partnerships, which is how University Medical Center operates, the fate of residency programs would become uncertain. He also noted that one in four professional psychiatrists left New Orleans after Katrina, and those who did stay are aging. This makes it more difficult for individuals seeking psychiatrists in private practice in New Orleans. 


\section{Current Behavioral Health Services in Louisiana}

Under the Louisiana Department of Health, the Office of Behavioral Health $(\mathrm{OBH})$ provides services to Louisiana residents with mental illness and addictive disorders. OBH coordinates between other agencies and partnering entities to deliver and manage components of care for the behavioral health population through acute units, behavioral health clinics, and inpatient psychiatric facilities (OBH 2018b). Services through acute units are provided through various private and public hospital acute care programs including psychiatric, psychosocial, and medical services. According to the $\mathrm{OBH}$, "these units are closely linked to community-based services and support networks so patients can return to their homes faster and with greater continuity of care" (OBH 2018b). However, if these public-private partnerships and the link between inpatient psychiatric services and community partnerships actually consisted of better continuity of care, residents in Louisiana would not be so confused about how to access mental health services.

As Figure $3^{3}$ shows, much of individuals' access to services, hospital or communitybased, is based on insurance. Without health insurance, residents are limited to using public behavioral health clinics.

\footnotetext{
${ }^{3}$ Figure 3 is a decision tree created by staff at Vista, where I conducted fieldwork, to help people calling in and asking about where they can access mental health services. I took a picture of the decision tree and interviewed staff at Vista about the major obstacles to accessing and receiving mental health services in New Orleans.
} 


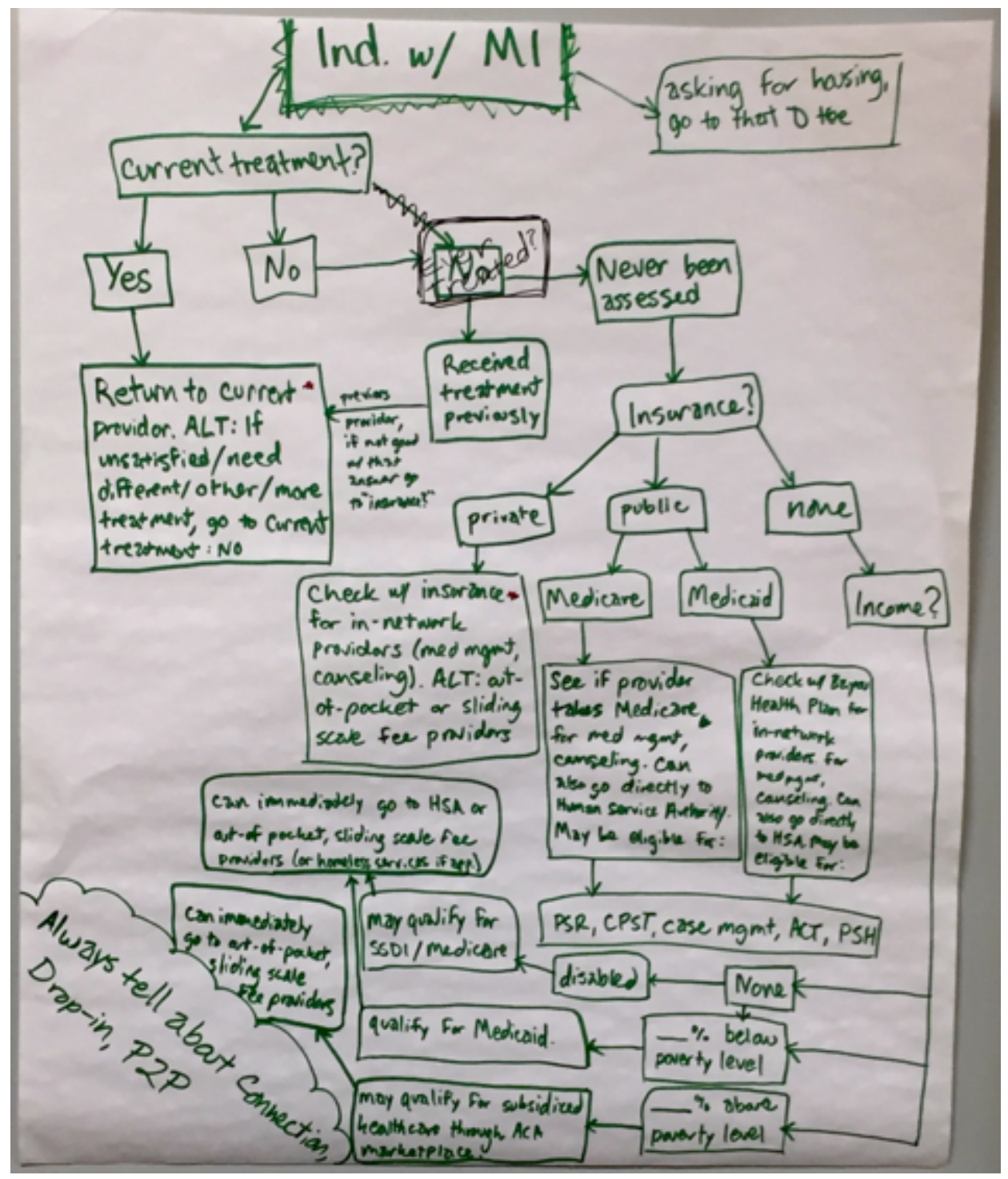

Figure 3: Decision Tree Created by Mental Health Professionals

The behavioral health clinics provide a variety of outpatient services, including screenings and assessments, emergency crisis care, individual evaluations and treatment, and clinical casework services (OBH 2018b). Louisiana legislation mandates that independent health care districts or authorities, also referred to as local governing entities (LGEs), operate the local administrations of the Louisiana behavioral healthcare system (OBH 2018b). The LGEs run the behavioral health clinics, treating adults and children with mental illnesses throughout the state. Ten LGEs currently exist in Louisiana. 


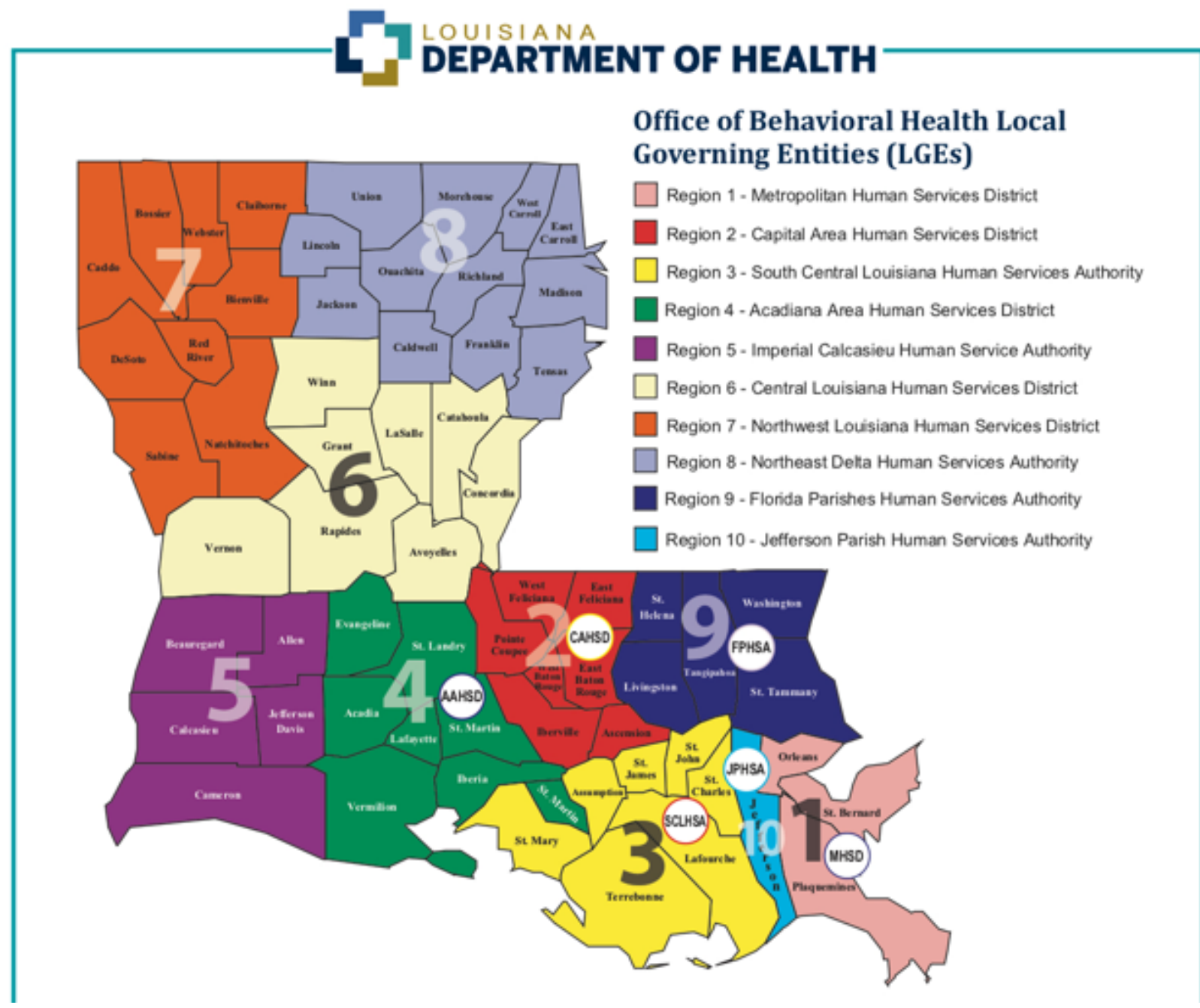

Figure 4: Local Governing Entities (LGEs) in Louisiana

For my research, which was conducted in Orleans and Jefferson Parishes, Region 1 (Metropolitan Human Services District) and Region 10 (Jefferson Parish Human Services Authority) are the relevant LGEs, which compose the greater New Orleans area. Metropolitan provides services for residents in Orleans, St. Bernard, and Plaquemines Parishes, while Jefferson Parishes Human Services Authority only provides services for residents in Jefferson Parish. Where residents live is important because it dictates where they receive services. Residents in New Orleans utilize Metropolitan Human Services District, with Central City Behavioral Health \& Access Center as the most used clinic amongst my research population. Other clinics include the Algiers Behavioral Health Center, Chartres-Pontchartrain Behavioral 
Health Center, New Orleans East Behavioral Health Center, St. Bernard Behavioral Health center, and Plaquemines Community C.A.R.E. Some of these clinics are decades old, such as Chartres-Pontchartrain and Central City, but may have operated and been run by other agencies before the LGEs were created. Other locations, such as New Orleans East Behavioral Health \& Access Center, opened more recently in 2015. While the Louisiana State Legislature authorized the creation of Metropolitan Human Services District as the LGE for the region in 2003, Metropolitan struggled to meet its mission for five years, and retired Judge Calvin Johnson was hired as the Executive Director in 2008 (MHSD 2019a). During my time working at City Hall, Metropolitan struggled to keep up with demand for services after Hurricane Katrina, where staff often mentioned how clients could not get through an outdated phone system where people would often just hear a busy signal in the immediate years after Katrina. Under the direction of Judge Calvin Johnson, Metropolitan created its first crisis care continuum, which includes a variety of services that are both immediate and long-term; by 2013, Metropolitan was awarded a three-year accreditation from the Commission on Accreditation of Rehabilitation Facilities (MHSD 2019b). While Metropolitan has made significant steps towards providing services for residents, the clinics under its jurisdiction, particularly Central City, continue to receive a bad reputation for the quality of care and turnover of psychiatrists who work there. Figure 5 shows the clinic locations for Metropolitan in Region 1 (MHSD 2019b). 


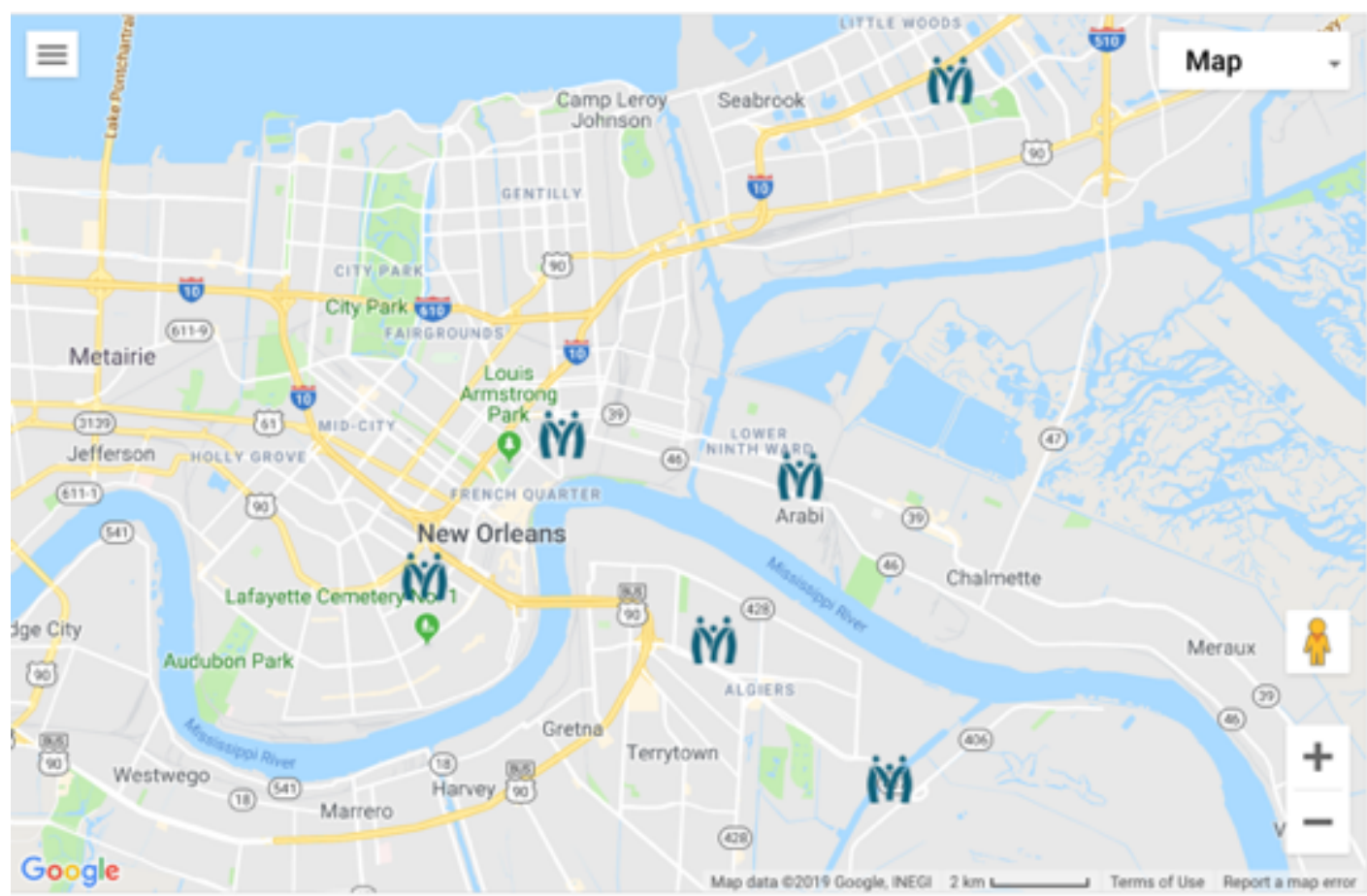

Figure 5: Clinic Locations for Metropolitan Human Services District

In Jefferson Parish, into which many residents in New Orleans started moving because of a cheaper cost of living, residents had to utilize Jefferson Parish Human Services Authority if they did not have private insurance. However, at one point in my research in 2016, there was a six-month waiting list to see a psychiatrist through the Jefferson Parish Human Services Authority. 


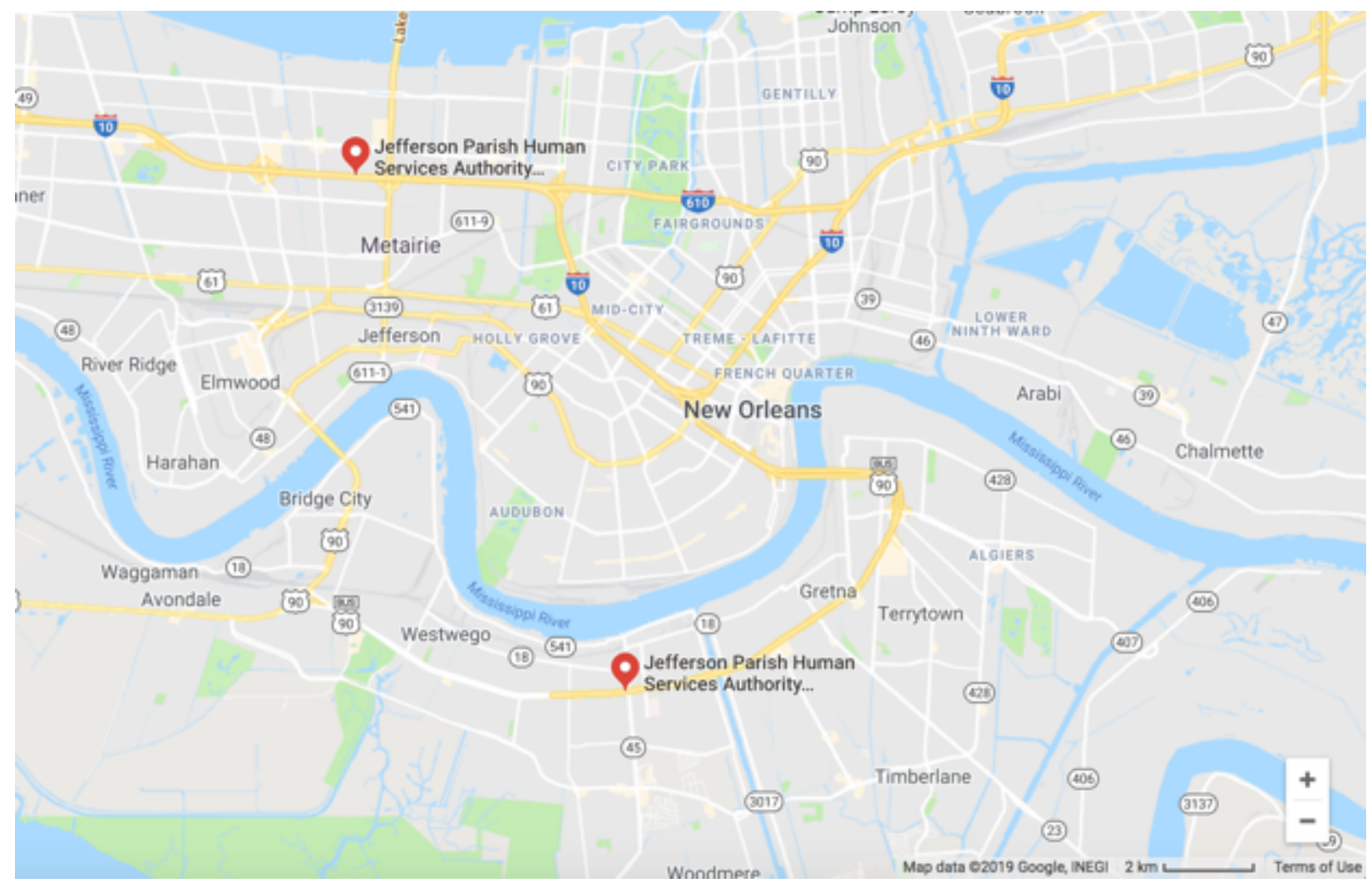

Figure 6: Jefferson Parish Human Services Authority Locations

Furthermore, Jefferson Parish Human Services Authority only has two clinic locations: one in Metairie, on the East Bank side of the Mississippi River and one in Marrero, on the West Bank side of the Mississippi River (JPHSA 2019), despite having a larger population estimate $(437,038)$ than Orleans Parish $(388,182)$ (Census FactFinder 2017).

OBH currently operates two state psychiatric facilities: Central Louisiana State Hospital (CLSH), located in Pineville, Louisiana, and Eastern Louisiana Mental Health System (ELMHS), located in Jackson, Louisiana. These facilities provide treatment and rehabilitation services for adults who have severe and persistent mental illnesses. However, The TimesPicayune, the local newspaper in New Orleans, ran a column series in late 2018 on "How the 
State's Health Care System is Failing Its Most Vulnerable Residents," describing how these hospitals have more forensic beds than civil beds with long waiting lists $^{4}$ (Sayre 2018b). In 2009, Louisiana added Assertive Community Treatment (ACT) and Forensic Assertive Community Treatment (FACT) teams as part of its commitment to provide community-based services in the Greater New Orleans area (Louisiana Department of Health 2010). ACT teams have existed since the 1970s and have been studied by anthropologists (Estroff 1981), even though none existed in Louisiana until 2009. FACT teams are similar but are designed to "provide treatment and support to adults with frequent interaction with law enforcement" (Louisiana Department of Health 2010). ACT and FACT teams provide 24-hour treatment and support services for individuals in Louisiana. With these teams, the mental health team goes to individuals to their homes. ACT and FACT teams work well when an individual actually has a home. When the teams were initially introduced in New Orleans, vouchers were given to homeless individuals; however, once those vouchers for homeless shelters expired, the psychiatric mobile teams had no way to find their patients in the community. The ACT and FACT teams also have a long waiting list, as mental health professionals shared with me that there are not enough of these type of programs in the community.

One final challenging piece of the puzzle that has complicated the mental healthcare climate in Louisiana in general, and New Orleans in particular, is the state budget deficit. In 2008, Louisiana had a billion-dollar surplus as a result of post-Katrina economic activity and an influx of federal recovery dollars (Moller 2009), so budget cuts were not a concern for many people. By 2012, the billion-dollar surplus turned into a billion-dollar deficit. Louisiana has been

\footnotetext{
${ }^{4}$ Forensic psychiatric beds refer to beds for patients who have entered the criminal justice system in Louisiana, as opposed to civil beds, which can still be associated with courts orders. Patients in the forensic system may not necessarily be sicker or more dangerous; they may just be "at the wrong place at the wrong time" as told to me by a psychiatrist.
} 
in a budget deficit ever since. During a deficit situation, education and healthcare are unprotected areas in the Louisiana constitution for budget cuts. Thus, during budget deficit years, funding for education and healthcare continuously get cut. Within healthcare, mental health services are usually the first to be cut.

My primary research population, men and women diagnosed with chronic mental illnesses, most who received Supplemental Security Income (SSI) or Social Security Disability Insurance (SSDI), often came from poor, underserved communities. This dissertation highlights the challenges they face in receiving mental health services during these budget deficit years through the exploration of race and how it intersects with gender and class. I also examine what role stigma played in accessing mental health services.

\section{Diagnostic Controversies: A Note on Terminology}

Anthropological literature often switches terminology between mental illness, mental disorder, mental health problem, emotional disease, psychiatric disorder, and psychiatric illness without clearly distinguishing the differences, if any, among them. Furthermore, many anthropologists focus on just one mental illness in case studies such as depression (Mendenhall 2012; O’Nell 1996), schizophrenia (Barrett 1996; Myers 2015), dementia (Leibing and Cohen 2006), bipolar disorder (Martin 2007), eating disorders (Becker 2007), and post-traumatic stress disorder (Finley 2011) to name a few. Often, the classification of these illnesses is based on the International Classification of Diseases (ICD) or the Diagnostic and Statistical Manual (DSM) of the American Psychiatric Association, but psychiatric classifications have undergone significant changes since the 1970s (Desjarlais et al. 1995, 36), and more changes occurred with the release of the $D S M-5$. Furthermore, some anthropologists avoid applying psychiatric labels to the populations with chronic and severe mental illnesses that they study because labels "tell us 
precious little about who these people are, what their lives are like, how they experience themselves and others, and what meaning their existence" holds (Estroff 1981, 11; see also Desjarlais 1997). Further, anthropologists often do not carefully define mental illness or mental health. Diagnoses, especially psychiatric diagnoses, are controversial and socially debated spaces (Smith-Morris 2016). For these reasons, and to remain true to goals of ethnography, I use the diagnostic labels that my interlocuters shared with me, even though they themselves often did not know if their diagnosis was accurate.

This approach frames my own deployment of key terminology in this dissertation. The term "severe mental illness" is often used by clinicians to delineate the population I interviewed. But what makes one diagnosis more severe than another? Given the various diagnoses my interlocutors had, I use the phrase chronic mental illness instead of severe mental illness for three reasons: 1) the severity of the same mental illness and diagnosis can vary for different individuals; 2) the severity of the mental illness can change within the same individual over time; and 3) the mental health professionals I interviewed often used severe mental illness and chronic mental illness interchangeably. Lastly, most of my interlocuters rarely had one diagnosis. Many had co-occurring disorders. Thus, I prefer using chronic mental illness to capture the range of health issues for my research population.

\section{Overview of Chapters}

Chapter 2 provides an overview of my research methodology, how I entered my research sites, details about my research populations, how I addressed ethical concerns, and methodological limitations of my research. Chapter 3 discusses stigma and disclosure, insights from scales I used to measure stigma and their limitations, and how stigma may have impacted an individual's disclosure of mental illness. Chapter 4 focuses on minority mental health and 
how mental illness affects this population specifically at the community level. I discuss the common concerns African Americans face and how these are different from my white interlocuters. Chapter 5 addresses how religion and spirituality can be used as a way to reach the African American community for mental health outreach instead of a barrier as a form of medical pluralism. In Chapter 6, I discuss the problems many people of color face when trying to receive mental health services and how to address this through the stories of both clients and providers. Chapter 7 provides an overview about the challenges of caregiving, primarily through the story of Anita. I use the frameworks of therapeutic governance to discuss how some caregivers are able to find a balance through boundaries and the Sojourner Truth Syndrome, which explains why black women are often more burnt out. Chapter 8 focuses on the institutional circuit, why so many of my interlocuters had trouble finding housing in New Orleans, and how the criminalization of mental illness has become the norm in the city. Finally, in Chapter 9, I conclude by introducing the term synergistic activism as a way to address the mental health challenges and disparities that exist in Louisiana. 


\section{CHAPTER 2}

\section{RESEARCH METHODOLOGY}

In this chapter, I discuss my methods for conducting research. To outline these methods, I begin by describing the organizations with which I collaborated while conducting research. I then describe the methods I used to reach my research objectives. I end the chapter with reflections on fieldwork in terms of my research questions, my positionality, ethical considerations, and the challenges of conducting fieldwork in a place one also calls home. I also address specific methodological limitations.

\section{Fieldwork and Research Sites}

During the summers of 2012 and 2013, I conducted preliminary research to determine how I could access the key population for my research: individuals diagnosed with a chronic mental illness. In the summer of 2012, I called Lorraine Landry, a Licensed Clinical Social Worker, whom I had met during my time working at City Hall. Lorraine was heavily involved with the mental health community when I worked at City Hall, and I kept in touch with her after I left my job at City Hall; thus, I asked her if I could shadow her for two weeks. I explained to Lorraine the purpose of my dissertation project, and Lorraine surprisingly said yes with few questions regarding me shadowing her. She just told me where to show up and when. Lorraine was retired at the time I called her but was volunteering at Genesis House, a shared living program, in Central City and working part-time at Vista, so I initially met her at Genesis House. Because of Lorraine's extensive network with other mental health professionals, I learned about 
the various places individuals diagnosed with mental illness access because she was affiliated with many of these programs in some way. I spent the rest of the summer of 2012 at these places, thus utilizing a site-based approach to determine where individuals with mental illnesses accessed services (Arcury and Quandt 1999). The site-based approach is helpful in locating hardto-find populations, so I went to sites frequently used by individuals with mental illnesses.

Lorraine spent much of her time that summer volunteering at Genesis House in Central City, a neighborhood known for its violence which underwent rapid gentrification during the time I conducted fieldwork. Lorraine introduced me to the director and other staff members of Genesis House, a faith-based nonprofit and shared living program for individuals with mental illness that was fairly new when I first visited during the summer of 2012. She was also working part-time at Vista, ${ }^{5}$ a community-based psychosocial rehabilitation program, where she was counseling family members of individuals diagnosed with mental illnesses. I learned that many of the clients ${ }^{6}$ from one site were also involved with another program. This is how I heard about Mental Health Court, which is housed inside Orleans Criminal District Court, a building on the corner of Tulane Avenue and Broad Street, a busy urban intersection close to civil and criminal courts, the offices of public defenders, bail bond offices, and Orleans Justice Center, otherwise known as OPP. These three facilities, Genesis House, Vista, and Mental Health Court, were my primary field sites during preliminary fieldwork.

\footnotetext{
${ }^{5}$ Both Genesis House and Vista are pseudonyms as are names of individuals in this dissertation, unless I am referring to public officials or people described at events open to the public.

${ }^{6}$ The terminology for individuals with mental illness changed at different locations: common terms I heard were members, clients, consumers, patients. In this dissertation, true to ethnography, I use the terms that I heard during fieldwork.
} 


\section{Genesis House}

On a street with many dilapidated buildings, Genesis House stuck out as a recently renovated building that looked like an apartment complex. I actually drove past it when looking for it the first time because I could not find the numbered address nor any signage on the building. Lorraine had given me an address so that I could meet with her at her office there. I drove back around the block taking a guess at which building was Genesis House. As I learned later, many shared living programs or group homes for those with mental illnesses are not labeled in the city. These types of programs are often viewed negatively by neighbors, often as one of those "not in my backyard" (NIMBY) places. The intentional non-labeling of these programs is to avoid looking like "mental health housing" to clients. When I got out of my car, I saw the neighbors across the street watching me from their front porch, which is typical in New Orleans. I waved at them, and they waved back, which signified an unspoken code that it was okay for me to be there.

If you paid attention closely, the gated fence and locked entrance door, often manned by a house manager, was what made it obvious that Genesis House was not a regular apartment complex but a shared living program. When a staff member was not at the gated door, I had to call someone at the front desk or ring the doorbell and wait for someone to open the locked gate. That first day, when I arrived at Genesis House I encountered a staff member at the gate. I told him who I was and that I was meeting Lorraine in the office. Saying Lorraine's name seemed to be magic. No one questioned my presence after that, and I was ushered into the office quickly. Lorraine explained to the other staff members that I would be shadowing her for the next two weeks. As a Licensed Clinical Social Worker, Lorraine conducted intake for many of the clients 
but also provided crisis intervention training to the staff members at Genesis House. Thus, she held a lot of respect among both clients and staff at Genesis House.

During the time I was at Genesis House, I mostly observed Lorraine and other staff members. The mornings at Genesis House started with staff meetings between the director, staff, and house managers. The house managers lived in a unit at Genesis House, supervising other individuals who had mental illnesses in those units. The program aimed to put individuals with similar illnesses or developmental capacities in the same units. The house managers did not get paid but were allowed a place to live rent-free, which was the trade-off for the work they did at Genesis House. Some of the house managers were initially clients of Genesis House who were doing better and, in a way, "promoted" to become house managers. Others came from out of town. Rita, who was a house manager during the first summer when I conducted fieldwork, worked on a contractual basis for the Federal Emergency Management Agency (FEMA), which is how she ended up in New Orleans, but she became unemployed after her contract ended. She ended up at Genesis House, which provided her a place to live while she figured out where to go next. Other house managers were from New Orleans, had lived in Houston and other places after Hurricane Katrina, and were looking for a place to live when moving back to New Orleans. Thus, some house managers had been at Genesis House for a few months while others had just arrived and were only there until they could find more permanent work and housing. Most of the house managers were African American, of the same race as clients, except for clients who also had substance use issues in addition to their mental illness, who were often white.

Most clients at Genesis House came from local psychiatric hospitals or were homeless. Lorraine's role at Genesis House was to assess and do intake for new potential clients, counsel clients, and show up when a crisis occurred to deescalate the situation. During the first week I 
shadowed Lorraine, we went to Community Care Hospital, a small psychiatric hospital located in Uptown New Orleans. Lorraine drove to the hospital; although Lorraine is from New Orleans and had been to Community Care many times, the one-way streets in New Orleans are confusing, so she ended up driving in circles before eventually finding the hospital. "I can never find this damn hospital on the first try," Lorraine told me while I was in the passenger seat of her car. I thought about pulling up the GPS from my phone, but we would probably be driving in circles again when looking for street parking. After finding a parking place, we entered the hospital. Lorraine said hello to the front desk person who seemed to be familiar with her, and we took an elevator to another floor. After knocking on the door, Lorraine explained who she was, entered the patient's room with permission, and introduced me.

While Lorraine explained why she was there, Clara, seemed frightened more than anything else. Clara, a white woman, had been living in a low-income housing facility in downtown New Orleans before her hospitalization but did not feel safe returning there. She said many of the other residents had drug addictions, which did not help with her own drug addiction, and the men made her feel unsafe. Lorraine gave a description of Genesis House and asked Clara if that was the type of place where she would like to stay. Clara seemed interested, but it also did not seem like she had many other options for living situations. Two days later, discharged from the hospital, Clara arrived at Genesis House as a client.

Other clients were often homeless and came from "under the bridge," the common phrase used for the homeless camps under the Ponchartrain Expressway and I-10 overpass on Claiborne Avenue. Genesis House, along with other homeless agencies, routinely met at these locations, talked to the homeless, and asked if they wanted to live somewhere else. Those who expressed interest in housing went into a van operated by Genesis House. Someone on staff did 
intake on these individuals; those without a mental illness went to other housing programs that were also operated by staff at Genesis House. If there was space at Genesis House, individuals with a mental illness stayed in a unit there.

A routine day at Genesis House, from the staff perspective, was giving medications to clients around $7 \mathrm{am}$, where they each lined up by the window to get their medications from the nurse. The staff, which included the owner, managing director, house managers, nurse, and Lorraine met around 8 am and discussed any issues going on. Genesis House provided three meals a day to clients, so the meal schedules were discussed. Clients were encouraged to participate in other activities in other programs during the day. Some went to doctor's appointments or participated in group therapy guided by a social work student who came to Genesis House, but most clients stayed in their rooms. The building complex had a courtyard, but most clients did not come outside during the middle of the day because of the heat and humidity in the summer months. At the end of the day, the staff met again in the evening to discuss any problems or issues that came up during the day. The staff often decided which clients were progressing or if anyone needed to be seen by a psychiatrist or hospitalized. While a psychiatrist came to Genesis House on a volunteer basis each week, a lot could happen within a week. Some clients were moved to other housing owned by the same individual who owned Genesis House, but with more flexibility and less structured schedules. Clients moved to other housing locations were expected to cook their own meals. In the evening, before clients went to sleep, they lined up again at the office window to get their nighttime medications. Clients who were doing well often became house managers themselves. A joke was often made when a new visitor arrived when the owner asked them, "Do you think this person's a client or staff?" Given 
that no one had name badges, and everyone dressed casually, it was often hard to tell who a staff member or client was.

Three times a week, two house managers would take any interested clients to Drop-In at Vista, a community based psychosocial rehabilitation program within walking distance from Genesis House. Drop-In is a low-barrier program at Vista, open to anyone with a mental illness. During my first week at Genesis House, Lorraine received a call from the director at Vista saying the air-conditioning was broken, so Drop-In was closed that day until the air conditioning could be fixed; thus, she did not want clients from Genesis House to walk to Drop-In only to walk back because of the broken air conditioning. When the air conditioning was fixed at Drop-In, I walked with clients from Genesis House to Drop-In at Vista.

Vista

Vista is a grass-roots based non-profit in New Orleans that provides a psychosocial rehabilitation program for individuals with mental illnesses. In addition to the psychosocial rehabilitation program, otherwise referred to as the day program, Vista offers peer-to-peer education programs, support groups for peers, support groups for family members of individuals with mental illness, and a low-barrier Drop-In program, where anyone with a mental illness can walk in. Drop-In is located in the same place as the day program but operates during different hours.

The day program at Vista is structured during the mornings and followed a Clubhouse model. The Clubhouse model, based on Fountain House, which was the first Clubhouse established in New York City in 1948, works by providing people with chronic mental illnesses opportunities to participate in employment, education, wellness, and other initiatives so that 
members play an active role in their own recovery and their peers by working alongside staff to organize and run programs (Mowbray et al. 2006).

A calendar was made each month by staff with a schedule for the month's programs in the day program. The calendar included activities, from light exercise units in the morning, reading about recovery, arts and crafts, and outings including going to Wal-Mart and other stores, the bowling alley, or to the park. Those who attended the day program were often referred to as members and followed a schedule. They had an option to buy coffee for 50 cents in the mornings before the day's schedule began. During this time, members would also decide if they wanted to buy and eat lunch at Vista, which was usually at noon. Lunch was one dollar when I was doing preliminary field work, but the price rose to two dollars later on to cover the rising costs of supplies and to get better meal options. Members could pay for lunch for the month in advance or on a daily basis.

The lunch was also made by members. Each member was assigned to different units, so while some did clerical work, others were assigned to "house and gardening" where they watered the plants outside, and some were assigned to the kitchen to help prepare lunch. Members were supervised by staff in the kitchen, and a weekly schedule showed what was on the menu for lunch. After lunch time, members of the day program cleaned up. Each member signed up for a different chore: wiping tables, mopping the floor, emptying the trash cans, or washing dishes. Some members would leave after lunch, but on Drop-In days, many members would stay for Drop-In hours. Some members came in every day of the work week for the day program, but many came in two to four times a week, sometimes taking a day or two "off." Some members, including those who were employed or elderly, would go to their other jobs or to a senior center on the days they did not come to the day program. Drop-In was open from 1:30 to 4:30 pm two 
to three times a week. During the beginning of my fieldwork, Drop-In was open twice on weekdays and one day on a weekend. The weekend hours were run by a social work student. Fewer people came in on the weekend, and eventually Drop-In closed on the weekend.

The point of Drop-In was to be a low-barrier service for individuals with mental illness. People who came to Drop-In just had to sign-in on a sheet in a binder that was left on one of the tables. No one really checked the names or signatures; the sign-in sheet was just to keep track of how many people were coming in. Those who attended Drop-In the first time filled in a one-page sheet with their information, given by a staff member; besides that, no questions were asked about anyone's diagnosis. New attendees for Drop-In were often told about the program by their social worker or case manager. One day of Drop-In coincided with a peer support group, so some Drop-In attendees would also participate in the peer support group. The staff for Drop-In were also peers, so the regular staff at Vista typically stayed in their offices or out of the way during Drop-In hours unless they were short-staffed, or an issue came up.

Drop-In offered free coffee and a light meal or snack to those who came in. Thus, it was attractive to many individuals with low incomes. Sandy, a Drop-In staff member, who lived on the West Bank side of the river, used public transportation to get to Drop-In, located Uptown on the East Bank. Because she had to take the bus and the streetcar, and she did not want to risk coming in late, she often arrived early and ate lunch at a nearby McDonald's before walking to Drop-In. This McDonald's attracted a lot of homeless individuals, and sometimes Sandy would talk to these individuals and tell them about Drop-In. Other individuals, who technically did qualify to be members of the day program at Vista, chose to just come in during Drop-In. They did not want to participate in the structured nature of the day program, but Drop-In allowed them more flexibility. On a typical Drop-In day, members would wait for the coffee to be ready, play 
games such as UNO, Scrabble, or Monopoly, use the desktop computers which were connected to the internet, wait for the meal to be served, and just socialize with others. Some members who came to Drop-In regularly eventually became members of the day program at Vista. Others, who were homeless or living in a transitional environment came to Drop-In for a few days or weeks and then disappeared, probably leaving town. During the summers, the air-conditioned environment, food, and clean restrooms attracted them to Drop-In.

Members in the day program at Vista were used to hosting students, including nursing and occupational therapy students. On Wednesdays, occupational therapy students from a local college came in with various types of activities, and during other parts of the year, nursing students from another university came in and planned activities with members during the day program and Drop-In. My presence was therefore not that unusual; the biggest difference was that I was an anthropologist while other students were usually associated with some healthcare field.

\section{Mental Health Court}

During the first summer I conducted fieldwork, 2012, I also attended Mental Health Court. Mental Health Court means different things in different cities. In New Orleans, Mental Health Court is more of an intensive probation program which meets inside of the Orleans Parish Criminal District Court building. To be eligible for Mental Health Court, an individual arrested had to have their mental illness as a reason for their arrest. Those who successfully completed the program would have the charges against them dropped. In the summer of 2012, I attended Mental Health Court when it met, usually every two weeks.

Anyone could attend Mental Health Court, but I could not bring my cell phone or any type of recording device inside the Criminal Court building. For me, this just meant leaving my 
cell phone in my car and taking notes via paper and pen. For most members of Mental Health Court who used public transportation to get to the building, this meant paying one dollar to leave their cell phone across the street at a bail bond location.

Although I could attend Mental Health Court, the social worker assigned to Mental Health Court could not tell me any information about individuals in the program due to confidentiality. However, the same social worker would often provide details openly to the judge during Mental Health Court: how well a person was doing, if a person was looking for a job, or if a person was successful finding a job. Quentin, who was a house manager at Genesis House, was also enrolled in Mental Health Court and would often explain to me what was going on, since I was unfamiliar with how courts work. Mental Health Court often met at the same time as Drug Court, and according to one of the social workers affiliated with the program, this was because of the similarities between the programs and clients. Eventually, Mental Health Court and Drug Court were combined.

During the same summer, I also attended and participated in programs at Genesis House, Vista, and Mental Health Court to get an idea of how things worked in the city regarding mental health services and programs. There was a lot of overlap regarding members in different programs; I often saw the same individuals in other programs. When I returned to New Orleans during the summer of 2013, I focused primarily on Vista because I wanted to focus on the recovery aspect of mental illness and what that meant to individuals. Most of the people I encountered who felt they were "in recovery" were at Vista, where I met them. Vista had the most consistent staff and members, for both its day program and Drop-In.

For Mental Health Court, the social worker assigned to the program seemed to change each time I would attend Mental Health Court in 2013 and later. During 2012, the meeting times 
of Mental Health Court could change at the judge's discretion because of a holiday or some other conflict. In addition, if the judge for Mental Health Court left the program permanently, it was unclear if the program still continued without disruption. I could only keep up with the meeting times because of Quentin, who would let me know the meeting times and in exchange, I would give him a ride.

While there are anthropologists who also identify as mental health professionals in the U.S. as clinicians (Kleinman 1988; Lester 2013), I do not identify as a mental health professional nor did I want to be viewed as one. This was the primary reason I did not return to Genesis House. During my time there, it was difficult for clients not to view me as a mental health professional. People would automatically assume I was staff or a mental health professional, and the staff often wanted me to conduct intake for new clients. While this work helped me learn much of the language used by mental health professionals, I decided to avoid doing this type of work during long-term fieldwork.

For long-term fieldwork, which I conducted for 30 nonconsecutive months ${ }^{7}$ between January 2015 and December 2017, the majority of my interviews were conducted at Vista. Vista has two locations, one in Orleans Parish in an Uptown neighborhood on the East Bank; the other location is in Jefferson Parish on the West Bank. In 2016, I also began to attend Drop-In hours at the West Bank location. The primary reason for this is that more clients began to move to Jefferson Parish because the cost of living in New Orleans was increasing. While the executive director was the same for both locations, the West Bank location received some funding through

\footnotetext{
${ }^{7}$ During the time I conducted fieldwork, I left New Orleans for short time periods to teach at SMU's campus in Taos, New Mexico during intersession terms in January or August. In the summer of 2017, I also spent five weeks in Tallahassee, Florida during the summer as part of the Health Equity Alliance on Tallahassee (HEAT) Ethnographic Field School, sponsored by the National Science Foundation. Hence, why I say 30 nonconsecutive months of fieldwork between January 2015 and December 2017.
} 
the Jefferson Parish Human Services Authority ${ }^{8}$ for Drop-In, which impacted how services were implemented on the West Bank. The East Bank Drop-In was funded by fundraisers. I discuss the impact of funding from Jefferson Parish Human Services Authority on the program and peers in the conclusion. Drop-In on the East Bank is self-funded through fundraisers; thus, the staff and peers at Drop-In on the East Bank had more autonomy on how to run the program.

\begin{tabular}{|c|c|}
\hline Time Period & Methods \\
\hline Summer 2012 & 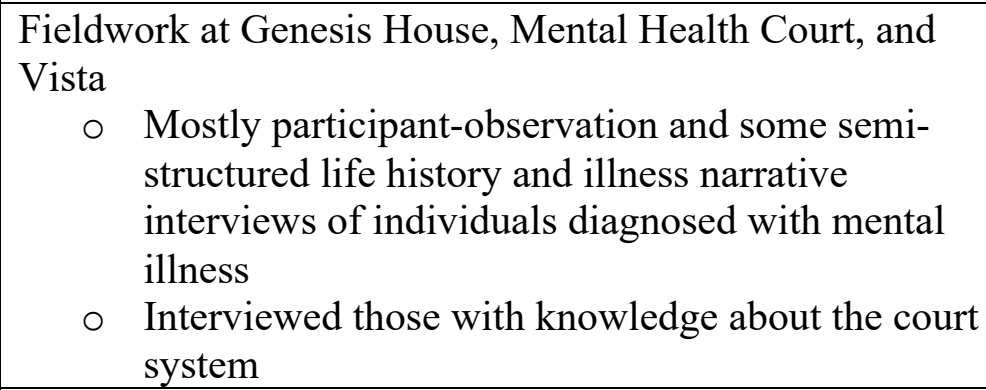 \\
\hline Summer 2013 & $\begin{array}{l}\text { Fieldwork at Vista and Mental Health Court } \\
\circ \begin{array}{l}\text { Mostly participant-observation and some semi- } \\
\text { structured life history and illness narrative } \\
\text { interviews of individuals diagnosed with mental } \\
\text { illness }\end{array} \\
\end{array}$ \\
\hline January 2015 to December 2017 & $\begin{array}{l}\text { Fieldwork at Vista (primarily at the East Bank location } \\
\text { and at West Bank location from } 2016 \text { to } 2017 \text { during } \\
\text { Drop-In) } \\
\text { O Phase 1: Conducted stigma scales and vignettes } \\
\text { ○ Phase 2: Life history and illness narrative } \\
\text { interviews } \\
\text { Phase 3: Utilized the MINI life history and time } \\
\text { diaries } \\
\text {-Participant-observation throughout this time at Vista and } \\
\text { at meetings about mental health (NOLA Partnership, } \\
\text { City Council, Behavioral Health Day) } \\
\text {-Interviewed caregivers } \\
\text {-Interviewed mental health professionals and housing } \\
\text { advocates at both Vista and other programs providing } \\
\text { mental health services }\end{array}$ \\
\hline
\end{tabular}

Table 1: Breakdown of Various Field Periods and Methods

\footnotetext{
${ }^{8}$ The Jefferson Parish Human Services Authority (JPHSA) provides services for behavioral health, developmental disabilities, and primary care. Metropolitan Human Services District (MHSD) provides similar services in Orleans, St. Bernard, and Plaquemines Parishes.
} 


\section{Research Populations}

My primary research population was individuals diagnosed with chronic mental illnesses. The most common diagnoses for these individuals were schizophrenia, schizoaffective, and bipolar disorder. I do not focus too much on the diagnoses because of the problematic nature of the diagnoses themselves. During the time I conducted fieldwork, the Diagnostic and Statistical Manual of Mental Disorders was revised with the DSM-5 (APA 2013). ${ }^{9}$ This change was noticed by some of my interlocuters who, when I interviewed them, were unsure if their diagnosis was still the same or not. For instance, William, a 44-year-old white man, remarked, "I think my diagnosis is still schizoaffective under the new DSM." Others changed their diagnoses while I interviewed them during different phases of my research. Brenda, a 52-year-old black woman, initially told me she had major depression but then said her diagnosis was bipolar disorder for Phase 2, after taking a peer support class and realizing what her diagnosis really was after learning about it more in the peer support class. I discuss some of the other problems with diagnoses in Chapter 4, but many of my interlocuters had more than one diagnosis. Amongst my black interlocuters, they also had physical health issues including high blood pressure and diabetes. Overall, I interviewed 40 individuals with various mental illnesses over the course of my research. Table 2 breaks down how they self-identified ${ }^{10}$ :

\footnotetext{
${ }^{9}$ The director of the National Institute of Mental Health (NIMH) at the time, in 2013, declared the DSM-5 to be weak because of its "lack of validity" (Insel 2013).

${ }^{10}$ While there are different opinions about the use of race or ethnicity among anthropologists (Gravlee and Sweet 2008; Guarnaccia 2009; Mukhopadhyay and Moses 1997; Smedley 1998), given the various populations comprising the greater New Orleans area, I asked individuals what ethnicity and gender they identified as open-ended questions in an attempt to break away from the ethnic pentagon categories used in the U.S. Census Bureau, which "relies on categories of white, black, Asian, Latino, and Native American" (Hannah 2011, 36).
} 


\begin{tabular}{|c|}
\hline Individuals with a Chronic Mental Illness: \\
\hline 10 black or African American women ${ }^{11}$ \\
\hline 9 black or African American men \\
\hline 13 white or Caucasian women \\
\hline 5 white men \\
\hline 1 black Hispanic man \\
\hline 1 white Hispanic woman \\
\hline 1 Chinese woman \\
\hline
\end{tabular}

Table 2: Ethnicity and Gender of Individuals with Chronic Mental Illness

This breakdown makes sense given the demographics in Orleans Parish (see Table 3). In Jefferson Parish, I only attended Drop-In on the days it was open, and while there were more white men there, I found that they were often sicker and did not have the capacity to consent to participate in my research. I did fieldwork both in Orleans Parish and Jefferson Parish because Vista had two locations, one in each parish. Because people were moving to Jefferson Parish due to the rising costs of living in Orleans Parish, I decided to follow some of my interlocuters to Jefferson Parish. Despite being located next to each other, the populations of these parishes are quite different. Orleans Parish is predominantly black, although less black post-Katrina with the influx of transplants. In Jefferson Parish, white individuals make up the majority of the population, according to the "2013-2017 American Community Survey 5-Year Estimates" (Census FactFinder 2017). Table 3 breaks down the total population and the composition of each parish by percentages. While Orleans Parish is often considered a sea of blue in a red state,

\footnotetext{
${ }^{11}$ In this dissertation, I use the category people self-identified as when sharing their stories. Amongst my interlocuters, those who identified as "African American" used this term interchangeably with black. Outside of interviews, I use the term "black" as this was the most frequent term I read in literature.
} 
Jefferson Parish had the highest number of Trump voters in Louisiana while Orleans Parish had the highest number of Clinton voters in the 2016 election (Politico 2016).

\begin{tabular}{|l|c|c|c|}
\hline & Total Population & $\begin{array}{c}\text { Black or African } \\
\text { American }\end{array}$ & White \\
\hline Orleans Parish Population & 388,182 & 232,127 & 132,202 \\
\hline $\begin{array}{l}\text { Orleans Parish \% of } \\
\text { Population }\end{array}$ & --- & $59.8 \%$ & $34.1 \%$ \\
\hline Jefferson Parish Population & 437,038 & 116,282 & 276,284 \\
\hline $\begin{array}{l}\text { Jefferson Parish \% of } \\
\text { Population }\end{array}$ & --- & $26.6 \%$ & $63.2 \%$ \\
\hline
\end{tabular}

Table 3: Population in Orleans and Jefferson Parishes (Census FactFinder 2017)

In Orleans Parish, many of the white men were in transit in the sense that they came from other cities and were only in New Orleans for a brief time before moving on to another city. For instance, one white man who attended Drop-In at the East Bank location in Orleans Parish told me he was leaving New Orleans to go to Alabama the next week because, "The streets were too hard in New Orleans." He, in fact, was gone the next week, but two weeks later, returned. When I asked, "I thought you went to Alabama?," he responded, "I couldn't get an ID in Alabama. You need a birth certificate." He did not have a copy of his birth certificate, so he returned to New Orleans.

The majority of individuals whom I interviewed received Supplemental Security Income (SSI), Social Security Disability Insurance (SSDI), or were in the process of applying for one of these. Thus, most of my interlocuters had monthly incomes less than $\$ 1,000$. The average was about $\$ 730$ a month. Those who also had part-time jobs had an income of about $\$ 1,000$ a month. The one exception was a white woman who was a school teacher at a private high school in New Orleans who saw one of the flyers about my research project and contacted me to participate in it. 
Of the 40 individuals diagnosed with chronic mental illnesses in my research population, seven were peer-support specialists at some point while I conducted fieldwork. These peersupport specialists were individuals who had a mental illness and were hired and trained by Vista to facilitate peer groups or give a presentation about their recovery around the community at churches, synagogues, college campuses, and neighborhood centers. Metropolitan and other mental health agencies also had peer-support specialists, but they have their own training programs. The peer support specialists I interviewed were all working for Vista.

When possible, I also conducted semi-structured interviews with family members of individuals. My initial idea was to interview family members of the individuals I already knew to gain a relational aspect of my research; while I was able to do this with a few individuals, for the most part, this did not happen for several reasons: 1) many of the individuals do not have family members or the family members live in another part of the country; 2) some family members were the cause of distress for individuals I interviewed; 3) for many people of color I interviewed, their family members do not discuss mental illness even though they are aware of the diagnoses. Most of the family members who participated in my research were part of a family support group at Vista and contacted me through IRB approved flyers the Education Coordinator at Vista left or announced at the support groups.

\begin{tabular}{|l|}
\hline \multicolumn{1}{|c|}{ Caregivers: } \\
\hline 3 black or African American women \\
\hline 2 white women \\
\hline 1 white Hispanic woman \\
\hline
\end{tabular}

Table 4: Ethnicity and Gender of Caregivers 
In preliminary fieldwork, I interviewed three individuals familiar with Mental Health Court and to determine how individuals end up in jail instead of hospitals. I also interviewed 13 mental health professionals, including social workers, counselors, psychologists, and psychiatrists, both at Vista, and at other mental health agencies. I waited until the final stages of my research to do this because I did not want their perceptions of individuals to bias me during fieldwork, and the staff were more comfortable talking to me toward the end of my research anyway. These interviews were designed to understand how state policies and budget cuts were affecting mental health services in New Orleans.

\begin{tabular}{|l|}
\hline $\begin{array}{c}\text { Mental Health Professionals, Legal Advocates, } \\
\text { and Housing Advocates: }\end{array}$ \\
\hline 6 white women \\
\hline 3 white men \\
\hline 2 black men \\
\hline 2 black women \\
\hline $\begin{array}{l}1 \text { black/South Asian genderqueer/nonbinary } \\
\text { individual }\end{array}$ \\
\hline 1 white/Chinese genderqueer/nonbinary individual \\
\hline
\end{tabular}

Table 5: Ethnicity and Gender of Mental Health Professionals, Legal Advocates, and Housing Advocates

Lastly, I interviewed two housing officials and advocates from various housing agencies in New Orleans. Because homelessness and lack of affordable housing were big issues with my primary research population, I conducted these interviews to gain a better sense of how individuals with mental illnesses can receive permanent supportive housing, why individuals with disabilities were getting evicted from mixed income housing, and the problems and issues associated with homeless shelters and other types of transitional housing. 


\section{Research Methods}

My methods largely relied on participant-observation at Vista, both in the day program and during Drop-In. In the day program, I participated in the same activities as members. I introduced myself as an anthropology student and announced the purpose of my research; and told them that if anyone wanted to learn more about my research, had questions, or were interested in participating, they could contact me while I was at Vista. I made similar announcements a few more times while doing research because the day program would get new members, and I wanted to make it clear I was at Vista as a student researcher and not as staff. During lunchtime, I ate with members instead of staff, who usually ate together in a larger office, to avoid being seen as staff during the week. When possible, I ate the lunch members made in the kitchen, but because the food sometimes contained pork, I usually brought my own lunch or grabbed food from across the street.

I also had flyers approved by the SMU Institutional Review Board (IRB) with the topic of my research project and contact information posted at Vista. These also served as reminders for individuals about why I was there. For Drop-In, I explained why I was at the program to any new people who came and talked to me. There were peer group sessions held during Drop-In, though I did not attend peer group or family support group sessions. The director of Vista told me that in the past, students were in these and their presence impacted the way the sessions were held. That was the main reason I did not attend these, but I also did not attend group sessions because I thought I might conflate what people would tell me individually with what people would share during group sessions, which were confidential and brought about methodological and ethical considerations. 


\section{Interviews}

For interviews of individuals diagnosed with chronic mental illnesses, I utilized a threephase design. In Phase 1, I used stigma scales and vignettes about disclosure. In Phase 2, I utilized life history and illness narrative interviews. And in Phase 3, I utilized the McGill Illness Narrative Interview (MINI) for certain interlocuters to gain a better understanding of their life history and illness; in addition, my interlocuters completed time diaries in Phase 3. Only 30 of the 40 total participants are included in the three-phase design because I did not utilize the stigma scales and vignettes in preliminary fieldwork.

\section{Phase 1}

In Phase 1, I used stigma scales to measure various types of stigma related to mental illness. These included the Internalized Stigma of Mental Illness (ISMI) Scale (Ritsher, Otilingam, and Grajales 2003) and the Perceived Devaluation and Discrimination (PDD) Scale (Link 1987). ${ }^{12}$ Both of these scales include statements where the participants list a number on a scale between 1 to 4 or 1 to 6 on how much they agree or disagree with the statement. Because of anticipated low literacy rate amongst individuals in New Orleans, I read the statements and waited for participants to respond instead of having them read and fill out the form themselves. I found that the scales did not work or did not tell me the information in the ways intended; sometimes, participants did not want to provide an answer with an exact number, which the scales required. When they could not give a number, I asked if they could choose one, but if they could not, they would just ask to skip that statement or would respond with "neutral." Participants did often have specific reactions to the statements, which I found more interesting,

\footnotetext{
${ }^{12}$ The statements for the ISMI and PDD scales can be found in Appendix A. I chose the ISMI and PDD scales because they had the highest internal consistency (ISMI $\alpha=.90$; PDD $\alpha=.86$ ) assessing stigma by people with personal experiences of mental illness (Brohan et al. 2010).
} 
and thus recorded those. I also used hypothetical vignettes about situations of whether individuals would disclose their mental illness or not, which were based on themes about work and relationships since these were these topics came up frequently during preliminary fieldwork. The responses to these and the stigma scales will be discussed in Chapter 3. I found what people say they will do and what they actually do (based on participant-observation) to be different.

\section{Phase 2}

During Phase 2, I conducted semi-structured interviews to elicit life histories and illness narratives. Phase 2 consisted of a smaller sample than Phase 1, who self-selected to participate. The illness narratives I originally conducted in this phase consisted of explanatory models approach formulated by Arthur Kleinman (1988).${ }^{13}$ However, one of the questions in Kleinman's illness narrative, "How does it affect your body and your mind?" (Kleinman and Benson 2006, 1674), confused some individuals and heightened the mind-body dichotomy when some individuals were confused if their illness was supposed to only affect their body or mind or both. I found the McGill Illness Narrative Interview (MINI) ${ }^{14}$ worked better with some individuals, especially for people of color because it integrated the life history with the illness narrative, so in Phase 3, I redid the illness narrative using the MINI (Groleau, Young, and Kirmayer 2006). I used the illness narrative approach because it provided more insight on how my interlocuters perceived their mental illnesses. I was able to conduct most of the interviews in an empty office or a conference room if it was available at Vista, providing some privacy. Some individuals preferred to be interviewed at a nearby coffee shop or at McDonald's because the location was easier to get to than Vista.

\footnotetext{
${ }^{13}$ The questions for Kleinman's illness narrative questions are in Appendix B.

${ }^{14}$ The questions for the McGill Illness Narrative Interview (MINI) are in Appendix C.
} 


\section{Phase 3}

During Phase 3, I also gave participants a composition notebook, and they used the notebooks to complete time diaries where they wrote what activities they did each day outside of Vista and how they were feeling for two weeks. As one staff member at Vista said to me, "They just sit at home and watch TV all day." Was this actually true? I was curious to know what people actually did when they were not in the day program or Drop-In. Initially, I did not give specific instructions and just asked individuals to write what they did outside of Vista for two weeks. However, some participants shared that they were worried they "were doing it wrong," so to put them at ease, I asked for each day, to write 1) what they did; 2) how they felt; 3) and what they were grateful for. The time diaries were experimental in a way because I told people who completed them that "there was no one right way to do these." Twelve of the 40 interlocuters I conducted interviews with participated in Phase $3 .{ }^{15}$ Some wrote long descriptions of their day, some wrote just a few sentences each day, and some drew pictures describing how they felt. For those who did not know how to write well, I told them they could draw pictures and call me before the end of each day about what they did so that they would not be disenfranchised from participating. The time diaries did offer insight that I did not gain through other methods.

\section{Attending Mental Health Related Events}

Outside of Vista, I attended events that were related to mental health services or impacted the community I was working with. Each May, on Behavioral Health Day, representatives and members from organizations around the State went to the State Capitol in Baton Rouge advocating for mental health services. I went to the State Capitol as well, along with a bus load

\footnotetext{
${ }^{15}$ As my fieldwork progressed, my sample size decreased. The 12 participants who completed time diaries were from the original 40 participants. They consisted individuals who were still interested in my research and who I got to know more personally.
} 
of other individuals from New Orleans for Behavioral Health Day, usually organized by NAMI Louisiana and other mental health advocacy organizations such as Mental Health America of Louisiana. ${ }^{16}$ In addition, an organization called NOLA Partnership for Mental Health held community meetings open to the public with various panels on different topics about mental health such as addiction and mental illness and homelessness and mental illness. The New Orleans Behavioral Health Council, a partnership between Metropolitan Human Services District and the City of New Orleans Health Department, also held community meetings on various topics. I attended these community meetings to gain a sense of the most pressing issues in the community. Each Fall, the National Alliance on Mental Illness (NAMI) ${ }^{17}$ had a walk, usually in September or October to raise awareness about mental health and end stigma. I attended the local affiliate for these walks. In addition, I attended the annual NAMI State Conference during the time I conducted fieldwork, once in Baton Rouge and once in New Orleans, to gain a sense of what was happening around the state. When relevant, I attended or watched City Council meetings in New Orleans when it concerned mental health services. During the time I conducted fieldwork, the expansion of "mental health beds" at the newly built jail, Orleans Justice Center, was the most relevant meeting city councilmembers voted on. Lastly, peers at Vista often conducted presentations in the community, explaining their mental illness and recovery at community centers, churches, and to police officers undergoing Crisis Intervention Training

\footnotetext{
${ }^{16}$ Mental Health America (MHA), founded in 1909, is "dedicated to addressing the needs of those living with mental illness and to promoting the overall mental health of all Americans" (MHA 2019).

${ }^{17}$ The National Alliance on Mental Illness is "the nation's largest grassroots mental health organization dedicated to building better lives for the millions of Americans affected by mental illness" (NAMI 2019). It began in 1979, has more than 500 local affiliates, and provides support and education about mental illness (NAMI 2019).
} 
(CIT). I attended these presentations when I could and saved pamphlets from many of these events.

\section{Methodological Reflections on Fieldwork}

\section{Trust and Ethics}

For individuals whom I got to know well, I was invited to their homes for Thanksgiving dinners and other holidays. For those who did not have family to celebrate with, I was invited to Christmas lunch buffets at various restaurants. In addition to birthday parties, local festivals, and other events, I got to know people and what they did beyond the site-based approach. Thus, my fieldwork evolved during the course of my research. When these invitations to lunch or dinner first came up, I was worried about how to explain my presence to family members or friends. I had detailed conversations with people before attending these events, explaining that people know what I am researching and might ask how I know others outside the context of Vista or might guess that someone has a mental illness. Many did not care. Most of the people who invited me to these dinners and lunches worked at Vista as peers, so they told me to just tell other people I knew them through work. Others had gone through periods of psychosis, where they were sure their neighbors and friends knew they had been sick and hospitalized and were confident people already knew they had a mental illness. Some of my interlocuters invited me to their appointments with their psychiatrist at Central City, a public mental health clinic in New Orleans. I asked, “Won't the doctor ask who I am or why I'm there?” The response I got was, “Just say you're a friend.” In fact, no one even asked why I was present. I think the workers assumed I was a case manager, as case managers usually accompanied individuals to many of these types of appointments. 


\section{Positionality}

My visibility as a Muslim woman who wears a headscarf probably seemed to have more of an impact on my research than my concerns for other people's privacy. For instance, I was invited to a dinner buffet at a restaurant on the West Bank with two peers at one point during fieldwork. When I sat down and was about to begin eating, Susan, a peer at Vista, who frequents the restaurant where we ate commented, “This is the first time I'm meeting you outside of Vista.” I responded with, "I don't think that's true. I was at the NAMI Walk at Audubon Park, and I remember talking to you there." Susan responded saying, "That's Orleans Parish. It's different. This is Jefferson Parish." Susan had a point. Jefferson Parish is completely different, demographically, from Orleans Parish, even though it is right next to Orleans Parish. Susan was more concerned that she was eating openly with a Muslim woman in Jefferson Parish than any notion I might provide a clue about my research or her diagnosis. She disclosed before meeting me that she thought about how others might view her eating dinner with a Muslim woman but decided she did not care. This was a few months before the 2016 presidential election, and Jefferson Parish had the most voters for Trump in Louisiana. In contrast, Orleans Parish is a dot of blue in a sea of read with more liberal policies. A few months later, for Susan's birthday, I took her out to dinner. Susan does not talk to her mother anymore, but her mother called her at her workplace on her birthday (Susan blocked her mother on her cellphone). When her mother asked her what her plans were for her birthday, Susan said she was having dinner with a Muslim friend and then hung up the phone. Susan told me, "I purposely left out the fact that you're a woman. My mom's probably having a heart attack thinking I'm on a date with a Muslim man." Besides being used as a means to annoy family members, my identity came up during fieldwork at different points. Even though New Orleans and the surrounding suburbs have 
substantial Vietnamese, Palestinian, and Honduran populations, most of my interlocutors identified as black or white. To many, my ethnicity was ambiguous. During the first summer of preliminary work, a client at Genesis House came up to me and asked, "Are you black or white?" Before I even had a chance to respond, a white staff member at Genesis House responded back to the woman saying, "She's mixed." The staff member then asked the woman, "What are you?" To this question, the client replied, "I'm black, African American." The staff member asked her, "Are you sure?"

I found it odd that the staff member was certain she knew what my ethnic background was but questioned the client's. But religion and ethnicity-wise, I shared little in common with most of my interlocuters. If anything, this led people to ask me questions out of curiosity. I let people know that I was the daughter of Pakistani immigrants if they asked, but I think my headscarf led people to see my religion before they thought about my ethnicity. Many would say something to the fact that they had never met a Muslim person before. It would probably be more accurate to say they had not knowingly met a Muslim before, as many of the corner stores and gas stations in New Orleans, where many of my interlocuters bought cigarettes, are owned and operated by Muslims.

At another point, a manager at Genesis House asked me, "Saira, when you have the time one day, can you share the story of how you came to this country?" I laughed and responded with, "I can tell you the story of how I was born at Charity Hospital." He responded with excitement, "You're a Charity baby? I am too!" Being a Charity baby is sort of a mark of citizenship in New Orleans (Lovell 2011; 2014), and this opened up other conversations. 


\section{Challenges of Conducting Fieldwork at Home}

As someone who was born in New Orleans and raised in the surrounding area, there are some challenges to conducting fieldwork in a city I call home. While early discussions of insider/outsider status assumed researchers were predominantly insiders or outsiders and that each status carried with it certain advantages and disadvantages, recent discussions unveil the complexity inherent in either status and acknowledge that the boundaries between the two positions are not clearly defined (Merriam et al. 2001). However, acknowledging particular and personal locations is "to admit the limits of one's purview" from positions of power and representation (Merriam et al. 2001, 416). Prior to conducting fieldwork for this project, I had never heard of or attended the mental health programs that I mention in this chapter. However, as a creature of habit, I was worried that being in a city I was so familiar with would somehow prevent me from gaining insight in other ways. To challenge myself, I went to places and participated in things I would not have considered before. This could be as simple as riding the streetcar, even though I had a car, but using public transportation gave me insight into some of the barriers my interlocuters encountered when they had doctors' appointments or were trying to get to Vista.

\section{Ethical Considerations in Consent Processes}

Before conducting the interviews, I had to assess whether people had the capacity to consent to participate in my research. Decision tree and sample quiz instruments have been traditionally used to determine capacity to consent. I was required to have these for my IRB. While the decision tree I had in my IRB protocol was helpful conceptually to determine who could participate, it was less useful in helping determine how to conduct explicit assessments to determine if members could participate in my research. One of the assessments I used that was 
IRB approved was a quiz to evaluate decisional capacity. The challenge with the quiz was it made potential participants nervous because it evoked an examination or test-taking situation with an implication of judgement on correct or incorrect answers. For IRB standards, potential participants had to answer all questions correctly on the quiz in order to participate in my research. ${ }^{18}$

Because of the difficulty of using the quizzes, I found card games and board games a better way to evaluate how people were doing and were a better way to assess people's capacity to consent (Mehmood forthcoming). For instance, at Drop-In, during the beginning of my fieldwork, some of the members at Vista showed me how to play Rummikub, a game that requires a decent amount of concentration and a little math. However, one of the women who taught me how to play ended up getting sick later on during my research. Usually, people who were getting sick (eventually going into psychosis and hospitalized) would show disinterest in participating or have an extremely difficult time concentrating. In addition, the board games often allowed me to assess how well a person could read. During a game of Monopoly, some of the members would just hand me the cards if they landed on Community Chest or Chance, and I realized it was because they had trouble reading, a problem common in New Orleans.

Because there were different phases to my research design, someone who participated in the first phase could get sick and be hospitalized a few months later. Assessing whether they were healthy enough to participate in later phases required more attention, if this was the case. If someone was hospitalized for psychiatric reasons while I was conducting fieldwork and still expressed interest in participating, I waited at least three months before interviewing that individual, per IRB requirements.

\footnotetext{
${ }^{18}$ The sample quiz instrument is in Appendix D.
} 


\section{Methodological Limitations}

One of the challenges of interviewing individuals with chronic mental illnesses, especially with life history interviews, is they often do not remember parts of their lives when they were the sickest, usually when they were in psychosis. I usually encountered and interviewed people when they were at their healthiest points, mentally. Thus, they could tell me bits and pieces of when they were hospitalized, but many of these accounts were blurry. In addition, some of my interlocuters had difficulty remembering when certain events took place or when they came to New Orleans, if they were not from the city originally. Some medications taken for mental illnesses also affect memory. People would remember major events that occurred in New Orleans, so we used these events as a timeline. For example, Hurricane Katrina occurred in 2005 and the New Orleans Saints won the Super Bowl in 2010. Thus, for those not from New Orleans, I could get a rough idea of when people came to the city when they would say something to the likeness that it was right before the Saints won the Super Bowl.

Furthermore, I have a reasonably balanced sample size of white women, black women, and black men for the population representing individuals diagnosed with a chronic mental illness. I conducted few formal interviews with white men. Only one individual identified as Chinese, one person identified as black Hispanic, and one person identified as white Hispanic. This may partly be reflective of the population in New Orleans, which is primarily African American, though the population in New Orleans has fewer African Americans since Hurricane Katrina. My lack of interviews with white men can partly be explained by fewer white men coming to Vista for the day program. I may have been able to interview more white men at the West Bank location of Vista in Jefferson Parish, but even the white men whom I saw there were frequently hospitalized. On the East Bank in Orleans Parish, more white men came to Drop-In, 
but they were often in the city temporarily. This population was more likely to be homeless, passing through the city and using the resources at Drop-In while they were in New Orleans. While I did have many informal conversations with White men during Drop-In, I have few formal interviews because I would only see them for a few weeks at a time. Some of the white men also had substance use issues, which explained why they suddenly stopped coming to Vista. I often saw them on the streets in other parts of the city.

\section{Conclusion}

This chapter explains how I entered my research sites and who were included in my research populations: individuals diagnosed with chronic mental illnesses, caregivers, and mental health professionals, legal advocates and housing advocates. I discuss the methods I utilized, and the three-phase design I used at Vista. I end with methodological reflections discussing trust and ethics, my positionality, challenges of conducting fieldwork at home, ethical considerations in consent processes, and methodological limitations of my research. In the next chapter, I focus on stigma and disclosure, what I found from the stigma scales and hypothetical vignettes I used, and how stigma is related to people's perceptions of recovery. 


\section{CHAPTER 3}

\section{STIGMA AND DISCLOSURE}

In June of 2018, the National Alliance on Mental Illness (NAMI) held its national convention in New Orleans. Since the convention was being held close to where I was living, I decided to volunteer a few shifts so that I could attend for free and observe the various sessions and exhibits at the convention. During one of my volunteer shifts, I sat near the registration desk where I printed out name badges for individuals who were registering on-site. At one point, another volunteer stopped by and left a basket of pins which said \#CureStigma and had a link to a website. Curious about the pin, when I went home later that night, I went to the website to see what the pin and messaging were all about. I was directed to a page asking, "Have you been infected by stigma? Take a 3 question, multiple choice quiz to find out and get a free gift to spread the cure" (Cure Stigma 2018). The three questions are listed below (Cure Stigma 2018):

I think people with mental illness...
A) Need to snap out of it
B) Did something wrong to cause it
C) Need our love and support
D) Are sometimes faking it

Which of the following is a myth about stigma?
A) It makes people feel alienated or feel "less than"
B) It's not really a big problem for people with mental health conditions
C) It prevents people from seeking help for symptoms
D) It makes people fear judgement if they share their story

If someone in your family is diagnosed with a mental illness, you should:

A) Treat them differently than you used to 
B) Distance yourself from them

C) Feel sorry for them

D) Listen to them and show support

After answering these three questions, the quiz asked about my age and gender. The website then asked if I wanted to share my email to receive an emoji pack that would help me share how I feel or support someone in need. More importantly, I got a "Congratulations! Your results show that you are \#StigmaFree" result. I was slightly relieved that I did not fail the test. The website had a pledge that I signed to, "Continue to be any ally to people with mental health conditions. Together, we can \#CureStigma." The three question \#CureStigma quiz did not really excite me. The questions are more about what to do in a situation where someone has a mental illness and less to do with where stigma arises. The \#CureStigma aspect also insinuates that people who do not understand mental illness just need to be cured of ignorance, and somehow stigma will disappear. This was interesting to me since NAMI's mission, as the largest grassroots mental health organization in the U.S., is to work in communities to raise awareness, provide support, and education to those affected by mental illness (NAMI 2019). The quiz seemed like an indirect way of discussing stigma.

In the remainder of this chapter, I discuss the notions of belief and healing and their relationship to stigma, the tools I used to analyze stigma among my research population, the hypothetical vignettes I used and what they reveal about disclosure. I then examine how my interlocuters understood recovery and what this reveals about stigma.

\section{Belief and Healing}

In "The Sorcerer and His Magic" (1963), Claude Lévi-Strauss argues that for any healing system to work, three things need to occur: 1) the healer must believe in his/her power to healor act the part; 2) the patient must believe in the healer's power to heal; and 3) the broader social 
group must believe in the power of the healer and in the possibility of recovery. In psychiatry, I argue that none of these things actually occur.

Psychiatrists often admit that their peers in other branches of biomedicine do not respect what they do. In 2016, at a community meeting where the director of Metropolitan gave an overview of the programs it offers, an audience member asked her why there seem to be so few psychiatrists in the New Orleans area. The director, a psychiatrist herself, responded saying she became a psychiatrist because she enjoyed it. But members of her own medical class who had family members as surgeons and involved in other specialties would look down upon them if they had chosen psychiatry as their specialty. As the first physician in her family and a black woman, this was not something she feared like her classmates who came from families with other physicians.

The field of psychiatry has shifted from one that utilized psychoanalysis to a more biomedical approach (Luhrmann 2000). With the publication of the DSM-III in 1980, institutional changes and pressures from insurance companies, and a collaboration with pharmaceutical companies, a significant increase "in the use of psychotropic medications for mental health issues" occurred (Brereton 2018, 6-7). However, the use of these medications is controversial. At one NOLA Partnership for Mental Health community meeting I attended, the psychiatrist on the panel said he spent more time taking his patients off medications that other psychiatrists had prescribed. The panel itself was on addiction, but there was disagreement about the best ways to receive treatment.

From the patient perspective, many are in denial during initial psychosis, or have little belief in the work of psychiatrists, especially when there is little rapport to begin with. Jordan's story in Chapter 6 reveals how as a black man, he had little trust in a mental health system that 
failed him for years and revealed how he faced institutional and systemic racism. With a focus on medications prescribed by psychiatrists but lack of access to other types of therapy in their mental health treatment, my interlocuters were frustrated by their experiences seeking help. Out of the 40, only two individuals consistently saw a therapist, paying out of their own pocket for co-payments. One white man, Paul, was part of the ACT team in New Orleans, so he should have had other mental healthcare professionals as part of his treatment, but he was only in New Orleans for a few months. Of the mental health professionals people did see, only two of my interlocuters were happy with their psychiatrists. These were two white individuals who had established rapport and had seen the same psychiatrists for years. Robin, a white woman, whose story I mention later in this chapter, discussed with me who "the best psychiatrist in the city" was, but shared that he did not accept Medicaid, so she could not see him. In contrast, those who went to Central City, one of Metropolitan's clinics, had an appointment once every few months. For individuals to be members of the day program at Vista, they had to have Medicaid or be a patient at Central City, so several saw their psychiatrists at Central City. Susan, a white woman, whose story about finding a job I share later in this chapter, went to Central City but never expressed anything positive about her visits there. "It's just not welcoming. The first thing you do is walk through a metal detector and then you wait a long time to see the doctor," she shared. I went to an appointment with Tina, a 48-year-old African American woman who attended DropIn on the East Bank. Tina actually wanted me to come with her to her psychiatric appointment at Central City. After waiting for more than hour after her scheduled appointment, the psychiatrist spoke to her for 10 minutes, focusing more on the computer screen and typing in responses than making eye contact with Tina. I am not even sure the psychiatrist noticed me. When the psychiatrist finished asking Tina questions about her medications and if they were working, 
Tina's next appointment was scheduled six months later. With so little focus given to patients at these appointments, it is not hard to see why patients have little faith in some services. I asked Tina if she saw a social worker or case manager at Central City, but she responded that she was not able to see anyone on a consistent basis.

Lastly, the public, if not impacted by mental illness themselves or know someone impacted by a mental illness, often do not understand what depression and other diagnoses feel like. The budget cuts to mental health services in Louisiana and the criminalization of mental illness in New Orleans perpetuate ideas that mental illness is not a legitimate concern or ailment. The poor connection between belief and healing in psychiatry perpetuates a stigma about mental health services in general.

\section{Reconceptualizing Stigma}

In a collection of The Sociological Review Monographs (2018), the authors view their project as a way to rethink stigma, motivated by three goals: 1) how reconceptualizing stigma can better assist in developing enhanced understandings of contemporary problems of social decomposition, inequality, and injustice; 2) a way to decolonize the discipline of sociology as a way to interrogate its major theorists and concepts since Goffman's concept of stigma is ahistorical and apolitical ${ }^{19}$; and 3) putting class struggle and racism at the center of understandings of stigma as a form of power (Tyler and Slater 2018, 721-722). For these reasons, I find it more useful to conceptualize stigma through the lens of power. Who has power? How does this affect where individuals seek resources? How does this affect one's recovery?

While the scales I used to measure stigma only reveal information about how a person feels at one point in time, and as Tyler and Slater point out, often ignore questions about where

\footnotetext{
${ }^{19}$ I argue that stigma should be decolonized in anthropology as well.
} 
stigma is produced, by whom, and for what purposes, triangulated with other data such as participant observation and life history interviews, they can reveal more about stigma and recovery.

To answer one of my research questions, I used the Internalized Stigma of Mental Illness (ISMI) Scale (Ritsher, Otilingam, and Grajales 2003) and Perceived Devaluation and Discrimination (PDD) Scale (Link 1987) to measure stigma. I chose these two scales as a way to operationalize stigma and because they had the highest internal validity of the ones I found. I used these scales with 30 of my interlocutors. I read each statement to each participant as they followed along with a bright paper I gave to them with the numbers on the Likert Scale and the levels of agreement/disagreement they could choose from. Then, respondents told me how much they agreed or disagreed with each statement on a Likert scale.

To analyze the data statistically, the following process was used: for cleaning the data, 1) variables were first reverse coded if necessary; 2) variables were recoded so the range began at 0 (i.e. $1 \rightarrow 0,2 \rightarrow 1$, etc.); 3) data interpolated if $80 \%$ of the data was present (system missing variables replaced with the mean). Over $90 \%$ of the data was available (i.e. no more than three missing participant responses; 4) subscale variables were created if necessary. Some descriptives for this sample are listed below:

Age:

Range: $28-78$

Mean: 49.13

Standard Deviation: 10.41

Gender:

Female: $\mathrm{n}=18,60 \%$ of sample

Male: $\mathrm{n}=12,40 \%$ of sample

Level of Education:

College Degree: $\mathrm{n}=7,23.3 \%$ of sample

Some College: $n=13,43.3 \%$ of sample 
High school/GED: $\mathrm{n}=4,13.3 \%$ of sample

Less than High School: $n=6,20.0 \%$ of sample

\section{Ethnicity:}

Black: $n=14,46.7 \%$ of sample

Black Hispanic: $n=1,3.3 \%$ of sample

Chinese: $\mathrm{n}=1,3.3 \%$ of sample

White: $\mathrm{n}=13,43.3 \%$ of sample

White Hispanic: $n=1,3.3 \%$ of sample

\begin{tabular}{|c|c|c|c|c|c|c|c|c|}
\hline \multicolumn{9}{|c|}{ Correlations } \\
\hline & & age & Alienation & $\begin{array}{c}\text { Sterotype_En } \\
\text { dorsement }\end{array}$ & $\begin{array}{l}\text { Discriminatio } \\
\text { n_Experience }\end{array}$ & $\begin{array}{c}\text { Social_Withdr } \\
\text { awl }\end{array}$ & $\begin{array}{l}\text { Stigma_Resi } \\
\text { stance }\end{array}$ & PDD_Sum \\
\hline \multirow[t]{3}{*}{ age } & Pearson Correlation & 1 & -.101 & .191 & .073 & .142 & .183 & .116 \\
\hline & Sig. (2-tailed) & & .597 & .313 & .703 & .453 & .334 & .541 \\
\hline & $\mathrm{N}$ & 30 & 30 & 30 & 30 & 30 & 30 & 30 \\
\hline \multirow[t]{3}{*}{ Alienation } & Pearson Correlation & -.101 & 1 & .358 & $.709^{\circ *}$ & $.602^{\mathrm{kn}}$ & .026 & .366 \\
\hline & Sig. (2-tailed) & .597 & & .052 & .000 & .000 & .893 & .047 \\
\hline & $\mathrm{N}$ & 30 & 30 & 30 & 30 & 30 & 30 & 30 \\
\hline \multirow[t]{3}{*}{ Sterotype_Endorsement } & Pearson Correlation & .191 & .358 & 1 & $.463^{\mathrm{k}}$ & $.663^{* \prime}$ & $.391^{\circ}$ & .120 \\
\hline & Sig. (2-tailed) & .313 & .052 & & .010 & .000 & .033 & .528 \\
\hline & $\mathrm{N}$ & 30 & 30 & 30 & 30 & 30 & 30 & 30 \\
\hline \multirow{3}{*}{$\begin{array}{l}\text { Discrimination_Experienc } \\
\mathrm{l}\end{array}$} & Pearson Correlation & .073 & $.709^{\prime \prime}$ & $.463^{\prime \prime}$ & 1 & $.665^{*}$ & -.087 & $.608^{\circ}$ \\
\hline & Sig. (2-tailed) & .703 & .000 & .010 & & .000 & .647 & .000 \\
\hline & $\mathrm{N}$ & 30 & 30 & 30 & 30 & 30 & 30 & 30 \\
\hline \multirow[t]{3}{*}{ Social_Withdrawl } & Pearson Correlation & .142 & $.602^{\prime \prime}$ & $.663^{\prime \prime}$ & $.665^{* *}$ & 1 & .222 & .311 \\
\hline & Sig. (2-tailed) & .453 & .000 & .000 & .000 & & .238 & .095 \\
\hline & $\mathrm{N}$ & 30 & 30 & 30 & 30 & 30 & 30 & 30 \\
\hline \multirow[t]{3}{*}{ Stigma_Resistance } & Pearson Correlation & .183 & .026 & $.391^{*}$ & -.087 & .222 & 1 & -.017 \\
\hline & Sig. (2-tailed) & .334 & .893 & .033 & .647 & .238 & & .931 \\
\hline & $\mathrm{N}$ & 30 & 30 & 30 & 30 & 30 & 30 & 30 \\
\hline \multirow[t]{3}{*}{ PDD_Sum } & Pearson Correlation & .116 & $.366^{*}$ & .120 & $608^{\prime \prime}$ & .311 & -.017 & 1 \\
\hline & Sig. (2-tailed) & .541 & .047 & .528 & .000 & .095 & .931 & \\
\hline & $\mathrm{N}$ & 30 & 30 & 30 & 30 & 30 & 30 & 30 \\
\hline
\end{tabular}

Table 6: Correlation of Stigma Scales

Table 6 shows the correlations between the ISMI scale (which measures alienation, stereotype endorsement, discrimination experience, social withdrawal, and stigma resistance) and the PDD scale which measures perceived devaluation and discrimination. The Pearson's $r$ test reveals that stereotype endorsement is significantly positively correlated with discrimination experience $(\mathrm{r}=.463, \mathrm{p}<.01)$, while stereotype endorsement is also significantly positively correlated with stigma resistance $(\mathrm{r}=.391, \mathrm{p}=.033)$. There was no correlation with age. For other 
types of statistical tests, the scales showed no correlation with gender, ethnicity, or level of education.

The responses to the scales revealed some obvious flaws with the scales themselves. First, most of my interlocuters had a response to all the statements, but several decided to skip some statements. Others responded neutrally even though that was not really an option; nevertheless, I recorded the response as neutral or noted that they skipped the question. Instead of the numerical score people responded with, I found the unsolicited information people shared explaining why they picked a certain score much more interesting. One of the statements on the PDD scale is, "Most people in my community would treat a former mental patient just as they would treat anyone" (Link 1987, 111). After their responses to this statement, I asked my interlocuters how they defined community. Some responded with their neighborhood where they lived $(\mathrm{n}=7)$ or friends and family $(\mathrm{n}=3)$, the black community $(\mathrm{n}=1)$, but the majority stated Vista as their community ( $\mathrm{n}=19)$. This is not surprising given that I was conducting most of these interviews at Vista, a place where many of the respondents came as members of the day program or for Drop-In.

For other statements, like "People discriminate against me because I have a mental illness" under discrimination experience in the ISMI scale, one respondent shared, "I don't go around telling people. I think it's more stigma from the news." Under social withdrawal for the ISMI scale, the same individual, where the statement is “I don't socialize as much as I used to because my mental illness might make me look or behave "weird,"” the same individual responded that he did not socialize much because he did not have "much money" to begin with, not because of his mental illness. Under stigma resistance for the ISMI, the statement "I feel comfortable being seen in public with an obviously mentally ill person," Samantha a 42 -year-old 
white woman responded with "disagree" even though she herself was in severe psychosis and hospitalized just a few years earlier. She mentioned another member at Vista who was clearly in psychosis and thought about whether she hung out with him or not on social outings that Vista coordinated. Later on, Samantha discussed how the scales made her think more about her own experiences and behavior and wanting to participate more in community meetings concerning mental health. For the PDD scale, statement 12, “Once they know a person was in a mental hospital, most people will take his/her opinions less seriously," Samantha shared, "Once you're on record as mentally ill in the hospital, if you go to the ER for any physical reason, you will end up in the mental hospital." She continued, "They will say you're not really sick, just mentally ill." She explained how she thought she was having a cardiac episode, but the doctors were telling her she was having a panic attack, even though she was not panicked about anything or prone to panic attacks. When respondents would go into detail with responses like these, it was helpful to discuss later on for illness narratives and life histories.

Further, some individuals said things like "I used to feel that way but not anymore" to a statement, revealing how the scales only give a person's perspective about stigma at one point in time. The use of these scales from social psychology research that seek to measure, classify, and quantify stigma is limited by the tendency to produce an understanding of stigma as a static attitude instead of social process that is constantly changing and often resisted (Tyler and Slater $2018,731)$. In addition, Tyler and Slater $(2018,731)$ encourage social scientists to look up "to the forces which shape the emergence of stigma in everyday contexts," including taking "into account structural and structuring factors, such as history (time), geography (place), politics and economic conditions." 
In Louisiana, with state policies such as the closure of Big Charity and privatization of most of the other public safety-net hospitals in Louisiana, which population is the most stigmatized? With the proposed expansion of the Orleans Justice Center (OJC) for mental health beds by the New Orleans City Council, which population is most likely to end up at OJC? Of the 40 individuals I interviewed, one white woman had been in prison for defending herself from an abuser, one white woman spent one night at Orleans Parish Prison for stealing clothes from WalMart, and another white woman was being transported from a local hospital to Orleans Parish Prison (OPP), but because her foot was broken, OPP turned her away. Of the five white men I interviewed, only one man was arrested for being drunk, but his lawyer was able to get those charges expunged, and another white man was caught trespassing on private property, but his grandmother was able to make some calls to make sure he did not get charged.

In contrast, of the 10 black men I interviewed, one man got his diagnosis of schizophrenia at OPP after being stabbed in the head by another inmate, three other men had spent significant time at Angola, the maximum-security prison in Louisiana, or other prisons in the state, and two other black men had been in OPP, and countless others were just terrified of the New Orleans Police Department (NOPD). Six out of the 10 black men in my research population who identified as black or black Hispanic had been in jail or prison, a sharp contrast to my white interlocuters. One black woman tried calling NOPD to help her daughter who was being attacked by her abuser, but somehow her daughter ended up in jail. Every few months, NOPD officers would visit Vista as part of their Crisis Intervention Team training, and the staff would give a warning to those present if they wanted to leave. It was not coincidence that the black men would often leave. As one of the staff members at Vista reiterated to me, "They see 
the police, they get frightened, and they think Mandeville" (referring to the psychiatric hospital on the Northshore). They were probably also thinking jail.

Brenda, a 52-year-old black woman whose story I describe more in Chapter 4, worked at Angola as a guard during Hurricane Katrina. She recounted how often she gets stopped by the NOPD just because she is black. However, when they find out she used to be a guard, they tell her "Oh, you're one of us." She recounted to me, "I let them think I'm one of them, but I'll never be one of them."

\section{The Effect of Stigma Perceptions on Disclosure}

Since I was interested in how perceived stigma affects how and whether people disclose their mental illness, I used two hypothetical vignettes where I read a story, asked people if the person should disclose their mental illness, and if they were in that situation, what they would do. ${ }^{20}$ The first vignette involves work and the second deals with relationships. I chose these two themes because during preliminary fieldwork, the most common discussions had to do with experiences at other workplaces and relationships. For instance, Susan, a 57-year-old white woman, shared while playing a game of Rummikub during Drop-In with me and Estelle, a 50year-old white woman, that as a peer support specialist, she was not allowed to date anyone at Vista. Estelle responded, “Why would you want to date someone from here? Wouldn't you want to date someone who was normal?" The conversation turned into the benefits of dating someone who also had a mental illness and then the availability of men in general.

The two vignettes are below:

Work: John recently gained employment at a new job where he has been happily working for three months. However, in the past week, the symptoms from John's illness are beginning to flare up. John has been diagnosed with schizophrenia for the past ten years,

\footnotetext{
${ }^{20}$ These vignettes were approved by SMU IRB. I would have liked to have the stories a bit more nuanced but could not change the story from what was approved by my IRB. They focus on work and relationships because these were the topics my interlocuters discussed frequently during preliminary fieldwork.
} 
and the symptoms of his illness are beginning to affect John's work at his new job. He has missed several workdays, shows up late when he does come, and has a hard time concentrating and finishing his tasks. Should John tell his employer he has a mental illness?

Relationships: Donna is a 45-year-old single mother of two girls. She hasn't dated anyone for several years, but she just started a new relationship with a man she met from her church. She has been dating Kevin for one month. Kevin doesn't know Donna has been diagnosed with bipolar disorder. Donna wants to tell Kevin about her illness, but she is afraid telling him about her illness will scare him away. Should Donna tell Kevin she has bipolar disorder?

For the vignette about work, two responded with "don't know," two responded with "no," but everyone else said yes (26 out of 30). For work, they explained it was better to tell the employer than risk getting fired, and the employer would probably find out anyway. My white interlocuters were also aware of disability laws, noting that one could not simply be fired for having a disability.

For the vignette about relationships, there were more differences. Out of 30, 19 people said the individual should disclose the diagnosis. Ten people said no, and one person replied with “don't know." There was no correlation with gender, but there was with ethnicity. Nine out of the 10 who said no identified as black or African American. In fact, with ethnicity and level of education, a crosstab test revealed that those with higher levels of education (college degree or some college) were more likely to say no to disclosing mental illness about the relationship. The responses to the rationale for these decisions were also interesting. Martha, a 63-year-old white woman, responded saying, "You are not your illness." She went on to say people should know you for all the parts that make you up. Susan, who I mentioned earlier during a game of Rummikub, responded with yes, but not right away for the vignette about relationships. She mentioned a strategy where she would first tell people where she works, explaining the services Vista provides. Judging how people reacted to where she worked, she would decide if it was 
worth maintaining the relationship. She explained that in the past, sometimes people would react by saying, "Is that the place for crazy people?," and this would deter her from disclosing that she had a mental illness. Others had the opposite idea. Tina, a 48-year-old African American woman, responded with no to the vignette about relationships, but said "I'd wait a year or two."

The responses to the vignettes then suggest that most of my interlocuters would disclose their diagnosis in the work context but not in a relationship. Disclosure was probably more likely to happen with those who were also peer support specialists and shared their stories in public at various community events. For instance, Martha's family knew she worked at Vista and all her friends knew about her diagnosis. Hence, when she asked me to come to her apartment for Mardi Gras, and I asked about privacy concerns, she said did not care. At her age, 63, she knew who her friends were and whom she could trust and did not bother spending time with people who did not understand mental illness.

But what people say they will do and what they actually are often not the same. Take for instance, Susan, who responded with yes to both vignettes. Susan worked as a peer at the West Bank location of Vista. She was a member of the day program at Vista on the East Bank but was one of the few people I knew who had a car, so she could easily get to work on the West Bank where she went four times a week as manager of Drop-In.

\section{Institutionalized Stigma: Obstacles to Finding a Job}

Towards the end of May 2017, the program director told Susan that Jefferson Parish Human Services Authority did not renew its contract with Vista due to budget cuts and a myriad of other reasons, so the Drop-In Program was closing. This also meant that Susan was losing her job. She could continue coming in on Fridays to run the peer group, but the cost of gas for her car and driving to the West Bank from her apartment on the East Bank for one hour a week was 
not worth it for what she would get paid. Susan was declined unemployment benefits because she refused the one-hour job running the peer group, and with unemployment benefits, an individual is not supposed to reject the first job offer they get. Thus, Susan was given two days' notice that she would be out of a job. With just her SSDI left, which was about $\$ 730$ a month, she was worried about paying rent, the notes on her car, and other bills. Finding a job during the summer in New Orleans is also difficult; many of the students from local universities leave during the summer, especially in the area Susan lives, and many businesses do not hire again until the college students return for the Fall semester. Susan called me the day she learned she was losing her job, and I ran into her at Vista on the East Bank later in the week, and she felt ashamed even though it was beyond her control. "You don't know what it feels like to be called into an office and told bad news that you've been fired," Susan told me. I responded, "Actually, I do. Believe it or not, I've been fired." "You?!," Susan responded in disbelief. "Yes," I replied. "No!," Susan replied. "Yup," I replied. "I need to hear this story," Susan responded. I told Susan about my part-time job working in the Provost's Office at SMU. "During my last semester in Dallas, I had a scanning job where I was just supposed to file things and scan them. But after three weeks, the lady in charge sat me down and said they didn't have room for the scanner. And that was my last day working in that office. Of course, the scanner was already there, so it didn't make sense that was the reason why I was fired." Susan then asked, "What was the real reason then?” I replied, “I think they were racist. They certainly weren't expecting a Muslim woman showing up at that office, which was clear by their reactions when I showed up." Susan was still in disbelief. "Anyway, technically you weren't fired. You were laid off," I responded in an attempt to make Susan feel better. "Did you do anything about your situation?," Susan asked me. It was my last semester in Dallas, I was about to move anyway, and it was my third job, and one 
that I did not particularly enjoy, so I honestly did not care. I told Susan, "I do think it was a racial thing because I asked the two white women who worked that same position before me, and they were convinced it was racist. But I also later found out that office got sued by another student for violating Title IX, so that made me feel better."

As we continued talking over a game of Rummikub, Susan was more concerned about how to pay her bills without the extra income from Vista. She reasoned she could cut down costs for gas which would be reduced anyway since she would not be driving to the West Bank anymore. But her rent bill worried her the most. "Aren't you in one of those housing programs that is based on income? Can't you get your bill reduced since your income is lower now?," I asked. Susan then realized she was but had forgotten. Susan's face lit up at remembering this, and she immediately contacted her housing manager. Since the housing program Susan was in charges 20 percent of one's income, Susan's rent would be reduced based on the lower income she now had. Susan said she was going to look for jobs in a warehouse type store, stocking equipment, since she had previous experience in this area. But after three months, Susan still had not found another job. She had gone to several temp agencies that had helped her edit her résumé, but the tests or skills they assessed made her "feel dumb." Although she had a certificate from a local community college and more education than many other individuals I interviewed, she felt that what she had learned in college seemed outdated and did not help with her job applications.

Another barrier for Susan was she did not have a personal computer, and most job applications are online now. She had access to use the computers at Vista on the East Bank, but she never had enough time to finish an application. The public libraries limited computer usage to 15 minutes at a time, so the online applications were becoming a frustrating obstacle. I ran 
into Susan at Drop-In on the East Bank when I saw her in August, and I offered to help her with the job applications. Susan took up on my offer, and we sat at McDonald's near her apartment on Labor Day.

Susan came prepared with a list of places she wanted to work, and I brought my laptop to connect to the free Wi-Fi at McDonald's. She was previously focusing on warehouse jobs in Jefferson Parish, but at that point, she was willing to apply to cashier jobs and expanding her search to Orleans Parish as well. Noticing that the McDonald's we were sitting in had a sign up that they were hiring, I asked Susan if she wanted to apply at McDonald's. Susan quickly responded with, “No. I actually used to work at McDonald's, this same one in fact, and I don't want to do what I was doing before."

Most of the job applications were similar. They asked for previous places of employment; you could copy and paste or just upload a résumé. They also asked for a reference. Susan used her reference at Vista; since she was laid off for reasons beyond her control, she was in good standing there. After the previous employment and references, the forms had questions about any previous felony convictions, and some of the applications had assessment and personality type questions. For this part, I would take a break to use the restroom and stretch my legs, while Susan completed these assessments using my computer. A few asked questions about disabilities, particularly the jobs at drug stores including Walgreens and CVS.

We had completed more than 10 applications that day. Several of the applications asked questions about disabilities through the "Voluntary Self-Identification of Disability" Form CC305. The application explained the reasoning for asking applicants to complete this form (U.S. Department of Labor n.d.):

Because we do business with the government, we must reach out to, hire, and provide equal opportunity to qualified people with disabilities. To help us measure how well we 
are doing, we are asking you to tell us if you have a disability or if you ever had a disability. Completing this form is voluntary, but we hope that you will choose to fill it out. If you are applying for a job, any answer you give will be kept private and will not be used against you in any way. If you already work for us, your answer will not be used against you in any way. Because a person may become disabled at any time, we are required to ask all of our employees to update their information every five years. You may voluntarily self-identify as having a disability on this form without fear of any punishment because you did not identify as having a disability earlier.

The form included a list of physical and mental impairments, shown in Table 7 below, and

Susan's diagnosis, bipolar disorder, was on the list. The response choices included "Yes, I have a disability (or previously had a disability)," where you could check off which disability you have; "No, I don't have a disability;" or "I don't wish to answer." I looked at Susan and asked her how she wanted to respond.

\section{How do I know if I have a disability?}

You are considered to have a disability if you have a physical or mental impairment or medical condition that substantially limits a major life activity, or if you have a history or record of such an impairment or medical condition. Disabilities include, but are not limited to:

- Blindness

- Deafness

- Cancer

- Diabetes

- Epilepsy
- Autism

- Cerebral palsy

- HIV/AIDS

- Schizophrenia

- Muscular dystrophy
- Bipolar disorder

- Major - Post-traumatic stress disorder depression (PTSD)

- Multiple sclerosis (MS)

- $\quad$ Missing limbs or partially missing limbs
- Obsessive compulsive disorder

- Impairments requiring the use of a wheelchair

- Intellectual disability (previously called mental retardation)

Table 7: U.S. Department of Labor Disability Identification Form

She sat at our table, thinking for a few minutes before saying anything, and then told me to click on "I don't wish to answer." Susan's rationale was she did not want to lie, but she also stated she did not know how the employer would use the info. Even though 'I don't wish to 
answer" was not the ideal response, it was the one Susan chose. Did it mean someone had something to hide or is a troublemaker?

Susan did not want to risk skipping any part of the applications, since she had been looking for a job for three months, at that point. She was already limited to where she could work. She had already applied to Michael's, World Market, Office Depot, and other stores in the area. When I asked her why Wal-Mart was not on her list, since they always seem to need cashiers, Susan replied saying she had been on Wal-Mart's no-hire list for more than 20 years. Susan had called a local Wal-Mart just to check, and apparently, she was still on the company's no-hire list. When I asked why, Susan responded saying, “I wasn't on my medications back then." A customer had complained about her, and Susan did not remember if she actually was rude to the customer or not, but she was fired and put on Wal-Mart's no hire list.

On the day I helped her fill out online applications, we looked at or completed applications to Target, JOANN Fabrics and Crafts, Home Depot, Walgreens, CVS, and grocery stores for positions either in the warehouse, stocking supplies, or as a cashier. Having thought of all the places Susan was interested in and completing those applications, we left McDonald's after a few hours. Susan was extremely grateful that I devoted the day to helping her fill out applications and said it would have taken her days to have completed that many applications. I told her maybe she would hopefully hear back from one of the places, and if she did not, we could spend another afternoon looking up more places. Fortunately, she heard back from one of the local grocery stores two days later and ended up working at the grocery store as a cashier within the next month, after she went through orientation and training. 


\section{Stigmatized "Productivity"}

Susan, as a white woman with some community college education, was at an advantage, but even with this privilege it took her more than three months to find a job after being laid off from Vista. Many of my other interlocuters also had part time jobs at either fast food restaurants or as janitors. But many, especially the black men, would not have made it far along the application, especially with the question about having a felony conviction. One of the most common questions that probably annoyed my interlocuters outside of Vista was, "What do you do?" Because of their disability, they had a hard time answering this if they were not working because unless they were clearly in psychosis, their disability was not a visible one. Samantha, a 42-year-old white woman originally from California told me people often asked her on the corner when she was waiting for transportation to Vista or when she was using public transportation, "I'm a disabled artist." But she also felt like she was "outing herself" with this response.

Others did not know how to answer what they did at Vista. Cornelius, an older black man who was a member at Vista during the day program, asked José, a staff member, what the program they are in is called during one of the units when they were discussing recovery. He knew it was a day program but shared, "I don’t know what to tell people when they ask." José responded, "You can call it a recovery or rehabilitation program. You don't have to tell them exactly what it's for. It's not their business." However, I thought, much of what we do is tied to our identity. Even the measurement of health conditions and its impact from health problems is tied to productivity. For instance, disability-adjusted life years or DALYs, is a calculation of the impact of health problems on productive activity in society. This is a common measure for health conditions including mental illness, though a controversial one (Anand and Hanson 1997). 
"Mental and behavioral disorders are one of the largest contributors to DALYs," accounting for $22.5 \%$ of the global burden (Kohrt and Mendenhall 2015, 14). While mental health has long been ignored in the global health community, the increased "attention that global mental health has received in recent years" may be linked to the growing use of DALY metric in epidemiology (Kohrt, Mendenhall, and Brown 2015, 25).

This idea of productivity is not new. The notions of productivity and having some contribution to society are reminiscent of what Foucault describes in Madness and Civilization: as the Hôpital Général served "to contain the unemployed, the idle, and vagabonds," the period of confinement, "acquired another meaning. Its repressive function was combined with a new use. It was no longer merely a question of confining those out of work, but of giving work to those who had been confined and thus making them contribute to the prosperity of all" (1988, 50-51). During the $17^{\text {th }}$ century, madness was associated with the condemnation of idleness, and with convenience, the need for community labor guaranteed madness (Foucault 1988, 58).

Neely Myers" notion of moral agency states that "in order for people to become the kind of person they want to be in the world, they must act in a way that helps others recognize them as the person they hope to be and hold them accountable for it" $(2015,156)$. Much of this rhetoric around the concept of recovery is tied to US cultural values about what it means to be a good, valued citizen (Myers 2015, 157), and this well-valued citizen is often translated as one who has a job and contributes to society.

Many of my interlocuters, I would argue, were productive even if they did not have full time jobs. Susan spent much of her leisurely time crocheting afghans and lap blankets, first for a hospice, then at a hospital where she volunteered in the arts and crafts department. Crocheting for her was a way to deal with her mental illness. She knew it calmed her down, and the focus 
gave her something to do. As long as she did not use the color black for yarn, she was okay. Susan often got requests to crochet black and gold colored blankets, the colors for the New Orleans Saints football team, but shared, "Black puts me into psychosis." Something about that color just was not healthy for her. Her designs were intricate and carefully thought out; the blankets she made easily could have sold for hundreds of dollars.

Robin, a 28-year-old white woman, worked at Drop-In on the East Bank for several years. In the summer of 2016, she went to Baton Rouge with her siblings to help gut homes that had been affected by the flooding from severe rain. She asked me if I wanted to join the next weekend. I went along, prepared with gloves, a hammer, and a mask as gutting homes was not something new to me. I thought the person whose home we were going to was someone Robin knew intimately; in fact, Robin did not really know the owner of the home. It just happened to be the grandmother of a friend of her sister's, but she lived alone and could use all the help she could gutting the drywall in the house. We spent two days at a stranger's home doing hard labor, and I cannot think of a better example of someone contributing to society.

\section{Nostalgia}

My older interlocuters did feel a sense of missing out on life by not having a consistent job. Martha, 63-years-old, sat next to me on a bus on the way back from Baton Rouge for Behavioral Health Day, a day each year, usually in May, where individuals come to the state capitol to advocate for mental health resources with legislators. Martha disclosed, "I regret not having a career." I was kind of confused because she was so involved with Vista as a peer support specialist, trained others, and was involved leading other support groups in the city, I viewed that as her career and mentioned that to her. While Martha got involved with Vista later in her life, as the oldest of several sisters, many with professional careers, she sometimes felt like 
she was not doing important work like her sisters or that they sort of looked down upon her. She mentioned the various part time jobs she had during her life, and how she enjoyed working them, but she felt like she missed out on life with her illness. Jordan, a 52-year-old black man, shared the same sentiment at the end of a presentation he was doing for the NOPD Crisis Intervention Team recruits. He told his usual story of how he was sick from a young age, was misdiagnosed for years, tried different jobs over the years but would always get fired, but it was not until he had the correct diagnosis that he felt like his life began. By then, he felt it was too late to go back to college. He looked over at the person in charge of the NOPD recruits and said, "I could have been you, standing there!" The other recruits responded back saying, "Trust me. You don't want to be him!"

For others, their opportunity for a career did happen. Robin, a 29-year old white woman who worked at Drop-In for several years, started off as a volunteer and then was offered the job to work at Drop-In on the East Bank. After several years of hearing voices, her parents found her an experimental treatment program in another state. Robin is unsure whether it was that experimental program or finally being on the correct medications, but she stopped hearing voices. She decided she wanted to do the type of work others did at Vista, so she applied to a social work program. Robin had finished her undergraduate degree in art, so she did not have the required statistics class to start the program. She took an online statistics class, did well and was admitted into the social work program. However, she only took one class at a time, so she would not get overwhelmed. Robin did not know if it was because of her illness or the medications she took, but she felt like it took her longer to process things when she was reading. She finished the coursework part of her program. When it came to start her internship, she had to quit her job at Vista as a peer and start somewhere else. But she is doing well. Others at Vista were happy for 
her, but she also had the resources to get the help she needed early in her psychosis. Her parents are both working health professionals who had the knowledge and resources to find the help Robin needed. Robin gets one of her medications in the form of a shot, but she has to do bloodwork consistently to receive the medication. Sometimes the labwork does not make it in time for her to receive her medication, often stressing her out. Her dad, who is a physician, will pull strings and call the pharmacy for Robin to get what she needs. Furthermore, Robin's tuition is paid for by a trust from her grandmother. Robin often explained to me, "My grandmother grew up in the Depression era and saved every single penny. She left my siblings and me money specifically for our education.” Through this fund, Robin can afford to pay for her social work program. When Robin left Vista, the other peers and members were happy for her, but Robin also had the resources to get the help she needed early in her psychosis and the resources that would make it possible to go back to school. She did not have previous arrests or convictions preventing her from getting a job like many of my black interlocuters did. In addition, her family had the resources to find her the best healthcare when she was in psychosis, helping her with her recovery. Lastly, Robin came from a wealthier family, and the funds from her grandmother enabled her to go back to school. Her status as a younger, white woman from an upper-class background allowed her the opportunity to pursue a career.

\section{Recovery}

Given how much language about recovery was discussed at Vista and at mental health fairs and community meetings I attended around the city, I asked my interlocuters, "What does recovery mean to you?" This question revealed another dimension to the intersectionality of stigma and what it means to be productive. 
A content analysis showed the differences between my white interlocuters and black interlocuters. William, a 44-year-old white man, stated, "It's a life-long process. I know I can improve myself in life. Reinvent yourself, spend your time wisely, be grateful for the gift of life." Samantha, who I mentioned earlier in the chapter, responded by saying, "The word's a little inaccurate. It's not a bout of flu. It's a process." She mentioned how she liked how other dimensions were incorporated into recovery, including emotional and spiritual wellness. Robin shared, "It's not a cure. My illness is well managed but never going away. It's easier to deal with." She mentioned her life is very different today than it was 10 years ago, but she had her mother and her sister to help with finding the best doctors. Catherine, the oldest person I interviewed, at 78-years-old, said "Recovery is not being ashamed you have a mental illness."

In contrast, my black interlocuters often mentioned taking medicines and coming to Vista as some dimension of recovery. Tabitha, a 51-year-old African American woman shared, "To me, you're stable, able to go to school, get a job if you qualify for it, doing what makes you happy legally, going out, getting to know people, all that relates to recovery. Being productive." Tina, a 42-year-old African American woman, shared, "Recovery is ongoing. It's staying healthy, taking medicine, following up with the doctor, and staying out of the hospital." Marcus, a 32-year-old black man, said, "I guess it means staying healthy, out of the hospital. It means taking your medicine, coming here, and doing what the doctor tells you.” James, a 57-year-old black man, had the response that was the shortest but perhaps most informative: "Being free. Not in jail." James had spent a good number of years in prison; thus, his response made sense given his history.

The racialized differences between the responses showed how my black interlocuters found some responsibility in their recovery. They viewed recovery as taking medicine, following 
orders from a doctor, and not getting in trouble. Many of my white interlocuters viewed recovery as a process. Recovery for them was in some way about improving themselves, but it was broader than "staying out of a hospital" or "taking medicine." They understood that sometimes even with doing everything in their power to stay healthy, they could still end up in the hospital. My black interlocuters in some way conceptualized recovery as staying out of trouble by doing what others had told them to do. By examining recovery in this way, I argue that my black interlocuters experience stigma syndemics. According to Singer, Ostrach, and Lerman, in syndemic interactions, "stigma is a primary driving structural or social factor" which affects "disease interactions through the stigmatized identities of the sufferers, the stigmatization of illnesses or health conditions, or both" (2017, viii). In other words, stigma can drive syndemic interactions and worsen health. My black interlocuters (nine out of 10), who did not want to reveal their diagnoses in the context of relationships, shared their own experiences of what happened when they did in the past after I shared the hypothetical vignettes. Not only do they carry the stigma of having a mental illness, they have to explain why they may not have a job, and how this is linked not only to their diagnosis but also to a past felony conviction.

\section{Conclusion}

This chapter began with a consideration of what stigma is and where it arises from. I analyzed the notion of belief and healing and how this relates to stigma. Here, I argue that healing really does not occur in mental health services because the belief in healing does not exist at the three levels Claude Lévi-Strauss lists: from the healer (especially amongst psychiatrists), from the patient, and from broader society.

I then examined stigma using the ISMI and PDD scales for individuals. While problematic on their own, the responses after the numerical answers revealed more about what 
people thought. For example, several interlocuters shared that they felt stigmatized by health professionals themselves when trying to seek treatment for physical ailments. By triangulating the scales with hypothetical vignettes, regarding whether individuals should disclose their diagnoses, the data revealed more about stigmatized "productivity" alongside the stories of Susan and Robin. For instance, even when unemployed or underemployed, Susan and Robin volunteered their time for others. Susan crocheted blankets to donate to local hospitals and Robin went to Baton Rouge several weekends when the area flooded to help others gut their homes.

I reconceptualize stigma to place class struggle and racism at its center. While all but one of my 40 interlocuters were poor, those from upper-class, white families had more resources and power to seek help. Robin, for instance, had the ability to get her medications, when there was a delay, through her dad, who is a physician; she was also able to return to school with money saved by her grandmother. Susan, while she had fewer supportive family members than Robin, still had some college education. Besides not being able to work at Wal-Mart, she had fewer obstacles to getting a job compared to the black members at Vista, many of whom spent considerable time in jail or prison in Louisiana.

I then examined how my interlocuters understood recovery and what this reveals about stigma. There is a considerable contrast between my white interlocuters, who viewed recovery as a process and something they have to learn to manage, and my black interlocuters who viewed recovery as following some type of command such as taking medications, listening to the doctor, and staying out of the hospital. James' response, defining recovery as, "Being free. Not in jail," reveals the anxieties and tribulations my black interlocuters think about on a daily basis; these did not plague my white interlocuters. 
This chapter has explored stigma at the individual level. In the next chapter, I focus on minority mental health and how stigma affects people at the community level. 


\section{CHAPTER 4}

\section{MINORITY MENTAL HEALTH}

This chapter addresses mental health issues affecting communities of color in the context of the aftermath of Hurricane Katrina. I begin by summarizing a panel I attended in July 2015 that focused on minority mental health. I then summarize some of the main themes from that panel along with other themes I found while interviewing people of color diagnosed with chronic mental illnesses.

\section{Minority Mental Health Month}

July is Minority Mental Health Month. On July 21, 2015, I attended a panel discussion focused on Minority Mental Health in New Orleans. The panelists included then Councilmember and now Mayor LaToya Cantrell, New Orleans Coroner and psychiatrist Dr. Jeffery Rouse, Charlotte Parent, director of the City of New Orleans Health Department at the time, retired Judge Calvin Johnson who started the first mental health court in Louisiana, Chantrelle VarnadoJohnson, a licensed personal counselor and a board member of NAMI New Orleans, and Lisa Romback, Executive Director of NAMI New Orleans. The panel was moderated by Jarvis DeBerry, a local columnist and editorial writer for The Times-Picayune.

One week before the panel, Jarvis DeBerry had written a column, "Mental Illness Can Push Even the Brightest People into Homelessness," (2015) where he cited an article from The Washington Post entitled, "The Homeless Man Who Went to Harvard Law with John Roberts" (McCoy 2015). The Washington Post article told the story of Alfred Postell, a Harvard law 
graduate diagnosed with schizophrenia who was homeless in Washington, D.C. Postell appeared at the D.C. Superior Court before Judge Thomas Motley, charged with unlawful entry. In court, Postell said he was a lawyer. This proclamation did not gather much attention, but then Postell said he graduated from Harvard Law School in 1979. This caught Judge Motley's attention because Judge Motley also graduated from Harvard Law School that same year and remembered Postell.

DeBerry wrote about Alfred Postell's story and referenced Pulitzer-Prize winning American poet Gwendolyn Brooks. The poem that DeBerry referenced was "To an Old Black Woman, Homeless and Indistinct." This poem reminded DeBerry of Postell's story, a welleducated black man from a modest background with degrees in accounting, economics, and law who held promise but somehow ended up homeless. Postell's story makes us rethink our assumptions about the people we encounter. Referencing Brooks' poem, DeBerry tells his audience that the poet tried to nudge us away from our assumptions when she concluded her poem:

Folks used to celebrate your birthday!

Folks used to say "She's such a pretty little thing!"

Folks used to say "She draws such handsome horses, cows and houses," Folks used to say "That child is going far."

After DeBerry's piece was published in The Times-Picayune, he was invited to moderate the July 21 panel discussion about mental illness amongst people of color one week later. That morning, DeBerry wrote a column, "How Easy Is It for People of Color to Get Mental Health Treatment in New Orleans" (2015). In this column, DeBerry, a black man, encouraged people to attend the panel in the evening and ask the panelists "whatever questions you have about mental health treatment in New Orleans and the New Orleans area" (2015). 
I attended the panel discussion that evening at the New Orleans Jazz Market on Oretha Castle Haley Boulevard, a quickly gentrifying area of the Central City neighborhood. Much of the first half of the discussion focused on the panelists, what roles they played within the mental health community, what resources for mental health treatment exist in New Orleans for individuals with mental illness and family members, how to access these resources, and what the city needs to work on. Many of the issues the panelists discussed were issues I would hear repeatedly during fieldwork: the lack of resources for people without insurance and how insurance makes a significant difference on the quality of care one receives. The panel also occurred in the months leading up to the Louisiana governor's election, with Republican Governor Bobby Jindal's term ending that year. The panelists kept making references to the election, repeatedly asking audience members to ask the candidates for governor if they would expand Medicaid in Louisiana under the Affordable Care Act.

After about 40 minutes, the panelists finally discussed minority mental health, when Jarvis DeBerry, as moderator, asked the panelists specifically:

This conversation is happening during minority mental health month. What's the difference between somebody, uhh, a white person in New Orleans who needs mental health treatment and a person of color who needs mental health treatment? Are there differences? Or is mental illness just mental illness? I'm guessing there must be some difference. Otherwise, we wouldn't have minority mental health month?

NAMI New Orleans director Lisa Romback jumped in first to answer DeBerry's question, saying minority communities are less likely to access treatment, less likely to receive treatment, often receive poor quality of care, experience higher levels of stigma, face culturally insensitive healthcare systems, bias or discrimination, language barriers, and low rates of health insurance. Romback went on to say, "I think in particular, with African American communities, the stigma issue is more pronounced. There tends to be this idea, you can pull yourselves up by your 
bootstraps or people are reluctant to seek care." Romback stated these issues can be found across the United States, but they are also true in New Orleans.

Judge Calvin Johnson stepped in after Lisa Romback spoke and referenced Hurricane Katrina. For those who were in New Orleans during Katrina, Judge Johnson talked about the people who were waiting on the bridges to be rescued, most of whom were African Americans. There were many elderly individuals with their children and grandchildren, who were six, eight, or ten years old on the bridges. Those children are now 20 years old or older. Judge Johnson asked,

What would be the impact for Calvin if he was on top of a bridge with his grandmother who died sitting next to him waiting for help to come, and it didn't come? Go with that for a second, then you think, so why is Calvin pissed off? Why is Calvin today angry? Why is Calvin mad? Maybe part of the reason is because no one came for him. See? And that may be part of the reason.

The trauma associated with Hurricane Katrina for many black residents is something many individuals have never really addressed. Judge Johnson continued, discussing stigma: "Black people have a real problem dealing with mental illness in the black community. Part of the problem is...it's lots of problems. But some of it deals with income in terms of poverty, and resources are not sufficient.” Judge Johnson continued, “And we are very religious. We believe we can pray our way out of this.” According to Judge Johnson, beyond the African American community, stigma exists, but it seems to be more pronounced in this community.

The last portion of the panel was dedicated to questions from the audience. Some of the questions were ones I had repeatedly heard in my work and centered around asking the panelists how to increase facilities and mental health resources in the city and where they could access existing resources. One question in particular caught my attention. A woman from the audience went up to the microphone at the front of the room: 
I have a very grim question. It's not pretty. What about the families of murder victims who are at the Coroner's? What about the parents of murder victims? Do we see them? Are we helping them personally? I'm a sibling of a victim. I don't recall a connection to mental health assistance. Are there any programs? Is there a system in place? Once a family identifies a body, it's the most unimaginable thing ever.

A few minutes later, another black woman who was a nurse at Charity Hospital in the psychiatric unit got up to the podium with similar sentiments:

My husband, who was an attorney, was shot and killed on the streets of New Orleans. My 18-year-old daughter was in the car with her boyfriend when a driveby came and shot him. He died in her arms. Had it not been for my knowledge of the mental health system and the extensive therapy that I had to take my daughters to because at the time of their father's death, they were five and 10 years old. Had it not been for my knowledge of the mental health system and my connection, I don't know that I would have made it through. Because it's very difficult for us, it was very traumatic, and to this day, talking about it is still very painful for me.

The nurse went on to talk about the importance of cultural sensitivity in efforts to engage patients into the mental health care system. The last question from the audience was from a woman who worked with the Latina/o community on an ad hoc basis for more than 30 years on issues concerning housing, education, and things the community needs for their children and themselves. However, she was trying to access mental healthcare services for a young boy after Katrina whose parents were Hispanic, but nothing was available. She expressed her frustration that there is still little available for those not speaking English, and almost no therapy available to someone on Medicaid. Her question to the panelists was what their ideas were to bridge those gaps.

\section{Trauma-Informed Care?}

The questions audience members asked at the Minority Mental Health Panel reveal what residents of New Orleans actually want but do not receive. I heard the phrase "trauma-informed care" and more requests for this type of care during the minority mental health panel and at other community events organized by the Behavioral Health Council of New Orleans. According to 
Clark et al. $(2015,5)$, “Trauma-informed services are those that incorporate an understanding of the impact of violence and psychological trauma in the lives of consumers of mental health, healthcare, and social services." Following the DSM-5, Clark et al. $(2015,6)$ define trauma as “exposure to actual or threatened death, serious injury, or sexual violence, through one (or more) of the following: direct exposure, witnessing, learning about the occurrence of, or experiencing repeated or extreme exposure to traumatic events." When I did hear mental health professionals discussing trauma-informed care at events organized by the New Orleans Behavioral Health Council, it often focused on children in New Orleans and how educators in schools could intervene to address trauma. While acknowledging and addressing the trauma children experience is important, these community meetings failed to address adults who have experienced trauma.

Everyday violence, especially gun violence, that residents experience in New Orleans is something that is still not fully addressed by the mental health community. People of color, who are more likely to experience everyday violence, did not know how to seek trauma-informed care, even amongst those with higher levels of education. One pattern I noticed while I was conducting life history and illness narrative interviews was that the white individuals I interviewed were prepared to share their stories with me. Many of the white women who spoke to me were victims of domestic violence, sexual assault, and other forms of abuse. They were ready to talk about their lives with me, both the good and the bad, because they had already received the care they needed and had spoken to their own therapists and mental health professionals long before meeting me. Sharing their stories with me was something they had already done many times before. 
With many of the black men and women I interviewed, my experience was a bit different. Even though I had established rapport with them, I found that I learned more through participant observation and informal questions than the interviews I conducted. For example, several of the black men I had interviewed had spent years in jail or prison, at Orleans Parish Prison, in New Orleans, or at the Louisiana State Penitentiary, commonly referred to as Angola, a maximumsecurity prison plagued by many problems, or other prisons in the state. Most of these men were convicted of drug possession.

During my interviews with these men, they told me the basics of their lives: where they were born, where they grew up, what types of jobs they had, and how they ended up at Vista. However, the traumatic experiences they had were not something they automatically shared during their life history interviews with me. For example, Terry, a 55-year-old black man diagnosed with schizophrenia, could not walk with his coffee cup from the kitchen window back to his chair at Vista. His hands would often shake and holding a hot cup of coffee was not the best idea for him, so he would often ask another individual to bring his cup of coffee to the table where he was sitting. Sometimes he would ask me, politely, "Ms. Saira, can you bring my coffee to the table?" I brought Terry's cup of coffee and sat down next to him; one day, I just asked about the visible scar on his throat, "Terry, how did you get that scar on your throat?" Terry responded with, "I was shot and left to die." A passerby who was walking his dog called an ambulance, after the dog smelled the blood; if that passerby was not there, Terry probably would have died then. I heard similar stories from other black men at Vista. Cornelius, another black man in his fifties, walked with a pronounced limp, so one day I asked Cornelius, "What happened to your leg?” I received a similar response: “I was shot several times when I was 
younger." The bullet wounds in his leg caused so much damage, much of the tissue in his lower leg was not there. Cornelius also showed me the scars from bullet wounds on his arm.

Brenda, a 52-year-old African American woman, worked at Angola as a corrections officer during Hurricane Katrina. She described the job as "babysitting adults," and did not have any problems with the inmates. "They used to love me." Brenda treated the inmates with respect because as she told me, "There are thousands of them and one of you." During Hurricane Katrina, she could not get in touch with her family in New Orleans while she was at Angola, two hours northwest of New Orleans. Anyone with a 504-area code phone number had a difficult time getting phone calls through, so Brenda had no idea where her brother or mother were, and whether they had evacuated the city or not. When she was able to leave Angola, she was able to get calls and figured out her mom was in Atlanta, and her brother was in Tennessee. But when Brenda went back to work at Angola for her next shift, she resigned because her superiors were trying to blame something on her that she did not do: they accused her of being asleep when she was not supposed to be, conducted random drug tests on her, searched her car, and found any way to discriminate against her. Brenda decided to resign, but she had a nervous breakdown after her resignation. She felt lost and depressed because she did not have anything anymore, started drinking, and hanging out with "not the best crowd." She sought help at a clinic on the West Bank side of the city and was brought to University Hospital when she admitted she was thinking of suicide. Brenda just remembers being "doped up" at University Hospital: "They give you pills, you eat, go to the bathroom, and sleep." She does not remember how, but she somehow ended up at the psychiatric hospital in Mandeville for two and a half weeks. Brenda remembered being on suicide watch while in Mandeville and signing herself out after the two and half weeks, otherwise she would have become a ward of the state, and her family came to get her for her 
release. She went back to living at her mother's house and described the psychiatric hospital as "not the place for her." It was not until a few years later, in 2010, when she started receiving her disability check and found a case manager who actually helped her. Brenda's case manager was the person who told her about Vista, where she first attended Drop-In and then started going to the day program.

The stories Terry, Cornelius, and Brenda shared with me elucidate a pattern I found repeatedly amongst black individuals from New Orleans: they never really received traumainformed care for their gunshot wounds or their experiences during and after Hurricane Katrina. Terry was evacuated via helicopter by the U.S. Coast Guard from his home in New Orleans in the days after Katrina and was not reunited with his family until eight months later. Brenda shared with me after I interviewed her, that I was the only person besides Victoria, a staff member at Vista, who knew her "entire story now," despite it being one of the quickest life histories I had ever conducted. Victoria is not technically a therapist or social worker, but as one of the few black women employed at Vista, Brenda found Victoria a "good person to talk to who listens." Since many of my interlocuters had either Medicaid or Medicare, most have trouble finding a therapist who accepted these types of insurance, let alone someone who can relate to them.

If people do not have anyone to talk to, how can they receive trauma-informed care? Most people of color I talked to spent 15 to 20 minutes with their psychiatrists every few months, but they mostly just discussed their medications and if any of the medications needed to be tweaked. I asked my interlocuters who else they sought for care, but only three had a therapist they spoke to regularly, and they paid out of their own pocket for this care. 
At the minority mental health panel, Dr. Rouse, the elected coroner of New Orleans at that time, spoke of having a victim ally and beginning that initiative for family members of murder victims in 2015. The purpose of the ally is to be available for the family, but Dr. Rouse also admitted, "We can do more." Charlotte Parent, director of the New Orleans Health Department, spoke of the prevention piece and an initiative to train school teachers where two weeks of training are dedicated around trauma, learning what to look for in children who witness or experience trauma. While these initiatives were a starting point to help family members and children, resources that my interlocuters could access did not seem to exist.

At Vista, I met Linda, a 46-year-old black woman diagnosed with schizophrenia. Linda loved playing Monopoly during Drop-In, but whenever she landed on a Chance or Community Chest space during the game, she would automatically hand the card over to me. I realized quickly it was because she had trouble reading. This impacted the type of resources Linda sought. For a few months during Drop-In, Francesca, an employee for Metropolitan Human Services District, would come in once a week and lead a group session on various health topics. She encouraged people to sit around a table, introduce themselves, and would give out pamphlets and papers about the topic for that day. Francesca would ask each person around the table to read a section from the papers. For this reason, Linda never felt comfortable participating in Linda's sessions. She would sit near enough to the group to listen in but did not sit at the table to face the risk of being forced to read.

A few months later, when I went to Vista for Drop-In, Linda asked me, "Saira, how do you spell sandwich?” I spelled it out, but then I asked, "Why?" Linda answered, "My doctor wants me to write down what I eat every day for my diabetes." I then suggested she might want to make it more detailed and write down the type of sandwich as well, which was a turkey 
sandwich. The food journal was a good idea in theory, but one that Linda struggled with. I was not sure if her difficulty in reading was because of her literacy skills or because her eyesight was bad; it could have possibly been a combination. Linda also had glaucoma and often had eye appointments because of the pressure levels in her eyes. But the small notebook she was given to complete her food journal may not have been the best way for Linda to manage her diabetes, and I was concerned her physician may have thought she was "noncompliant" if she did not complete it fully. I never thought Linda really received proper healthcare for her physical health problems. She was often in and out of the emergency room for her blood pressure, and she would show me the discharge papers the ER physicians had given her, explaining she did not really understand them. I would look at them and had a hard time understanding them myself. Linda's physical health issues were just one problem. During the life history interview I conducted, she shared that she was raped when she was a teenager. Linda never had a therapist she could see one-onone to discuss her trauma. Even though Vista had a social worker, I learned later that the social worker saw few of the members one-on-one and spent more time focusing on paperwork to get preauthorization from insurance companies for the units Vista conducted in the day program.

\section{Understanding of Illnesses or Medications}

Within the black community, another pattern I found with individuals was that they were less likely to understand their diagnoses or treatment. Often when I asked about what medications individuals took, members of the black community were more likely to have a written list of their medications folded up in their wallet or purse and hand that paper to me when I asked about their health problems, or they could not recall their medications at all. For those with a list, it was obvious they had the list in case of an emergency or a meeting with a doctor, but they did not really understand what the medications were used to treat, physical or 
psychiatric. This was a sharp contrast to many of my white interlocuters who could tell me their exact medications, dosages, what the medications were for, and how long they had been taking them.

With James, a 57-year-old black man, when I conducted the illness narrative and asked him about his health problems, instead of verbally telling me anything, he just showed me the Medical ID bracelet he was wearing that listed all of his health conditions. These included diabetes, asthma, hypertension, bipolar disorder, and schizophrenia. I wrote down the health conditions, but when going through the interview, James initially referred to his psychiatric diagnoses as "bad nerves." He did not really have an explanation of what this meant, but said he was given the medications for "bad nerves" when he was young. I had heard variations of this term from a few other individuals at Vista, but it was used in a context of how people were feeling that day. For example, some individuals would say, "My nerves were good today," instead of a euphemism for mental illness. Interestingly, during the life history interview with James, he revealed he had hepatitis. He used to be a cook and food manager, and when he started in the day program at Vista, he worked in the kitchen unit but was taken out of that unit when the program staff learned he had hepatitis. However, his medical ID bracelet did not list hepatitis as one of his health conditions. This omission made me question how accurate the other ailments listed on his medical ID bracelet were. While James shared that he "used to hear voices a long time ago," the voices had gone away. He was first given medications at the age of 16, but then given more medications when he was in prison at Angola. James did not have a list of the medications he took; he just knew they changed over time. However, he revealed smoking crack in his teens and early twenties, so I could not tell if his history of psychosis was a result of the drugs, the conditions in Angola, or a completely different reason. 


\section{The Sojourner Syndrome}

Leith Mullings uses the term, "the Sojourner Syndrome," as a framework to describe the combined effects and joint influence of race, class, and gender in structuring risk for African American women. This intersectional approach requires analyzing how the axes of stratification intersect, emphasizing the ways in which "race, class, and gender are not additive but rather interlocking, interactive, and relational categories" (Mullings 2005b, 80). This framework also integrates a history of resistance, allowing for the exploration of agency (Mullings 2005b, 86). The Sojourner Syndrome represents "a survival strategy for fostering the reproduction and continuity" of the black community, but its costs include health consequences including chronic stress, which for impoverished women, "the multiplicative effects of race, class and gender are frequently a life and death issue" (Mullings 2002, 35).

During my time conducting fieldwork, I could not help but notice how the black women I talked to have more responsibilities but also more health conditions to deal with. Tina, a 48-yearold African American woman, came to Drop-In as a client. She also serves as a caregiver for both her husband who has a disability and her daughter and felt immense pressure to take care of her household. Having her daughter was high risk in itself; she went off the medications for bipolar disorder for a year because of the complications of taking them during pregnancy and suffered a miscarriage before having her daughter. Tina told me she knew she had "a high risk of dying in childbirth," but she had her daughter when she was 37 and thought it was her last chance of being a mother. As the primary caregiver in her household, she tries to figure out the best way to keep costs down for groceries. Tina often takes the bus to neighboring St. Bernard Parish because the sales tax is cheaper in that parish than in New Orleans. Figure 7, from her time diary, illustrates the time constraints she has just navigating the city. 


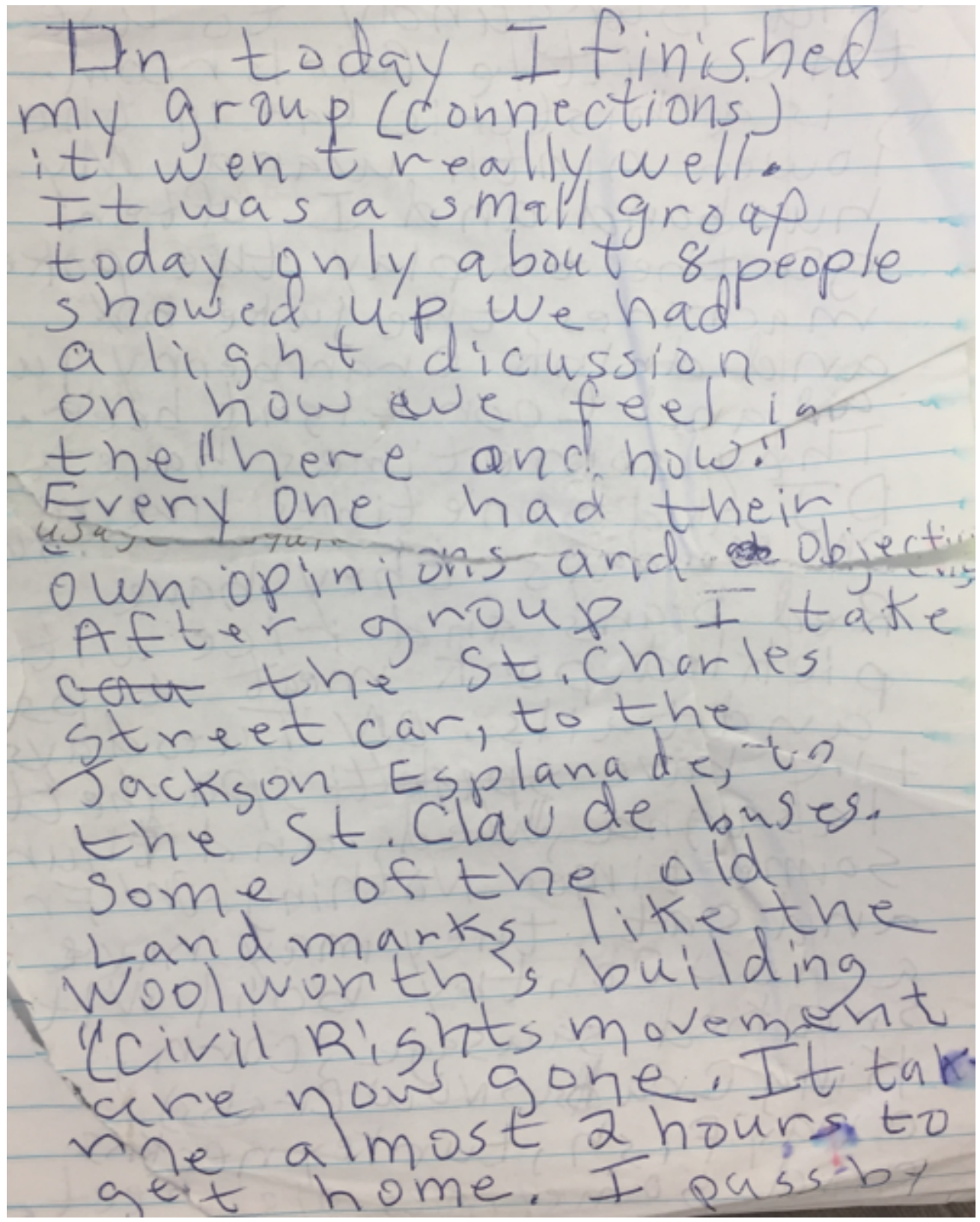

Figure 7: Tina's Time Diary

She constantly worries about her daughter and her neighbors. I picked Tina up in my car from her apartment in the Lower Ninth Ward one morning because it was quicker to meet her that way than for her to use public transportation to meet me. When I was waiting for Tina in my car, I noticed her neighbor staring at me from his front door. When Tina got into my car, she told me not to worry about the neighbor. "He's a crackhead," she said. But she was worried about this 
neighbor being so close in vicinity to her daughter and the impact he might have; Tina had already lost a brother in 1996 to drugs.

Despite living below the federal poverty level for her household, Tina seeks resources where she can. As a patient at Central City, she has an assigned case manager but does not find the resources there adequate enough. She takes the two buses and streetcar to Vista once a week to take part in the peer-led support group session since it is one of the venues where she can "release a lot of frustrations." The 2018 NAMI National Convention took place in New Orleans, and Tina volunteered two shifts during the convention, so she could attend other sessions at the conference for free. She is also aware of how the state budgets cuts affect healthcare and told me it is "important to get out and vote" and raise awareness, but I often wonder how much she may be overworking herself. Her last episode of psychosis, in 2015, was the worst she had and was a "wake-up call" for her that she really needed help. Tina knows she has to take care of herself to take care of her daughter, and if she takes her medications and gets enough rest, she "will be alright." While Tina is going out of her way to find free resources to understand and cope with her mental illness, she also has Type 2 diabetes and high blood pressure, which she tries to keep under control. As a mother, caregiver, strategist for her household, and trying to manage her multitude of health problems, Tina epitomizes the Sojourner Truth Syndrome.

\section{Conceptualizing Mental Health Services}

From the perspective of black interlocuters who came to Vista for the day program or Drop-In, I noticed that they identified with the programs and resources offered as a school or educational program. The day program, as a psychosocial rehabilitation program, is technically a skills-building program. Members are assigned to different units in the day program including the garden unit, kitchen unit, and clerical unit. This set up, with times devoted to reading and 
learning about mental health conditions, recovery, and self-care, made it feel like an educational program.

One morning when I parked my car and was about to go inside Vista, I stopped and chatted with Mary, an older black woman. She was describing how she had been coming to the day program for 10 years and was going to "get a certificate" for participating in the program. I am not sure if there was such a thing as a certificate, but she viewed it as an accomplishment like going to school. In other conversations and interviews with black interlocuters, they described aspects of the program and peer support groups specifically as "classes" and the program as "school." In this manner, the programs at Vista were something they could be proud of participating in.

In my interview with James, he specifically referred to the units in the day program as "classes" and said, "It's like going to school." In my last interview with Brenda, I went to her house, where she lives with her mother, because she had broken her leg and could not come to Vista. I initially thought her diagnosis was major depressive disorder because when I asked her what her diagnosis was in our first interview, she responded with major depression. However, at her house, she had a newsletter from Vista framed on the dining table; this issue included a picture of Brenda on the newsletter, describing her recovery. Brenda had completed a peer-topeer course with Vista that is open to people diagnosed with a serious mental illness, and I noticed that she was now calling her diagnosis manic depression or bipolar disorder. From the initial interview I had with Brenda, she seemed much more confident about her diagnosis and how to maintain her symptoms. She was proud to have participated in the peer-to-peer program, a 12-week course anyone with a mental illness could take to learn more about various mental illnesses. For many black individuals, who were not able to finish high school or college, 
conceptualizing the day program as "school" was a way to participate in something they could be proud of and view as an accomplishment.

\section{Language Barriers}

Much of what I have described in this chapter concerns the African American community. In 2008, the U.S. House of Representatives announced July as Minority Mental Health Awareness Month Congress in honor of Bebe Moore Campbell, who wanted a national campaign to destigmatize mental illness, especially for African Americans (NAMI 2018). But other communities of color in New Orleans also face barriers to seeking mental health treatment. The last question from the audience at the 2015 minority mental health panel asked the panelists about resources for those who do not speak English and how to bridge those gaps. The New Orleans area has a significant Vietnamese population, and since Katrina a larger Latina/o population after the influx of construction workers. What resources exist for non-English speaking populations?

At the Minority Mental Health Panel in 2015, none of the panelists really had knowledge about resources for the growing Latina/o community in New Orleans. Dr. Rouse, the Coroner, answered saying when he hired new employees, he looked to see if any applicants were bilingual, but none of the panelists actually named any organizations or entities working on this. Three years later, at a Behavioral Health Council public forum meeting, I asked the participants in this forum what mental health resources exists for non-English speaking populations in the community? Dr. Rochelle Head-Dunham, Executive Director of Metropolitan Human Services District and co-chair of the New Orleans Behavioral Health Council, responded with an answer that Metropolitan opened its newest clinic in New Orleans East, where a heavy concentration of the Vietnamese community resides. The staff at that clinic location are working with Vietnamese 
organizations in that area, but nothing specific about language and cultural needs was stated.

Several community organizations in New Orleans were established to address the absence of linguistically and culturally appropriate health support in the non-English speaking communities post-Katrina. These include The Latino Forum and VAYLA, both created in 2006, which work together closely on many related issues for the immigrant and migrant communities in New Orleans. The mission of the Latino Forum, now called the Louisiana Language Access Coalition (LLAC), is to promote "full and meaningful participation in public life, without barriers based on language, for all people" (LLAC 2018). VAYLA is a "progressive multi-racial community-based organization in New Orleans that empowers youth and families through supportive services and organizing for cultural enrichment and positive social change" (VAYLA 2018). Erin Tooher, an anthropologist who works closely with the migrant communities in New Orleans, shared that the Latino Forum and VAYLA work together closely on many related issues, connecting the Vietnamese community in New Orleans East with the Latina/o communities in New Orleans. However, the largest barrier, according to Tooher, is connecting health-serving organizations together and making sure information from the monolingual English community is known in non-English speaking communities, and vice versa; "Latino Forum and VAYLA help with the former part of this connection, but there is nothing in the monolingual English-speaking community working on the other part of the connection" (Tooher, personal communication).

\section{Conclusion}

In this chapter, I turned attention to the common challenges marginalized communities encounter when addressing their mental health needs, focusing mostly on the African American community. The noticeable lack of understanding or knowledge about diagnoses, what 
medications individuals take, or the purpose of medications illustrates that some mental health professionals do not engage with people of color, particularly the black community, enough. When I asked Brian, a white case manager working at Vista, about the lack of knowledge about medications and diagnoses, Brian described it as a "provider issue."

In many of the foras and panels I attended during fieldwork, the speakers were able to identify common problems and issues about mental health concerns in New Orleans, but they still failed to address many questions from audience members relevant to communities of color including how to address trauma-informed care and engaging with this population at community forums. Most of my black interlocuters experienced some type of trauma, ranging from gun violence, abuse as a child, rape, violent death of a relative, to being abandoned in the aftermath of Hurricane Katrina. However, none actually received trauma-informed care. Only one black woman had the diagnosis of posttraumatic stress disorder (PTSD). Does this disconnect between meeting the criteria of PTSD but not actually receiving the diagnosis mean that PTSD is a white diagnosis? It may have more to do with access to and quality of mental health services, since many of my black interlocuters struggled to find facilities they actually liked.

For non-English speaking communities, organizations like LLAC and VAYLA exist, but English-speaking communities need to do more work to engage with these organizations in New Orleans. Making people of color part of the care decisions is necessary to engage individuals successfully within the mental healthcare system. Tina, who epitomizes the Sojourner Truth Syndrome, struggles taking care of herself in addition to her husband and daughter. She attends Drop-In at Vista and the peer-led support group once a week because it is one of only venues she can express her frustrations. However, more of these types of programs need to exist. If this is actually done, as the poet Gwendolyn Brooks referenced in her poem, perhaps the children will 
go far. Traditional mental health services, especially the public health clinics in New Orleans, may not be the best source of care for mental health amongst the African American population. The next chapter describes how accessing churches can be utilized to reach certain populations as a form of medical pluralism. 


\section{CHAPTER 5}

\section{MEDICAL PLURALISM: SPIRITUALITY AS MEDICINE}

Each year in Louisiana, usually in May, Behavioral Health Day occurs at the state capitol in Baton Rouge. It is usually sponsored by Mental Health America of Louisiana, and the purpose of it is a rally to raise awareness about mental health issues in the state. Since it usually occurs during the time state legislators are deciding on budgets for the next fiscal year, the rally often focuses on speakers who advocate for better mental health services and asking legislators to not make budget cuts in behavioral health, which seemed to be the case each time I attended Behavioral Health Day.

In 2018, Behavioral Health Day occurred on May 10. There were several speakers aligned from various organizations, and the NAMI Louisiana President introduced each speaker. Much of the audience had trouble hearing many of the speakers because of issues with the microphone. It was an extremely hot day as well with few clouds, to the point where my cell phone automatically turned off from overheating when I left it on my chair. Thus, people were more focused on staying hydrated or seeking shade than listening to the speakers. However, toward the end, the NAMI Louisiana President introduced Jasmin Pierre from New Orleans, a suicide survivor, life coach, mental health advocate, and motivational speaker. Instead of speaking behind the podium with the microphone that did not really work like the other

presenters, Jasmin stood in front of the podium and projected her voice so that everyone could 
hear her. ${ }^{21}$ Her voice certainly woke some people up, with no microphone necessary as she began her speech:

Good morning everybody. Mental Health challenges affect all races, but today I want to talk about how they affect minorities, in particular, the black community. When I was a little girl, I remember watching this TV show. This black woman was talking to her friends. She told them that she wasn't feeling like herself, and she felt she needed to see a therapist. So one of her friends says, 'Girl, we're black. We don't go see therapists. We go to church.' And the whole studio audience laughs because that's a common, stigmatizing comment we hear in the black community when it comes to mental illness. I've also heard things like that depression is just a demon. You're just supposed to just pray it away. You're supposed to be a strong black woman. Mental illness is just a weakness. It doesn't affect our race. It doesn't affect our race at all. And mental illness is just for white people. It doesn't affect black people.

At this point, the people sitting behind me were disagreeing but still listening attentively. Jasmin

continued her speech:

I've heard stuff like this my entire life. But when you continually hear stuff like this and you haven't been educated on mental health issues, you would actually start to believe these things. And I did when I was diagnosed with major depressive disorder. And in doing so, I felt the shame. Because for the longest time, my community said we aren't supposed to go through these issues. But when I did, I was like, why is this happening to me? I didn't understand why. But you want to know something? Being ashamed is exhausting. So I finally decided to go get help for myself. And it lifted a weight off my shoulders. And the same weight that was lifted off my shoulders is the weight I want to lift off the black community's shoulders with this app I created called The Safe Place. The black community is $20 \%$ more likely to experience serious mental health issues than the rest of the general population. Yet, many still do not wish to receive help. The Safe Place is a free mental health app for the black community. It has things like black mental health statistics, self-care tips, self-assessment questions, videos, articles, and more. It's on iPhone and Android. I created this app for three reasons. One: because I need the black community to realize just how seriously these issues do affect us. Two: because I want to help erase the stigma that has been on my community for generation after generation when it comes to mental illness. And three: it's because I generally care.

The audience starts clapping at this point, and Jasmin continues:

My hope starting this app is not to just save minds, but it also helps to save lives. I care about everyone's mental health, but being another black woman, and knowing what's going on in my community, I had to do something about it. And so I did. I want to leave you with this. Many in the black community feel, since our ancestors got through slavery,

\footnotetext{
${ }^{21}$ I recorded the speakers while also taking extensive notes during Behavioral Health Day.
} 
we can't be weak because many times, mental illness is associated with weakness. But let me tell you something. If our minds are not free, we are not free.

I heard a loud amen from the audience after the last statement, and Jasmin finished her speech, with the audience clapping: "It's okay to be black and to admit that you have a mental illness. It's okay to go get help for yourself. That does not make you weak! It makes you strong! Thank you."

The notions that mental illness can be prayed away, that mental illness is a demon, and that mental illness is a sign of weakness were things I heard at other meetings and rallies but not necessarily something I heard from my interlocuters. Many of my interlocuters were older individuals, who had dealt with their mental illness for a long time, so their perspective was probably different from individuals who had recently received their diagnosis. However, many of my black interlocuters mentioned the importance of religion in matters of health, which can also be viewed as a form of medical pluralism, defined as "the simultaneous practice of multiple medical systems or traditions" (Brown and Closser 2016, 177). Seeking support services from a trusted member of one's church can be useful in addition to the services provided by public health clinics, where much distrust still occurs.

\section{Support Services in the Community}

During the time I conducted fieldwork, Vista held several presentations in the city where peer support specialists shared their stories of mental illness and recovery. These presentations occurred at various community centers and religious sites, usually in the evenings, and were open to the community. One of the first ones I attended was at a church in Central City, a historically black neighborhood in New Orleans, but one that was gentrifying quickly during my time conducting fieldwork. Jordan and Patty, two black peer support specialists, were the speakers for this presentation. When I arrived, I was happy to see that the church was full. I saw 
some of the usual people from Vista, but I encountered many new people as well from the neighborhood, who seemed to be there because the pastor had encouraged them to attend. Jordan and Patty both shared their stories about mental illness, and then the discussion was open to questions from the audience. Many of the questions were about where people could access services and what resources exist for family members. Vista had a table with pamphlets for its various programs, which are all free, as well as information on how to access psychiatric services in the city, which audience members were interested in learning about more.

A few months after this presentation, I attended another one sponsored by Vista at a community center. This time, the presentation was at the Sojourner Truth Neighborhood Center, located in the Lafitte neighborhood. I thought I was late to the presentation, getting stuck in heavy traffic on the way, but when I arrived, only Vista employees, Jordan as the intended presenter, several Vista board members, and an employee from the Center were present. Besides the neighborhood center employee, no one from the community was present. Thus, instead of the intended presentation, it turned into a strategy meeting about why no one showed up and what could be improved.

The neighborhood center employee expressed her frustration that no one showed up, saying she knew there were families in the neighborhood and members of the community center she could think of who would have benefited from the presentation, but that the stigma of mental illness was one of the reasons people did not show up. Some of the employees from Vista asked how well the neighborhood center's relationship with nearby churches was, and if that could be a possible way to build rapport. However, the neighborhood center employee said the ministers from nearby churches were not really involved and definitely did not seem interested in mental health issues. The conversation then turned into one about race. One of the board members of 
Vista, a white woman, expressed her concerns about even showing up that night. She was not sure if her presence would be seen as helpful or not as an upper-class white woman, who could be viewed as an outsider. At this point, Jordan interjected and said, "I would have wanted help from anybody who could have given me help when I was younger. I wouldn't have cared if they were black or white." Another Vista board member, a white man, asked if it was worthwhile to go door-to-door talking to people in the neighborhood, or if that would frighten people away. The center employee, to my surprise, said people in the neighborhood would not open the door for her as a black woman, but they probably would for him, especially if they knew he was a lawyer. They would figure out a way to utilize his services.

I have often thought about why some of the Vista sponsored presentations were well attended at some locations but empty at other times. The relationship with ministers and their support in specific neighborhoods in New Orleans seems key to this issue. But the notion that black individuals do not see therapists and instead go to church, a theme Jasmin Pierre repeated during her speech on Behavioral Health Day, was not necessarily always the case. I did interview some individuals, usually white members of Vista, who were weary or suspicious of organized religion; they had unintentionally joined a cult type church which had led them down a negative spiral. But others I interviewed, when I asked where else they had sought mental health services, often black members at Vista, said they received support services from their church.

Tina, a 48-year-old black woman with bipolar disorder who attends the peer support group at Vista, discussed how going to church made her feel energized; however, it took her some time until she found the right one. Tina felt the Baptist churches were "too long-winded" with their services. The church her mom attends has a social worker who would help with resources and Tina "loved it." Tina is married with a daughter, and her husband is disabled from 
two car accidents and a brain tumor and receives limited income. With their two incomes from SSI, Tina still struggled with being able to pay rent and afford things for her nine-year-old daughter. The information the church provided for health fairs and back to school fairs where she could get free school supplies for her daughter were extremely helpful. However, Tina eventually stopped going to her mom's church because it was too far from her apartment in the Lower Ninth Ward, one of the few neighborhoods in the city where she could find affordable housing. Tina switched churches again, and the people at her current church work with Vista, and the psychiatrist who sees members at Vista, a black woman, also attends Tina's church. Tina's relationship with her pastor is also significant; her pastor knows about her diagnosis and does not judge her for it.

Tina told me, "In the black community, there's stigma placed on diabetes, high blood pressure, and mental illness," all things Tina has, and for the longest time she wondered, "Why me? Why me? Why me?” But she continued with, "God chose me.” After her last manic episode, she realized how it was affecting her daughter, and accepted getting help: "Get help as soon as

possible. Don't be afraid. Don't let what other people think ruin you." I found Tina's perspective interesting because she has a Bachelor's degree in psychology, and I thought she would have accepted her diagnosis sooner since she had studied mental illness and the effects of trauma on the brain, but as Tina said, "Learning about it and referring to yourself are two different things." While Tina did not find helpful resources during the time she was hospitalized, she did find validation and faith at her church.

\section{Church Nurses}

In February 2018, after my formal fieldwork was finished, I attended a panel on addiction and mental health, sponsored by the NOLA Partnership for Mental Health. Before the panel 
began, Rhonda, a registered nurse who works at the VA and University Medical Center in the psychiatry unit, started talking to me and asked about my interest in the panel. I explained my research project, and she told me about her work as a church nurse. I had never heard this phrase before, and she explained to me that this was work she recently started doing after getting national training to be a church nurse. Rhonda works as a church nurse at her church in the Desire neighborhood, and she provides medical care and information to the patrons who attend the church. She said as a psychiatric nurse, it had been a while since she has actually dealt with blood and needles, but because her work as a church nurse is holistic, she had to go back to doing the typical things nurses do. She seemed proud of her work as a church nurse, and I thought this was another way people of color in the community could access and learn about mental health services; bringing resources and information to the community seems like a good alternative if people do not know where to get information.

\section{Accessing Audiences}

During fieldwork, I attended a forum sponsored by the NOLA Partnership at St. Anna's Episcopal Church. This forum discussed pressing issues about mental health in the community and was well attended by mental health professionals and university students. Towards the end of the forum, two staff members from Mental Health America of Louisiana discussed a new program for training peer support specialists, one that seemed to be affiliated with a university. I remember Jordan attended the forum, and if anything, seemed to be annoyed because he was already certified as a peer support specialist through a different program and wondered if this one was necessary and if it was something he needed to participate in. By the time the representatives from Mental Health America of Louisiana were speaking, many of the audience members had left, but they were also sharing free copies of a book by Marilyn Martin, a black 
woman with medical and public health degrees. I picked up a copy of the book, Saving Our Last Nerve: The Black Woman's Path to Mental Health (2002), to read later. By the time the books were left on a table to take, most of the people who were at the church for the forum had left. Even if they had stayed, I did not recount many black women in the audience.

I remembered Jordan also took a copy. When I saw Jordan again, a few weeks later, I asked him if he had read the book. He did not have a chance to read the book yet, but he took a copy to see if it might be a good resource for anyone who attended the peer group he co-led. I read the book myself and thought it useful as a self-help tool that offered resources on dealing with stress, provided information on common mental illnesses, and exercises on how to cope with common problems, written in an accessible format. Each chapter in the book also ends with a section on further resources about that topic, including books and popular movies. I was disappointed that there were not any black women at the community forum to actually take advantage of free copies of the book.

One of the themes in both Saving Our Last Nerve (2002) and the speech Jasmin Pierre gave on Behavioral Health Day was contradicting the idea that "You're supposed to be a strong black woman. Mental illness is just a weakness." Martin $(2002,35)$ discusses how the black community's resistance to seeking mental healthcare may come from a sense of not feeling worthy enough to receive care; the hesitancy and confusion is part of the legacy of racism. Jasmin mentioned the misconception of how black people cannot be weak because their ancestors got through slavery. However, during slavery, this community, Martin argues, lost some capacity to love themselves and others and is still going through the process of healing $(2002,36)$. Frantz Fanon (1991) said it was impossible to live in a racist culture without absorbing some of those racist beliefs. With the evolution of slavery in the U.S. to racial 
lynchings, segregation, mass incarceration, and police brutality, the process of healing for this community still has a long way to go. As six out of the 10 black men I interviewed had been imprisoned at one point in time, their experiences highlight how mass incarceration is a system of racial control (Alexander 2010).

\section{Cultural Sensitivity and Education}

During the question and answer session of the Mental Health Minority Panel in 2015 mentioned in the previous chapter, the same nurse whose husband was shot and killed in New Orleans and wanted more trauma-informed care in the city brought up the notion of cultural sensitivity to the panel and how to be better engaged with minority communities within the mental healthcare system. With her experience working in an acute care hospital, she told the panel, "I have noticed that patients will deal with, talk to, engage with treatment a lot better if it's with someone they understand where they are coming from. You know, they're culturally sensitive to what their life experience is. We can't leave that out of the equation." She emphasized the importance of having providers who are culturally sensitive to the population they treat:

At Charity Hospital, you know, the majority of the patients were indigent, chronically mentally ill, and black. And the majority of staff at that time were black. Now, you don't have to be black to be culturally sensitive, but you do have to have training in order to deal with that population. So, if you really want to engage patients into the mental health care system, you really have to understand where they are coming from."

She went on to say, "As Westerners, we think our way is the best way" but have to understand certain populations have a way of dealing with their feelings and we need to incorporate that into their care:

We need to make them part of the care decisions we make and not just do it for them or to them but find out what works best for them. So, I just want to make sure that in this discussion, we don't leave out cultural sensitivity in our efforts to engage patients into the mental health care system. 


\section{Spirituality as Medicine}

Mental health clinics and hospital may not be the best institutions to provide traumainformed care or services that are even culturally sensitive, but the churches in New Orleans have a history of engaging with the community, as places for black activists and religious leaders to organize in response to poverty and other conditions that marginalized communities experience (Carter 2014). Rebecca Carter $(2014,241)$ discusses how "the members of marginalized groups create and claim space for interaction, expression, resistance, and mobilization," and how churches are one of these spaces. With a per capita murder rate seven to eight times the national average within the last three decades in New Orleans, the violence disproportionately affects young black men, "who already suffer most directly from multiple forms of social, economic, and environmental vulnerability" (Carter 2014, 251). Focusing on the roles of churches in New Orleans post-Katrina, Carter discusses how church ministries continue to "cultivate the security, wellbeing, and social-spiritual growth of parishioners and their communities" who often live in "conditions of joblessness and underemployment, a failing system of public education, substandard housing, and uneven access to health care and other essential services" (2014, 251-252).

In examining the religious work of African American women in New Orleans who mourn and remember those who have died, particularly young black men who were victims of homicide, Carter examines the "everyday rituals that cultivate and assert the social and spiritual relatedness and value of the displaced and the deceased" $(2018,686)$. For mothers who were mourning the deaths of their sons, particular churches in New Orleans became the center for support groups of these grieving mothers. "The meetings provided space for the women to share their experience of loss; to process grief, anger, and other difficult emotions; and to find comfort 
and solace in prayer, bible study, and fellowship" (Carter 2018, 692). The mothers in New Orleans began to send flowers, each rose representing a homicide victim, to city officials as a way for the victims to be remembered instead of forgotten, since "violence, in all its forms, contributes to the systematic and effective erasure of poor" people of color (Carter 2018, 685). However, some clergy were frustrated with the lack of cooperation and communication within parishes: "Some affiliated churches, for example, declined to participate in ministries and programs that seemed too political or otherwise unsuitable" (Carter 2018, 701).

The same could be said of the educational outreach programs Vista held at various churches and community centers in the city. The presentation Jordan and Patty gave at the church in Central City was well attended, answered the questions those in the audience had, and it had the support of the minister who was also present and supported the initiative and outreach from Vista. The presentation that Jordan was supposed to give a few months later at the Sojourner Truth Neighborhood Center, however, never happened because no one from the community showed up. The director of the community center said there was not much support nor a good relationship with clergy from nearby churches. The other problem with this community neighborhood center was that certain staff were only there temporarily as part of a year-long service learning organization program. As many of these types of service and outreach programs now exists in post-Katrina New Orleans, locals do not feel the need to establish rapport with individuals who will only in the city for one or two years at the most.

\section{Conclusion}

The sentiments that Jasmin Pierre shared on Behavioral Health Days reveal common perceptions about mental illness within the African American community. But instead of the church being seen as an obstacle, it can be viewed as a form of medical pluralism, especially 
where church nurses already exist and provide support services. With distrust from black members utilizing traditional mental health services, churches can be a viable alternative for outreach, education, and support services for mental health. However, this can be best done at locations with long-standing relationship with the local community.

Spirituality was important to many black members of Vista for their well-being. To continue a sustainable relationship for educational outreach and to eliminate the stigma associated with mental illness, Vista and other mental health stakeholders can focus on outreach where churches are open to hosting and hearing about mental health. The next chapter will discuss cultural sensitivity and how mental healthcare providers can better engage with communities of color in clinical settings. 


\section{CHAPTER 6}

\section{COUNTING CULTURE? CLINICIAN-PATIENT MATCHING}

This chapter focuses on the relationships between health professionals and clients and examines the complexities that arise out of situations when the backgrounds of health professionals vary from clients. When does culture 'count' in patient care? Through participantobservation and interviews with mental health practitioners and clients, this chapter examines the challenges healthcare professionals and clients face because of their identities and offer suggestions for sustainable healthcare practices. The information for this chapter primarily comes out of field notes and interviews with an individual diagnosed with a mental illness who is also a peer support specialist, a community health worker, and a mental health professional. During the time I conducted fieldwork, I noticed some mental health professionals had been working at the same place for years. But I also noticed that some only lasted a few months and there was a high turnover rate. There were various reasons for this, but as the director of Vista told me, "It's hard to find good ones," referring to social workers and licensed professional counselors (LPCs). "It's not cute, fuzzy work. It's demanding." Many will see private patients, and "they don't want to do the type of work we want them to do" at Vista and other places that provide services for individuals from low-income or marginalized communities.

I provide three examples from conversations and interviews with Jordan, Jessica, and Danish to illustrate problems that arise when providing services for individuals who come from a low-income or marginalized community. The three examples include Jordan, who provides a viewpoint as both a consumer of mental health services and as a peer support specialist in New 
Orleans, and Jessica and Danish, who offer viewpoints from the provider standpoint. After discussing their stories, I examine the concepts of clinician-patient matching and recognition as a sustainable practice for mental health services in New Orleans.

\section{Jordan}

Jordan is a 52-year-old black man diagnosed with schizoaffective disorder, depression, and anxiety who also works as a peer support specialist at Vista. At the end of one of the first interviews I did with Jordan, I asked what, if anything he would change about his current treatment. His response was, "I'd like a black psychiatrist, but only if they were good." This response made me wonder if Jordan ever had a black psychiatrist or social worker, and I felt like I was missing part of Jordan's narrative even though I had heard him share his story about his mental illness and recovery several times around the city at churches, community centers, and to police officers undergoing crisis intervention team (CIT) training. I decided to utilize the McGill Illness Narrative Interview (MINI) with Jordan (Groleau, Young, and Kirmayer 2006). The MINI is a much longer semi-structured interview, with 46 questions that prompts multiple narratives, including help-seeking behavior in health research. When I talked to Jordan later using the MINI, his story highlighted a much more complicated medical history that I will share here.

Between the ages of 17 to 30 , Jordan described the treatment he received at Chartres, the public mental health clinic he went to as not helpful at all. In his words:

Between 17 and 30, I still was doing the daydreaming, I couldn't keep a job, I couldn't go to school because I was daydreaming so much that I would get the jobs, but I would lose them in less than three months because the daydreaming was consuming my time. So when I would go back to the mental health center and say I lost another job, they would tell me, you know what, snap out of it. From 17 to 30 years old, they would say, 'Snap out of it.' And after 17, I saw a picture of psychiatrists coming in and out of the mental health center. I had one social worker that I saw for about 12 or 13 years, and when I would lose a job and tell her about the day dreaming, she would say something to the fact, oh you just have low self-esteem. You really are not mentally ill. Why don't you go to college? Go to college, get a degree, and all of this will be over. 
Jordan used the word daydreaming to describe the feelings of grandiosity and mania he felt, but the daydreaming is his own term he used to explain the symptoms of his diagnosis. I asked Jordan if he ever saw a different therapist or counselor during the time he went to Chartres, the mental health clinic, but he only saw the social worker: "No, because I wasn't on social security [at that time], so I couldn't afford that. So, I went to Chartres and saw the social worker mainly, and she would listen to my woes. But she would always say, this is just your personality."

Given the response he told me previously, about having a black psychiatrist if he could find one, I asked Jordan about the ethnic background of his social worker. Jordan responded saying, "She was white." I asked Jordan if that made a difference. Jordan responded with, "Yes, it did." When I asked why, Jordan elaborated, "Because in some instances, white clinicians tend to treat black persons with severe mental illnesses differently, like we're looking for a check or we're lazy, so that has been my experience."

Between the ages of 17 to 30, Jordan was diagnosed with depression, but in his words, even "when the doctors at the mental health center said depression, they meant kind of like personality disorder. It wasn't an illness. It was somehow brought about by my own doing." Jordan's psychiatrists were white too, and he said a few were foreign, sometimes Indian or Pakistani. But he never had a black psychiatrist.

Going back to the questions from the MINI, I asked Jordan about any hospitalizations and what happened afterwards. Jordan responded with, "I was hospitalized for the first time when I was 17 years old, after I graduated, at Charity. All of my stints in the hospital were at Charity Hospital.” Jordan had seven hospitalizations at Charity Hospital, a public state-operated hospital that served low income communities in New Orleans for decades. The third floor of 
Charity focused on psychiatric services, but Charity Hospital never re-opened after Hurricane Katrina.

For his seventh hospitalization, Jordan stayed about a month and a half at Charity Hospital. Before that, it was no more than two to three days for each hospitalization. But when he would go to Charity, the same thing would be said to him at Chartres: "Oh, you look fine. You look high functioning. You look like you can go to college. You don't look like a person with mental illness." Between the ages of 17 to 30, Jordan said he lived an average life. He had jobs even though he couldn't keep them:

I had friends. I socialized. I had girlfriends. I had boyfriends. I could hold onto a job for two to three years. I really had an average life. I just suffered from mental illness. But when I got to be 30, the bipolar side of me crashed. I got into depression. I started thinking about suicide, and that's when I stopped all medications together, and I stopped going to Chartres. And six months to a year, I really literally thought for the first time in my life that I was Moses the Prophet. And I was picked up by the police several times.

I asked Jordan if he was ever arrested. He responded:

No. They would ask me if I wanted to go to the hospital, and when I would tell them no, they would leave me alone. 'You don't want to go to the hospital, we can't help you.' Which was Charity. So, at 30, it got so bad. Before I thought I was Moses, my daydreaming was under control. It was something I did in my bedroom to myself. When I got to be 30 and stopped all medications cold turkey, I believed my daydreams. I believed I was Moses. I believed I could cast spells on people. I walked in the streets and believed all these things. Let me also tell you this. At 30, I took my life into my own hands. I was quite aware, that if I stopped taking all meds and stopped going to the mental health center, that something was going to happen. Now what was going to happen, I did not know. But I took my life into my own hands because I figured out, at 30, I've been going to Chartres since 17, nothing has ever gotten better. So, I said to myself, let me take my life into my own hands and take my chances. If I wouldn't have did that, I would have been the same Jordan as today. Back around revolving door, revolving door.

Jordan was quite aware that stopping his medications was not a good idea, but it was good for him because "it got people's attention." And during his last hospitalization at Charity, when Jordan thought he was Moses, at the age of 30, that is when he learned of the diagnosis he has today. But even then, a doctor or nurse did not inform Jordan of his diagnosis. He looked at his 
medical chart himself one day and saw the word schizoaffective written on his chart and thought, "There's a name for what I have?"

Jordan now has a private psychiatrist and private therapist. He sees his therapist once a month and his psychiatrist every three months, and his current providers, according to him, are a huge help. Jordan has been with his current therapist for 17 years. His current therapist has told Jordan, "If you would have been caught earlier, you wouldn't be in my office. If you would have had blonde hair, blue eyes, you would have gotten better treatment at Chartres, and this is coming from a white therapist." I asked Jordan if the health providers did any tests or gave treatment for his condition back at Chartres or Central City (another public mental health clinic in New Orleans). He responded with, "They gave me pills, a pitcher of pills. And when one wouldn't work, I would go in for the mania, and they would say take these pills, but there was no follow up. Let me tell you something, from 17 to 30 years old, I never had a psychiatrist or social worker set me down and tell me that I had a mental illness."

Surprised to hear this, I asked Jordan, "What words did they use then?” Jordan responded with, "Low self-esteem, laziness, complacency. I live in poverty, so it brings on problems. Oh, my father, I never had a male figure, or another thing. The social worker I had for 12 to 13 years said don't drink any alcohol." I asked Jordan how he found the doctor he has now:

It's funny. My neighbor, the one who graduated from LSU with a master's, ironically, she couldn't counsel herself. I was talking to her, and we lived in the same housing program back in the 90s. She said, 'Oh Jordan, why do you go to Central City?' And I said that's where the doctors are. She said, 'Do you have Medicare and Medicaid?' This was in 1996. I said yeah. She said, come to Tulane. I said, come to Tulane? She said I'd get a private psychiatrist. And that's how I got a private psychiatrist.

From 1996 to 2011, Jordan saw the same psychiatrist, a woman, but she left the city to work at Jackson State Psychiatric Hospital. He now has a male doctor, who he has seen for four or five years. Responding to whether he liked his current psychiatrist, Jordan said, "He all right." I was 
not surprised by this response since most people I interviewed said they usually only talk to their psychiatrists for 10 to 15 minutes every few months. But Jordan's facial expression completely changed when he talked about his therapist:

But my therapist is a star. His name is Howard. He's my therapist, and I've had him since 1996, and he really is the nuts and bolts of my awareness of mental illness. He tells me facts, he tells me statistics, and he tells me reality. Like I never thought I would hear him say, he said, 'Jordan, had you been blond hair, and blue eyes, your treatment would have been a lot different at 17 .'

Even though Jordan's income is limited from his social security, he pays $\$ 35$ a session to see Howard every month. I asked Jordan, "The treatment you have now, it seems to be working well. Why do you think it works well?" Jordan responded with this statement laughing out aloud, "Cause they tell me I have a mental illness!"

\section{Jessica}

Jessica is a 26-year-old community health worker who identifies as Chinese and white. I met her in the audience at a panel on addiction and mental health in the city that was open to the public. At the panel, during the Q\&A session, Jessica explained to the panelists how she works with a lot of transgender clients, but she had trouble explaining to doctors outside of her workplace how to be respectful for using the correct pronouns for people and asked what more could she do to get these messages across. The panelists' response was to "come to more things like this." I later sat down with Jessica to ask her about the work she does. She is a community health worker, and I asked what that designation means and what her job entails. Jessica explained,

Community health workers work a lot in rural areas or where there are huge barriers to care where people need more access to care. The goal is to hire someone from the community that you're trying to serve, and if that community is historically a community that has barriers to higher education or trainings that would make someone qualified, then you need to hire this person. You need to hire this person that has been in prison, that has struggled with drug abuse, et cetera. 
Jessica works at a Federally Qualified Health Center (FQHC) in New Orleans, and she has a caseload of 25 clients. The team she works on is funded by the Centers for Disease Control and Prevention (CDC), so she only works with HIV+ and PrEP clients. She explained PrEP, or preexposure prophylaxis, as a pill you take every day to prevent HIV. Jessica specifically works with clients who have HIV but are falling out of care. If they have missed their last couple of appointments or if they are particularly at-risk (e.g. they are homeless, have behavioral health issues, are really young, or if their doctor does not think they have accepted their diagnosis), they will get assigned a community health worker to help them get through the process and access their medical care as best for them. For example, Jessica has a cell phone that her clients can text, which is really helpful for her clients. Her entire schedule is client-based because "the whole point of my existence is to make their healthcare as accessible as possible." Jessica explained her role further:

So, I'm basically like a case manager's extender's arms. It's like, case managers, have really big cases, at my workplace, more than 100, if a medical case manager, then fewer. When that happens, they can't reach out to every client on a personal level, and it might be three months where a client hasn't seen a case manager and is able to do something about it. And so, the goal is for us to come in right when they start to fall off, when it's much easier to get them reengaged to care. They still have the same phone, things like that. It's basically like emergency response case management. And I don't have like, I can't diagnose, or you know, I'm not a LCSW, I don't have a master's in social work, so I'm like triage kind of a situation, and also it kind of helps to have an informal case manager for some people. If they've been hurt by the system before, it helps to have someone who they can kind of identify with and then you can build that rapport and transfer it to their case manager too. Like start going to meetings with them, like help them build rapport, and just help them establish a foundation for them to access their own care.

I asked Jessica, "When you say they’ve been hurt by the system, can you give an example?"

Umm, we have a lot of clients who they have felt judged by providers, whether they were actually judged or if it was previous stigma they faced before, and the question the doctors were asking them made them feel like they were being judged there. Either 
because of their HIV status or just their life. I usually get the trans clients because I have a lot of trans cultural competency.

I asked Jessica if they assigned those cases to her:

Well, it's not like every trans client who comes through, they're like 'Jessica, they're assigned to you,' but if I have the availability, like it makes sense to put me on it because I'm already working on, I'm a member of the trans advisory committee at my workplace, which is a board of trying to making sure our workplace is the most culturally competent in trans issues because we've had, all medical places have issues in the past, but my workplace has had issues as well, and as a company that wants to be forward thinking, the shortcomings are pretty obvious. So that's a big one with trans clients, getting the wrong name, getting mis-gendered, or having doctors treat them differently, or see that their name is on the list but still using the wrong pronouns, just to kind of build an advocate for yourself. Because some people are perfectly able to communicate that and stand up for themselves but other people, like a doctor's office is already a vulnerable place. Like you're already going to someone who's going to tell you about your body in ways that you're not going to understand, and that's kind of a vulnerable position to be in. And then you add this aspect of them doubting your entire identity, it makes accessing healthcare really, really difficult in general, insurance wise, but also really difficult emotionally because you already have to advocate for your symptoms and your body, and now you have to educate for something as simple as your pronouns.

Jessica and I discussed the panel on addiction and mental health where we met. I asked her if that

panel was something she attended on her own or for work:

I was paid to be there. Trainings and things like that are important because part of being a community health worker is your presence of being in a community, so it helps in that regard, and also, we don't have that formal-like social work training, so the more information I can get on how people work, the better. And also, it's a good networking opportunity because if I have a client who has drug abuse or mental health issues and they don't want to see someone at my workplace, I need to know what else is out there for them and try to set that up. My workplace doesn't have a good addiction track. We work with clients who have addictions, but we don't work with medicated assisted, what's the word, don't offer suboxone or methadone. We're working on it, but we're also not able to handle somebody going through withdrawal, so I would need to find somebody else to offer those services.

I asked Jessica, "How did you become a community health worker?"

So everybody else on my team, [two others], they both have public health backgrounds. I'm like a PR mass communications major. I have an undergrad degree, but they did want to do a social media campaign, so I think that's part of why I got the job but also, like I didn't identify as nonbinary in the interview, but I do have a lot of trans friends and I am pretty queer, visibly queer, and uh, and I think I'm pretty good at talking to people, and I 
think that came through. And so, that's how I ended up in the position. I applied for the job and I am young and didn't have insurance and have a lot of trans friends and also have been in vulnerable situations that are reflected in my clients.

Jessica identified as part of the LGBT+ community and mentioned that she had also done LGBT nonprofit work in Baton Rouge prior to moving to New Orleans. However, after we finished the interview but before she left, she also recognized her privilege as someone who has spent much of her adult life around other queer individuals, and she acknowledged that is not something many of her transgender clients, especially from low-income backgrounds, experience.

\section{Danish}

Danish was 24-years-old when I spoke to them, ${ }^{22}$ had a bachelor's and master's degree in psychology, and did administrative tasks at a mental health clinic in New Orleans. Danish had some contact with clients at the mental health clinic where they worked, where the majority of the clients were black or people of color, and the majority of the staff was black as well. Danish identifies as North African, South Asian, and black.

My initial questions for Danish were about the services the clinic where they worked provided, but when I asked about what some of the main problems the clinic faced, Danish brought up the issue of hiring mental health workers who related well to clients. For example, the clinic was looking for a Licensed Clinical Social Worker (LCSW) for months at one point:

We had to hire a LCSW. In the state of Louisiana, there are only like $80 \mathrm{LCSWs}^{23} \mathrm{I}$ don't know why. Actually, I do know why. It takes like so much work to become a LCSW. First you have to get your bachelor's and master's in social work. That's already two levels of access that are knocking people out. Once you get a LMSW [Licensed Mastered Social Worker], you have to register and then do three years of work under supervision of a LCSW. Three thousand hours or something like that, then you take a

\footnotetext{
${ }^{22}$ Danish identifies as gender nonbinary and uses the pronouns them/they.

${ }^{23}$ There are over 3,000 LCSWs in the State of Louisiana (LSBSWE 2018). Danish may have been referring to looking for LCSW-BACS [Board Approved Clinical Supervisor], who can supervise other social workers and requires further training. In Louisiana, there are about $900 \mathrm{LCSW}-\mathrm{BACS}$, and probably fewer in the city of New Orleans.
} 
test, and then you get a license. So, it's a lot of levels, which is why it's hard to find a black LCSW in the city.

The other reason it's hard to find someone to work in our clinic, by that time, they're working in their own clinic, in a hospital, or somewhere more higher up than being a clinical supervisor at a small mental health facility. We were looking for a black LCSW. We were looking for months. We never had a single black or brown person apply for the position. Finally, we're getting desperate. We really need a supervisor and someone to head the program, so we hired this white lady who had worked at a community health center before. She was like from here but had lived in New York for a long time before moving back here. As I told them when they were hiring her, I feel like we should wait rather than hiring her because she's just not going to relate to our clients at all, especially because every other employee is black. It doesn't make sense to have a white supervisor. Within the first month or two, we had several clients who said they didn't want to see her because they didn't want to talk to a white lady about their problems. We had several clients who wouldn't let her into their house.

The first time I had to break the news to her. And she asked why. And I said because you're white. The social worker responded with, 'that happened at the old agency too. Clients wouldn't let me in their house.' And I was like wow, you should have told us that before.

At this point, I interjected, "Is it just because of what she looks like or is it something she's doing?" Danish continued:

So, I was talking to my boss about this, and my boss was saying the reason they don't trust white people in the house is because white people, when they show up to the house, it's usually child protective services or auditors. Or it's never good. There's never a good reason why there's a white person at your door. And some of these clients, it takes a while for them to let black social workers into their house too. They just don't trust people. But they're quicker to trust black people, and they're more likely to let a black person into their house.

Also, we do have a white social worker. But she's from here, and that makes all the difference. The way she talks to people, there's not a hint of condescension, there's not a hint of I'm smarter than you, which somehow implicitly comes out when white northeasterners come out to talk to black southerners. It just always is.

So, this social worker who I'm talking about, there's a hint of condescension, but after I told her that, she went and told my supervisor that I'm narrow minded and myopic. And I was just relaying what a client told me. I'm just the messenger. [That social worker] only lasted four months at our clinic. 
I asked Danish how important the person's background was for the clinic, especially since they

tried to find a black LCSW for four months. Danish gave me an example:

I came across this [paper] because a therapist at my workplace tried printing this but her printer wouldn't work, so I printed it for her. And there were like 12 statements like this. I asked her more questions about it. Basically, you're supposed to put the statements on the board if anyone else has ever said this to you or if you've ever said them to anyone else. So you're interrogating both sides of this. What struck me the most about this is the way some of the statements are so catered towards black folks, and white therapists would have never thought to put up.

Danish then read the statements to me:

Your hair isn't good enough to go natural. You should get a perm. Your edges are too thin. Your nose is too big. They had other ones that were kind of similar: You're too dark skinned. Stuff like that. You're too skinny. This is something a white therapist might not think is a problem, but it is a problem in black and brown communities, so yeah this really struck me. This is a clear way you can see a need for cultural competent care because when you have a therapist who doesn't understand the culture you come from, they're not going to understand so many things about you. And you can learn so much about a culture without being in it, but that's different.

I'll even give you an example. So like with Desi culture, there's so many things white folks don't understand, especially when it comes to LGBT kids and their parents. So like for me, I censor my queerness around my parents. I don't dress in the same ways. I go to the weddings, the mosque, and all this other stuff, and wear what they want me to wear. I do my own little rebellions with it. I also look like this. [Danish has a short haircut, nasal septum piercing with a circular barbell].

Danish's parents know they are queer, but they just don't discuss it:

But basically whenever I tell this to, I would say non-Desi folks, because even black folks have said similar things, where it's like, 'Go fuck your parents. Why should you care? You should just not do what they tell you to do.' That's just not how we do things. And I've even had other Desis tell me, man, your parents are so liberal. Mine would have kicked me out of the house. And I know a bunch of Muslim kids this has happened to. So for me, my parents are like so progressive, but Americans don't think of it that way, and so if I was disclosing that to a therapist, they would probably steer me into the direction of do whatever you want. I'm forgetting the terms I'm thinking of.

Eventually Danish remembered: "Individualistic vs. collectivistic cultures. That's a difference in culture. So yeah, the person from the community would be the best." 


\section{Clinician-Patient Matching}

I provided these examples because Jordan, Jessica, and Danish illustrate the complexities of finding health services from health workers with whom one can relate in New Orleans. This is a more significant issue in New Orleans post-Katrina, as one in four professionals left the city after Katrina and the influx of transplants are from various backgrounds. Jordan, Jessica, and Danish each gave examples of the problems experienced by providers and clients and reference the importance of some form of "clinician-patient matching" (Willen 2011, 112). The phrase “clinician-patient matching (or doctor-patient matching) is used to describe the efforts to pair patients with care providers on the basis of shared language competence, shared cultural or racial-ethnic background (generally in keeping with the U.S. racial-ethnic pentad), or a combination of the two" (Willen 2011, 113).

Cultural or racial-ethnic matching aims to resolve "more subtle issues that have been hypothesized to influence diagnosis and treatment, including, in particular, matters of mutual intelligibility and interpersonal dynamics" (Willen 2011, 114). This form of matching centers on intrinsic characteristics of both patients and providers, and according to Sarah Willen, one of the purposes for clinician-patient matching, especially for therapeutic motives, is because it "has been posited as a way to achieve higher utilization rates among particular patient populations, to strengthen rapport or therapeutic alliance, to achieve greater patient satisfaction from treatment, and ultimately to improve treatment outcomes" $(2011,114)$.

For Jordan, I would not just call his situation a mismatch. His story just resonates with racism at every possible level, with clinicians telling him he did not have a mental illness, telling him to "snap out of it," and misdiagnosing him for 13 years. For Jessica, one of her challenges was addressing the feelings of mistrust by her clients from previous health providers, and her 
background as someone who identifies as part of the LGBT + community helped her get the job as a community health worker and relate to her clients. For Danish, their example of the white LCSW the clinic hired, illustrated the mismatch between the white social worker and the black clients who would not let the social worker into their homes. In addition, Danish went into detail about the statements that the therapist at the clinic printed: Your hair isn't good enough to go natural. You should get a perm. Your edges are too thin. Your nose is too big. And for statements like that, clinician-patient matching has significance in therapy.

\section{Recognition}

But with each of these examples, there were also stories of successful treatment or encounters even when the client did not come from the same background as the clinician. To quote Elizabeth Carpenter-Song, "What, then, are we to make of happy patients?" $(2011,170)$. There is also "much to be learned from positive experiences of engaging in mental health services. For whom are experiences positive or negative? In what contexts? What makes a good clinician? A good patient? Taking positive experiences seriously opens up fresh analytic space for us as researchers to shift from documenting what's wrong toward specifying what may work" (Carpenter-Song 2011, 171).

Elizabeth Carpenter-Song advocates for an approach drawing on the concept of recognition. Unlike cultural competency models, which have been critiqued heavily by anthropologists for presenting culture as something static, conflating culture with race-ethnicity, and assuming it is a skill that can be easily acquired (Kleinman and Benson 2006), recognition is, "grounded in the experiences of patients and clinicians, facilitates approaching difference and otherness through openness" (Carpenter-Song 2011, 179). Instead of a skill "to be learned or a set of facts to be committed to memory, recognition implies a stance, an inclination toward the 
other that desires to know but understands the utter impossibility of realizing that longing" (Carpenter-Song 2011, 179).

Jordan to this day has never had a black psychiatrist, but the relationship Jordan has with his current therapist, who is white, and whom he refers to as "a star" speaks volumes. For Jessica, even though she identified with the LGBT+ community, she acknowledged she came from a more privileged background than her clients. In addition, her non-judgmental attitude and "openness" is what makes the FQHC where she works accessible to many transgender members of the community. Danish, at the mental health clinic where they worked, acknowledged the white social worker at the clinic whom black clients did trust because that social worker did not show any hints of condescension when she talked to clients.

How much of clinician-patient matching, along the lines of race, gender, class, sexuality, and other axes of identity, is necessary for individuals who come from low-income or marginalized communities? Is it necessary to have health professionals come from the same community as patients or clients to have successful health outcomes? These questions came up in casual conversations with staff at Vista, where I conducted most of my fieldwork. In a conversation between Laura, a white LCSW, Victoria, a black woman with a bachelor's in psychology who oversaw many of the day-to-day activities in the psychosocial rehabilitation program at Vista, and myself, they acknowledged that as mental health professionals, knowing what you project to people and how you come off to clients is significant. Laura referred to this as "self-awareness." As a white woman, Laura recognized that not every client is going to relate to her and disclosed that during her first job as a social worker, there were a lot of male, black teenagers who saw her. And she would help them as much as she could, but she also wondered how much she could relate to them. Laura disclosed, “They're going to have a set of concerns 
and issues that I might not even think of, and I often thought during that first job if a black, male social worker would be a better fit for those teenagers."

That statement then prompted a discussion between Laura and Victoria about how they have never really seen black, male social workers in New Orleans. In fact, the image of a social worker that often comes up is a white woman when they thought about it. They guessed that social workers are probably $80 \%$ women and $20 \%$ men, and even the men are usually white men. There are more LPCs (licensed professional counselors) who are black in the city, and they guessed this is probably because there are more LPC programs than social work programs in the state of Louisiana.

Is the lack of mental health professionals who are black or from other marginalized communities something that hurts clients coming from those backgrounds? In terms of what can be billed by mental health services and being able to diagnose individuals, titles such as LCSW do make a difference. Reflecting back on the cases of Jordan, Jessica, and Danish, their educational backgrounds also say something. Danish has a Master's in psychology and went back to graduate school for their Ph.D. in counseling psychology because they really thought it was important to have more counselors come from the same communities as clients. However, Jordan's and Jessica's cases illustrate one does not necessarily need specific degrees to work with the community. Through Vista, Jordan is trained as a peer support specialist. He barely finished high school, but his firsthand knowledge of living with schizoaffective disorder offers a lived experience perspective to other clients at Vista that even those with degrees in mental health fields might not be able to provide. In fact, some of the other black clients come to Vista once a week to participate in a free group session co-led by Jordan, despite challenges with transportation and other barriers. Jessica was hired as a community health worker to represent 
the community she identifies with the most, the LGBTQ+ community, and she advocates for her transgender clients. Her bachelor's degree is in mass communications, not public health like the two coworkers on her team, but she seems like a good fit for the clients on her caseload.

\section{Conclusion}

A significant aspect of doing any type of health work is finding "what matters most to another person," which is not a technical skill as cultural competency models suggest (Kleinman and Benson 2006). Laura used the term self-awareness when she spoke to me, but her outlook is not much different from Carpenter-Song's notion of recognition and maintaining openness within clinical encounters $(2011,180)$. For sustainable mental health work to continue in New Orleans, the ideas of recognition and openness are important for everyone working in these fields, regardless of their educational background. Those from low-income and marginalized communities might not ever meet a psychiatrist, psychologist, or LCSW reflective of their own backgrounds, but community health workers and peer support specialists can reach out to those communities, build rapport, and have the ability to bring these individuals into mental health programs, which is important because of the stigma attached to mental illnesses. Clinicians can maintain those relationships with recognition and openness. The next chapter focuses on caregivers and the common struggles they encounter when navigating the mental healthcare system in New Orleans. 


\section{CHAPTER 7}

\section{THE CHALLENGES OF CAREGIVING}

The previous chapters describe the challenges individuals with chronic mental illnesses face in accessing mental health services. I initially did not include family members in my research population. However, Vista provides support groups and services for caregivers, and several approached me interested in sharing their perspectives. Thus, I made an amendment to my IRB to include caregivers as a population in my research. The family members of individuals with mental illness whom I interviewed often mentioned the onset of psychosis as a difficult time when their family members were receiving treatment. Figure 8, a decision tree created by staff at Vista, demonstrates the obstacles caregivers face. The decision tree was created by the staff to help guide and answer questions for caregivers who called Vista for more information. It is similar to the Figure 3, which was a decision tree to guide individuals trying to navigate the mental healthcare system. The one notable difference in this decision tree is that it begins with “Loved one open to treatment?" Having a family member open to treatment in the first place is often an obstacle in itself. 


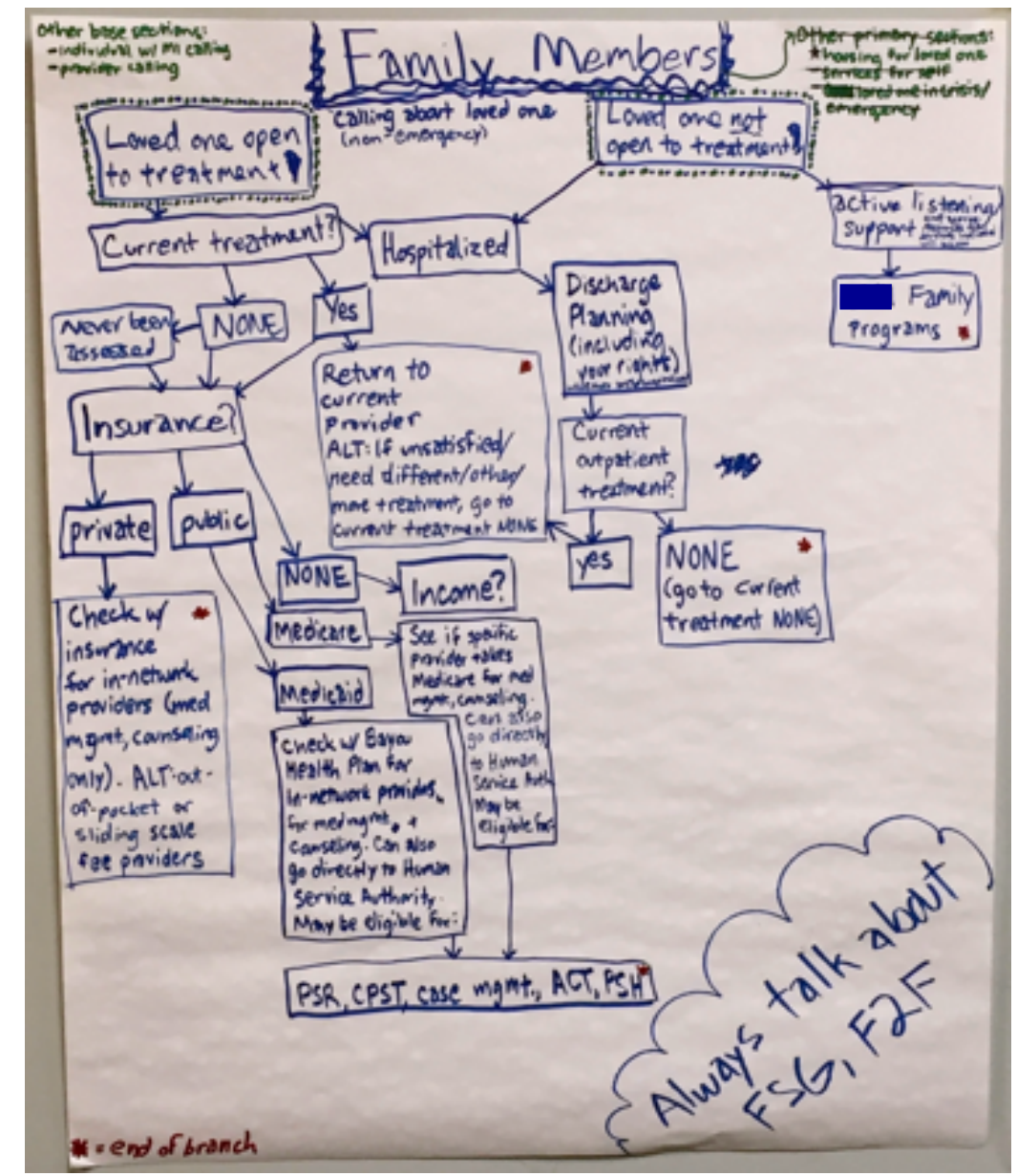

Figure 8: Decision Tree for Caregivers

While the challenges and struggles of treatment for individuals with mental illness is well documented from the perspectives of those living with a mental illness and of mental health professionals (Brodwin 2013; Desjarlais 1997; Estroff 1981; Myers 2015; Rhodes 1991), the burden caregivers face is less well documented from ethnographic perspectives. In this chapter, I share the stories of Grace Martin, Debra Green, and Anita Williams and the challenges they encountered as caregivers of individuals diagnosed with chronic mental illnesses. Grace Martin is a 48-year-old African American woman who grew up essentially taking care of her mother. Debra Green is a 69-year-old white woman who described the challenges of receiving care for her son while he was in psychosis. I focus in depth on Anita Williams, a 48-year-old African 
American woman, because Black Radical Tradition emphasizes storytelling to confront oppression and is also a form of resistance (Rabaka 2010; Robinson 2000). In addition, Anita's story highlights the institutional circuit with her daughter, which is further explained in the next chapter. Using the framework of the therapeutic process (Csordas and Kleinman 1996), I argue that caregivers also need to be engaged in the therapeutic process for healing to occur for both individuals diagnosed with chronic mental illnesses and for caregivers. I also argue that the black women epitomize what Leith Mullings calls the Sojourner Truth Syndrome, taking on more stress than many other people.

\section{Grace Martin}

Most of the family members whom I interviewed were parents or siblings. Grace Martin, a 48-year-old African American woman from New Orleans, discussed her role as a daughter whose mother, Sandra, was diagnosed with bipolar disorder in the 1980s. Living in a single parent home, Grace essentially served as the caretaker for her younger brother. While she received some financial help from other relatives, she did not get the emotional help she needed to take care of her mother. Living in an "unstable home" and "not knowing what was going on" were a huge strain for her growing up.

While Grace was in middle school, Sandra's symptoms and condition escalated when left untreated. Grace remembered her mother being hospitalized many times at both Charity Hospital and at Southeast Louisiana Hospital in Mandeville and having to seek involuntary commitment papers for her mother at the coroner's office at the age of 14. She told me, "It was tough sharing with the Coroner what was going on at home when I wasn't even of age yet." For over 15 years, Grace described her mother as being in denial about her illness: "This is the hardest part of mental illness. I knew something was wrong, but my mom wouldn’t accept her diagnosis.” 
Eventually, Grace said she, "learned the role I had to play" and how to go about "separating the mental illness from the person I love and not define the person by it."

For Grace, the best thing she could do for herself was developing boundaries with her mother. At the age of 24, Grace moved out of her house when she got married. With two sons of her own, she had her own children to take care of but still served as a caregiver for Sandra throughout her life. "I had to gain an understanding to not get so involved with my mother that I missed out on my own life," Grace shared with me. Eventually, Sandra's illness was more stable with more consistent medications and health insurance, but this came after more than 30 years of dealing with it.

"I wish there was a place to teach or make more available treatment plans that included family members," Grace shared with me. Sandra suffered from lithium toxicity after years of taking medication and was on dialysis for two years. Grace donated one of her kidneys to her mom and was impressed by how the transplant team included both her and her mother in the process. Grace shared that, "They explained everything that would happen to her and to me, the process, and answered all our questions." That never happened with Sandra's mental illness. Grace shared,

There still is not that big of a support group for family members dealing with mental illness. I wish I had that when I was younger. It would have helped with the uncertainty and not knowing. If there was team that gave scenarios and how to deal with those or signs to look for, that would have helped. It wouldn't have taken away her illness, but it would have given an idea of what to expect and how to deal with the trauma and pain.

Grace's advice for other family members is to "share the burden with other caregivers, be open and honest with other family members. Do not do this alone. It's very trying to do on your own." 


\section{Debra Green}

Debra Green is a 69-year-old white woman from New Orleans trained as a school counselor who also works as a school consultant in restorative mediation. She shared her experience with her younger son Justin, who was 36-years-old. When Justin was a junior in college in Connecticut, he suffered "a psychotic break" and barely got through the year, according to Debra. After his junior year, Justin decided to stay in New Orleans, primarily working as a waiter for most of the year. Within the next year, Justin enrolled at Tulane, but Debra described his experience as “difficult." He ultimately graduated but then suffered a psychotic break and was hospitalized in 2003, which Debra said was Justin's first hospitalization, "not counting the drug related hospitalizations." 24 Justin's initial diagnoses varied from schizophrenia, schizoaffective, and bipolar disorder. Eventually, "the schizoaffective diagnosis was the diagnosis that stuck," Debra told me. Debra described Justin's illness as, “three-year cycles where he would be okay, but then he would have another break." In 2012, when he had his last break, Debra said Justin had managed to alienate everybody. After his 2012 break, Justin was enrolled in the Assertive Community Treatment (ACT) team, which according to Debra, "worked out well." With ACT, Justin could remain in the community and have mental health professionals come to him. During this time, Justin also started volunteering at a church where he helped serve lunch. In March 2015, Justin decided he did not want to be in the ACT program anymore. For some reason, Debra did not really know why, he wanted to get Obamacare. Debra was worried Justin would lose his other benefits, but for some reason he just did not want to work with the ACT team anymore.

\footnotetext{
${ }^{24}$ In addition to his mental illness, Justin also had substance use issues, leading to several hospitalizations.
} 
Then, in July 2015, Justin became extremely anxious. Debra and her husband were certain Justin was going to have another break and were more alert and attentive to him. A nun at the church where he was volunteering was worried about him and reported he was being disrespectful. Justin left his apartment and stayed with Debra and her husband, but from the balcony of their condo, Justin jumped from the fifth floor. She said, "He was never suicidal. In fact, he said he was anti-suicidal and repeated it so many times.” After the jump, Justin had multiple broken bones, needed a shoulder replacement, had traumatic brain injury (TBI), and had problems with his vision. However, his psychosis disappeared. Debra shared, "He's morbidly depressed, which is brand new because he was never particularly depressed with his previous diagnosis. He would get manic but never depressed." According to Debra, when Justin was in psychosis, "He was unable to function," but now he can at least function. In addition, Justin's neurologist suggested trying TMS treatment. Debra described Transcranial Magnetic Stimulation (TMS) as an alternative to shock treatment, a form of magnetic stimulation, and Justin underwent TMS every day for six weeks. After the TMS treatment, Debra described Justin's transformation as "amazing." According to her, he sleeps better and is much less depressed. He lives in his own apartment now, and after completing all his speech and physical therapies from his injuries after jumping, "He's thinking about deciding what to do next."

As far as future concerns go, Debra is hopeful. Debra and her husband can provide for Justin's financial security for the rest of his life, and regarding caregiving, Justin's older brother and sister-in-law have promised to look after Justin when Debra and her husband can no longer do that. 


\section{Anita Williams}

Anita Williams' story resonates with other caregivers I encountered. Anita, a 48-year-old African American woman, was working in New Orleans at a local university but moved her home to Baker, Louisiana, about 20 minutes north of Baton Rouge in driving distance, after Hurricane Katrina. Thus, Anita was driving almost two hours one way from her home in Baker to work in New Orleans when I first interviewed her.

Anita has seven children whom she considers her own. None are her biological children, but Anita was in a relationship with the children's father from 1995 to 2000. Anita never married their father, but she was a significant part of the children's lives. When I asked her, "Did you stay with them as a family?," Anita responded, "No. What happened was the [biological] mom would have them during the weekdays, but I had them every weekend and the whole summer for three months." Anita described having "very unnatural but good relations" with the children:

I say unnatural because the mom's mother, I have very good relations with her. She would call me, and I would go and get food. The youngest one was two. He was still in Pampers. I kind of trained him because I couldn't afford a child in Pampers. I had to potty train all of them to go to the restroom. The older ones had issues because their childhood was such a mess. They would urinate in the bed at night and wouldn't go up to the restroom at night. I had to train them for everything and teach them everything. The father was not teaching them anything. The mom was not teaching them anything. I didn't know he was alcoholic until like the first year of the relationship. By this time, the children had gotten so attached to me, because I provided to them their only family atmosphere they had, so they were very clingy.

The children's biological mother was a compulsive gambler, and Anita explained this was the reason there was often no electricity or food in the house. The children's father worked offshore, "so he made a lot of money, but he spent all his money on alcohol and things like that, so I didn't have any help from him. . . our relationship was long over before the five years ended." Anita's relationship with the children's father ended because "he felt as though I liked the kids, and I didn't like him, so he at that point said I wasn't going to see the kids anymore. 
And I just told him fine. That's okay, because they're getting older. He doesn't realize they'll come to me on their own. That's essentially what happened."

Thus, years later, the children often saw and talked to Anita and referred to her as “mamaw." In 2008, the second youngest of the children, Diana, was attending Southern University in Baton Rouge. She was living off-campus in an apartment, and Diana's sister, Danielle, was staying with Anita in Baker, Louisiana. Danielle got word from another sister living in Houston that something was going on with Diana through Facebook. It was about 2 am, so Danielle woke Anita up:

We got dressed and went to her apartment. When we arrived, she didn't answer her door, but all the lights were on in the apartment. I'm concerned she's not answering her door, but her car is in the parking lot. We went from one driveway to another driveway to see if there's an emergency number at the office complex, a manager, or anyone who can give us access to her apartment to see if she's okay. In the process, we saw a police officer in the complex, and we thought to ask him what to do. But before we could do that, there were four other police officers who drove into the same parking lot. We never got to talk to the police officer. We were going to follow him into the parking lot where Diana's parking lot was, but before we could do that four other police officers came. Since they were all in the location near the apartment, I parked a little way. Then I realized they were going to Diana's door.

Anita realized Diana had called the police. Indeed, Diana had called the police and said somebody was at her window with a gun trying to do things to her. And then Diana said a lady

was trying to get her and harm her. That's when the police responded, according to Anita:

When they knocked on the door and said 'police,' that's when she opened the door. She opened the door and went to me in a hysterical manner. I talked to her. She went back into the apartment and brought myself and Danielle into the apartment. And one of the police officers came into the apartment. We went in and she was talking in third person, talking into the mirror to herself, saying 'Oh you're this, oh you're that,' and then she said, I don't want Danielle here. So I asked Danielle to leave the apartment. She took me to her bedroom and said, 'I need to tell you something.' I said okay. She said, 'I'm pregnant.' I said okay. So what's the problem with everything going on with you? She said, 'I'm pregnant by God.' This guy she knew on Southern's campus, his girlfriend sent her over to shoot her because she was pregnant by God. She was telling everybody that this person came to her window, lived right next door, and her car is a Mercedes. I'm thinking some of what she's saying might have some validity to it, so I tell the police 
officer that this person drives a Mercedes. The police officers checked and said there was no Mercedes anywhere in the parking complex. So we knock on the person's door, and of course that was not the person. I proceed to talk to the police officer, and I ask if there's somewhere they can bring her where she can be evaluated thinking she's suffered a breakdown or something. They said, no, they couldn't do that. So I said that I probably need to stay here and talk to her, but after a while, she got apprehensive of us being there. She kind of exploded, and said, 'I want y'all out of here. I don't want y'all to take everything I have.' And she's telling the police officers that we came in to take everything she has.

That's when Anita left Diana's apartment. She talked to the police officers outside, but they told her, "We can't do anything about it." The police officers told Anita in order for Diana to be evaluated, Diana would have to voluntarily go and be evaluated. That's when Anita became really worried because she knew Diana would not voluntarily get evaluated because Diana did not think anything was wrong with herself. She did not think she was having a mental breakdown. Anita asked the police, "What can I do? They're like, you can't do anything, so I'm like, 'Oh my God'.”

Anita was still in the parking lot in the early hours of the morning with her other stepdaughter, Danielle, to try and figure things out, but Diana told them, "Everybody, just get out of my apartment. I have to go inside and study because I have finals in the morning." Anita managed to talk to her enough outside the door before she left to ask her what time her final was. Diana told Anita her final was at 8 in the morning, so Anita offered to pick her up and bring Diana to her final. Anita said, "Because driving is not going to be a good thing for her. She's very unstable. And I didn't think she was going to school either, but I did want to keep a handle on her. Offer to bring her to school that morning. So she agreed to that if I left.” Anita and Danielle were in the mid-city part of Baton Rouge. Baker was too far for her to come in the morning, but there was a hotel a few blocks away, so Anita decided to get a room at the hotel. Anita explained: 
Danielle and I stayed there that night. She said she was going to be up studying and drinking coffee, so I kept calling her every hour just to see if she was okay. At first, she was answering, but as it got closer to daybreak, she stopped answering the phone. Not only did she stop answering, she turned off her phone because it was going straight to voicemail. So at 7:15, I got up and got my stepdaughter up, and we went to her apartment because she was supposed to be at Southern at 8 and so we should be there for 7:30. She wouldn't answer her door. Her car was still there in the parking lot, so I figured she was still there or someone else picked her up.

Anita and Danielle then went to the apartment complex office, which opened at $8 \mathrm{am}$. She told the staff that her stepdaughter suffered some type of breakdown, that the police was there last night, and she's trying to get her some help now. Anita wanted the apartment complex staff to unlock Diana's apartment, but they told her they could not unlock the apartment and let her in unless the police are present. Anita then called the police and asked them to come to the apartment complex. Anita told me:

Thank goodness this was two different police officers. The other police officers were not concerned, not asking anything if she was on medications, anything. They didn't ask anything. It was about 9 ish, the following morning and I talked to them before they entered the apartment, and I explained what had happened the night before or early morning. They said they would go and check it out. The manager came and unlocked the apartment door, and the police officers went in. They made me stay out and Danielle stay out, and they stayed in there for about 10 minutes, and they were talking to her. They said she seems to be fine. She says she has to go to school. I was here to pick her up, but she doesn't have to go until 10. I felt like she was trying to get rid of us.

The police officers asked Anita if Diana had any problems before, but she seemed to be okay and answered all their questions. Anita explained what happened during the night and how Diana was not behaving like herself. The officers then told Anita, in these types of cases, she would have to get an order from the coroner's office if Diana did not want to voluntarily be evaluated. Anita did not even know where the coroner's office was at the time, but she proceeded to go there to make a report. Anita continued:

I looked it up online. I Googled it. And I found it. I went to the coroner's office. This is about $11 \mathrm{am}$. So we get there and find the intake processer at the front desk, and we explain to her what the situation was, and she made a report with name, date of birth, and 
her location. They would dispatch a deputy to get her and bring her in for an evaluation. She instructed me, after she signed the papers, to go back to the apartment complex but not to her door because we described how she was, and she asked us has she been diagnosed with any mental illness, and she had not been, so she said we don't know how she's going to respond now because it's been a 24-hour period. If she's having a breakdown, she will probably be going in and out of that state of mind and could get stuck in that state of mind. She could be a danger to herself or us, so don't approach her, but go back to the apartment complex and let them know whether she's there and then to send somebody. So we went to the apartment complex, but when we got there, her car wasn't there. I called the coroner's office, and I told them I suspect she's not there because her car is gone. Her mindset was she was going to school to take her exams. They told us to go over to the school and get her schedule. I got the schedule and brought it to the coroner's office. In the meantime, I kept calling and calling, but she never answered the phone. Then we went over to the school, but she wasn't there anymore. She did have an altercation with a professor there. She hit one of her professors. The deputy talked to one of the academic advisors and one of the student affairs people. She left because they called the police. Now she was being charged with assault to a professor.

At this point, Anita had no idea where Diana was after she left the university. Danielle was working at Ochsner Hospital in New Orleans during the night shift, and Anita did not want Danielle to miss her night shift, so Anita and Danielle left for New Orleans. Anita called Diana's sister in Houston to let her know what was happening, and to let her know if Diana contacted anyone else or if they saw anything else on Facebook, to let her know. For three days, Anita had no idea where Diana was. Then, Danielle received a call from her sister in Houston saying somebody contacted her on Facebook, and Diana was in jail in Kenner, a suburb outside of New Orleans. Anita contacted the Kenner jail, but Diana was not there, and she contacted the hospitals in the area, but Diana was not in any of the hospitals. Anita then found out that Diana was in the Gretna jail on the West Bank side of the river in New Orleans for petty theft and resisting arrest. The clerk would not give Anita any details, so she called her godson, who is a police officer for Jefferson Parish, and asked him if he recalled any incidents in Kenner the previous night. Her godson said he had heard about an incident that happened in the airport. He just knew somebody was belligerent at the airport and there was a minor theft, and the incident stemmed from there 
where the police were dispatched to Armstrong International Airport. At this point, all the details

were not released, but Anita asked her godson if he could get in touch with somebody to get

more details and explained to him that Diana had a breakdown.

\section{Getting Lost in the Institutional Circuit}

Anita's godson got in touch with somebody and then called her back, and Anita learned

more about what happened to Diana:

He was told she was in the airport. And she went into some of the concession areas and got some food and walked out without paying for it. She proceeded to go to the gate or wherever she was going, and they called airport security. When airport security questioned her, she got belligerent. She started praying out aloud and saying they were doing things to her and people were doing things to her, and they knew something was wrong with her at this point. And then she was fighting the police officers and resisting arrest. They finally got her, and they transported her from the airport to Gretna. So I thank him for the information, and then I start researching more stuff. My next concern was the fact she actually has had a breakdown, something is wrong with her, and I called the jail and I request to speak to one of the captains or somebody in charge because I wanted her removed from the jail population. She's been in jail for two days. If you don't bail out at a certain time, then you can't be in a holding cell, you have to be in general population. So I asked them, I told them that she had a mental breakdown, and I had started the process of getting her picked up and evaluated in Baton Rouge, but she left before they could pick her up. Do you mind moving her to another area of the jail because she's not going to survive in the general population because if she does something to somebody or she says something to somebody, they probably will get angry and hurt her or something. And she's never been a child who's been in trouble or anything. This just happened.

Anita learned that the staff had moved Diana to the section where they hold prisoners with

mental illnesses because the captain called her back to tell her they moved her, but then Anita

was worried about Diana's release:

My next concern was since she didn't have any prior charges, they would let her out on her own cognizance [sic] because she would not have to pay bail. That made me alarmed because she would be out, and she wouldn't have any help. I contacted the mental area in the prison and wanted to speak to a doctor or psychiatrist or something, but the psychiatrist only comes once every two weeks. And I said, how are people getting help if the psychiatrist only comes once every two weeks? And there's a whole section, I want to say the nurse said 25-30 beds in there for this section. I knew I needed to find other kinds of help and resources for her because I knew I wasn't getting the cooperation there, and it 
just seemed like there's nothing legitimately in place to help these people even though they're in jail. I'm thinking about medication. They couldn't give her anything because she doesn't have a diagnosis. So what's happening to the other people in jail? Are there other people in jail who haven't had a diagnosis but just in there? There's no way to know anything going on in there.

Anita tried talking to the nurse who worked in the section of the jail where Diana was placed, and told the nurse she did not want Diana to be released because she really needed to be transported from jail to a facility because if Diana got released, she would not voluntarily go anywhere to get checked out because she still did not think anything was wrong with her:

The nurse was no help at all. 'Oh, we can't do that. You're going to have to come pick her up when it's time for her to get out and you're going to have to bring her somewhere.' So my hands are tied. I feel like I've exhausted all my opportunities as far as Gretna jail was concerned. My hope was to call the coroner's office back in Baton Rouge, and I called the intake processing person, I told her what happened, I told her she's left Baton Rouge. She said they can't cross parishes. She is confined now, she's in jail, she had an incident at the airport. I said they're going to let her out in a few days, and she can't get out in her own cognizance. She said well right now, she's going to have to have a court order. She, as a courtesy to me, contacted somebody in Jefferson parish. She said do not pick her up because she could be a harm to herself or to you, and then going through these traumatic events has probably brought her more over the edge, and she's probably further over the edge from her normal self. So she contacted somebody, and they were able to transport her from the jail directly to West Jefferson Hospital to the emergency room. And at that time, they called me to let me know that she was in the hospital. She stayed in the emergency room for a day and a night. I went to see her, and her condition had worsened. They had given her medication to calm her down. They said she was really hyper and over the top so now, the medication is taking effect, but she's still talking the same way she was talking before but at a normal level.

Diana told Anita at the hospital, "I told them that I'm pregnant, and they keep asking me about who and where and the last time I had sex, and I told them I didn't have sex, that God put the baby in me and things like that. And so, I know you came here to get me out. Get me out of here." Anita told the doctors she did not want to alarm Diana, but she went to consult with the doctors, and they repeated to her all the things Diana had said about the baby, but she was never pregnant: 
They did a urine test and a blood test. And she absolutely was not pregnant, but she kept saying she was. She was saying people were looking at her and talking to her, and now she's hearing voices that are telling her to do things in her head. The doctor's asking me about her history, and I explained some things to him and when I first identified that this happened was when we got a call. I had never seen anything that would indicate she had a mental illness or anything. I didn't want to sign any papers. I wanted one of the other parents, her relatives to do something. The doctor signed something, so she was a temporary ward of the State, and they transported her directly from the emergency room to West Jefferson Behavioral Center.

Diana was transported from the West Jefferson Emergency Room to West Jefferson Behavioral Medicine Center, where she received treatment and was evaluated. The doctors evaluated her, and in about a week they diagnosed her with bipolar disorder and schizophrenia. Anita regularly visited Diana at the Behavioral Medicine Center while she was there for three months:

After a few weeks, she thought I put her in there. I said I didn't sign any papers, but I need you to cooperate. She said nothing is wrong with me, I don't need the medication. But I said if there's nothing wrong with you, then the medication doesn't do anything to you. Just take them like your vitamins and cooperate because they won't let you out until you cooperate because they had to force giving her medication intravenously. She eventually started to take the medications, after about three weeks. I was also bringing her step-grandmother with me for visitation. I was picking her up and bringing her with me to the visits.

While Diana was still in-patient, Anita learned about the series of events that led Diana to New Orleans. Diana left Baton Rouge on a Friday, and she drove to the airport in New Orleans, where she purchased a $\$ 600$ ticket to go to Atlanta for graduate school. This did not make much sense to Anita because Diana had not finished her undergraduate studies yet. Apparently at the airport, people were bothering her. They said she stole food, but Diana said she did not steal it, and she did not resist arrest. Anita asked Diana where her car was. When Diana had left Baton Rouge, she had gotten into an accident on Airline Highway with some people. Anita does not know what happened to the other people in the accident or if they got hurt. She had run the car into a ditch, and the police came to the site. They brought Diana to a hospital in LaPlace, examined her, and released her saying she was okay. Diana had told Anita she stayed in a hotel for one night, and 
the next day she took a cab to the airport. That's when she ended up in the incident at the airport.

Later on, Anita learned the car had been towed to a place in LaPlace, and Anita ended up having

to go to LaPlace and retrieve Diana's things out of the car.

The hospital had sessions where family members could speak to the psychiatrist on

Monday or Tuesday mornings along with the patient, and Anita would attend these sessions,

meeting with the psychiatrist first:

We found out on her Facebook page, she had listed a whole lot of things on what people were doing to her, about how her life was, how she wanted to kill Oprah, and just a whole bunch of things. Random stuff. She didn't like Oprah. She kept talking about this other guy who gave her food to make her sick. And she kept saying she was pregnant by God, and people were jealous of her, and she was going to have this baby. It was just so many things. Then, she brought up things about her family, that they didn't like her, that her daddy is not her daddy, and somebody else is her daddy, and she doesn't have a mama because she never took care of them and so. After I discovered this on her Facebook page, it wasn't directly on her page, it was in the notes, this was where all this stuff was so you won't see it unless you click on it, so I printed out some of these things to give to the doctor because I figured it could help him get into areas that could help her out. He was just really stunned by all these things because I of course told him what she was saying, but she was kind of maybe a little cunning about it, trying to make them think she was okay when she was not okay. So when he saw this, he said she actually has some underlying issues we have not been able to touch because he didn't know. He only knew the circumstance, and I explained to him what my relationship was, and how it became about, and the reason why I'm just the prominent figure in her life instead of the biological dad and the biological mom, and this is why the step-grandmother is sitting here because these are the people who were the caretakers of when they were young and things like that. So we got to talk to him before she came in. And when she came in, she was like, 'Oh well. I'm glad to see y'all, but what are y'all doing here? I'm not taking the medications. I started taking it, but I don't really need to take it. It's not helping or doing anything to me.' He said she's still in total denial.

During the time Diana was hospitalized, the hospital assigned a social worker to her case.

Diana's student insurance coverage picked up some of the cost, and Diana received Medicaid that her social worker probably applied for while she was in the hospital:

I think this Medicare [sic] was probably emergency or temporary because when she was released, everything had to be paid for. Her medications, her sight visits, afterwards and things like that. I didn't have to pay for anything before she got out, but her follow up 
was to come. I was in Baton Rouge, but I worked here in the city, so I would prefer, if she needed to go to follow up treatment, I would prefer for her to go somewhere that was closer to the job or on this side of the river [East Bank] here in New Orleans, but there were no facilities. When they released her, I went to pick her up. Eventually her dad came, and he kind of screwed things up. He was put on the non-visit list, and he was upset with me about it, but I didn't put him on the non-visit list. She did. He's still bitter about not being in a relationship with me, so everything I do concerning the children, it's a problem.

Diana's sister, who lived in Houston, did not want to contact their father, but Anita eventually

contacted him because she felt the situation had escalated more than she had expected, and she

thought he should know what was happening:

However, he came in town and was not on the list to visit, but he explained to the doctor that he was the father, and I was not the person that should have been taking control of the situation and that I misrepresented myself. But Diana had been going to sessions and everything, and she explained to the doctor why I was an integral part of her life and her biological mother and father wasn't because of the gambling and drinking. The doctor already knew this and by knowing this and the father coming in and acting really irate about the situation and expressing discord against me, he ruled that at least that was one of the problems Diana was having with the breakdown and everything. So eventually she put him on the list and let him visit her, and everything that was said, everything he was telling Diana was, 'You're going to come back to Houston with me, you're not staying here anymore,' and I should not be involved with anything concerning her illness and that sort, and of course, she was not satisfied with his responses to her. I stopped visiting her during the time he was here to avoid conflict with him, so that prompted her to continue to call me because she was getting more aggravated about him visiting and saying these things and plus saying things about me in a negative manner.

I asked Anita, "She had no desire to go to Houston?"

No, not at all. And that's what the calls were about. 'I don't want to go with him. I don't want to go with him. I don't want to go with him.' And then he eventually got in touch with the biological mother, and she surfaced up and Diana wouldn't let her come see her, and that was another problem. The biological mother ended up calling me and cursing me out on the phone because she said she was the mother, and I was out of place. And she started mentioning some of the same things that the father was saying. I just didn't entertain it because it really caught me off guard when I answered the phone because I didn't know the number, I just saw the 504-area code and thought somebody from the center might be trying to contact me. And I answered the phone, and it was her, and I haven't talked to her in forever. I was stunned at the phone call. And I said who is this. She said, 'You put Diana in there?' And I just hung up. Where had she been? I had been trying to contact people, and of course I had no contact with her ever, and for me to get a call out of the blue was too much. So eventually, the father kept in touch with the doctors, 
and the doctor was explaining to him that she could actually function on a normal basis with the condition and people do, if she would comply, take her mediation, but she needs to be here where she's closer to getting the treatment she needs, unless he is actually stable enough to take her back to Houston.

At this point, I asked Anita, "How would the doctor know her father wouldn't be stable?"

Because Diana was telling the doctor about the alcohol, and he was still drinking heavily at that time. He has not been able to maintain a house, a residence or place to stay, or even working anywhere. Almost like a vagabond but being a recipient of housing assistance because of Katrina. Everybody was originally living on the West Bank before Katrina, and they evacuated to Houston, and they stayed there because there's free housing and other freebies. He had no responsibilities or anything. Diana was telling the doctor all these things, but by this time, she's taking the medications, so she's more mentally stable and talking clearer, so that's more reason for the doctor to say, if he could provide stability for her, then maybe she could survive in Houston with them, but he really didn't think that would happen because of what Diana had told him. The doctor told me because I continued to go to the sessions in the mornings once a week on Monday and Tuesday when the psychiatrist is there with Diana and a family member. He was never able to sit down because that's when the real meat of things came out in the open. He had no idea about the sessions that the family member was allowed to come to, and she was the person who selected who that person was, and then I was going with the step-grandmother, so he was not aware of those things. So the doctor knew a lot more than he even imagined the doctor could know about him, his situation, and the mother and her situation. So when he continued to visit her, towards the end of the time for her to be released, from the center, she was very adamant with him that she did not want to go to Texas with him. She wanted to stay with me, so that riled him up a bit.

\section{Challenges after Hospital Release}

Diana's release from the hospital brought another set of challenges for Anita. Anita picked Diana up from the hospital upon her release and brought her to her niece's house in Uptown New Orleans to monitor Diana from there. Diana was released with prescriptions for her medications, but that's when the Medicaid ended, so Anita had to pay for Diana's medications out of her own pocket. One of the medications was $\$ 100$ per prescription, and Anita knew Diana could not be off the medication. The doctors explicitly told Anita about the importance of Diana taking the medications. Diana could miss one day but not more than one day of medications. The hospital had released Diana with one vial of medication, but another prescription had to be filled. 
During this time, Diana did not want to take her medication and still did not believe anything

was wrong with her. Anita monitored Diana taking her medication, which she had to take once in the morning and once at night before bedtime, but Diana would not take the medication if Anita was not there to monitor her. Anita was also trying to figure out how to continue Diana's treatment. Diana was supposed to visit a psychiatrist once a week for follow up care, but at that point, everything had to be paid for. Because she was now outpatient, there was no more Medicaid coverage:

She didn't have student insurance anymore because she had to request medical withdrawal from school, so that ended her student health coverage. I went to St. Vincent de Paul, a pharmacy in Gentilly, where I could try to get her medication. When I went there, it was closed the first time. I was going to go back to make arrangements to see if I could get her medications paid. In the meantime, I went to Central City. I went there to see if I could get some treatment appointments made for her outpatient treatment. The place was horrible. The area is horrible. However, the social worker that we met was excellent. I can't remember her name, but she was excellent. And she was telling Diana, because Diana was going to school to be a social worker, that was her field of study. She explained to Diana that she herself had a mental breakdown and she was on medication for it, and she had been on it for six years, and she functions perfectly with it. When you go about and see her, you wouldn't know that. But she said as long as she takes her medication, she functions normal, there's no problem. And she was encouraging Diana to take the medication, telling her she could function normally, finish school, and do all things she wanted to do. We were supposed to schedule an appointment. We wanted a psychiatrist for her ongoing treatment. However, the facility was just horrible. And she didn't like it.

I asked Anita, "What was horrible about it?"

It was decrepit. People just randomly came in off the street. There was security, but it wasn't really secure. There was a metal detector that didn't even work, no one checked you in or anything like that, but the security people were there. I was uncomfortable with the place. Diana's a newly diagnosed patient, and for her to come in and see more serious mental illnesses, they looked like they should have been by the way they were acting, they should have been inpatient as opposed to outpatient. I was going to have to pay $\$ 25$ for every visit that she had. That was the cheapest way. I couldn't afford River Oaks. They were $\$ 125$ for each visit. It was private. There's no sliding scale and no payment plans or anything like that. And when I was looking for a place to bring her, they wouldn't even accept her coming there before she was inpatient.

“Why wouldn't they [River Oaks] take her?" I asked. 
It was a money issue. You have to pay in advance. Just to see her it was like $\$ 1,300$ for her to come in and do an evaluation. They didn't take people who came involuntary. That wasn't an option.

After going to Central City, a clinic part of Metropolitan Human Services District, Diana told Anita she was uncomfortable with that place and she did not want treatment there. Anita then asked her, "If I could find another place, could we do follow up treatment?" Anita researched and called New Orleans Chartres Mental Health:

I didn't even know if they were functioning. This is after Katrina, and a lot of things weren't up and running. So even the building was under some type of renovation or something. We made an appointment. They had sliding scale there. I explained what the situation was, and we did a pre-evaluation and got her an appointment for the psychiatrist, and we did that all within the second day of her getting out. That facility was much better. We made an appointment, and then she was able to get her meds for free from there. So when it was time for her to get them renewed, she would be able to get the medication free and care from the psychiatrist. So we made an appointment while we were there, got the information, they filled the prescriptions again, and she was supposed to go twice a week there. We got that to happen. Now, I'm still having problems with the father. He was still in New Orleans, and interjecting, and calling her on her cell.

At this point, Diana felt like she was living a normal life and would continue her normal life, and she wanted to go out with people. Anita, however, was unsure. Anita shared, "She's only been out the hospital two days. I said I don't think she should be going out with people you know because, she's not stable." But Diana wanted to go out, so Anita took her phone away that night and stayed awake the whole night to keep Diana from going out the door. "It was horrible." I asked Anita, “How long did you do this for?” She responded:

I only did it for three days. And it was only three days because on the fourth day, the father sent his father to come and get her, which I thought was very dangerous because his father is 80 something years old, and he sent him from New Orleans East to pick her up. So, I told her father she has these appointments she has to go to, and she has to take her medication, you know. So now because I'm saying you shouldn't go out, she's getting rebellious with me, so she tells the dad she wants to stay with the grandfather and the step-grandmother. She doesn't want to be by me anymore. As soon as she goes out there, and night falls, she calls somebody to go out. And I know this because the stepgrandmother calls me. So now she's missing. 
After Diana left her grandfather and step-grandmother's house in New Orleans East, nobody knew where she was. She was not taking her medication. Anita learned later that Diana ended up going back to Baton Rouge because she went back to her grandparents' house with another car. She told her grandparents she was able to purchase the new car with the money the insurance company paid off from the prior accident, and she had a check waiting for her meant for housing. The check was financial aid from school that she was supposed to use for housing, but Diana had ended her lease because she was in the hospital, but the check was still there, so she used that check and the money from the insurance company for the new car. She got into an accident with the second car, running it behind a canal behind her grandparents' house in New Orleans East. Diana stayed with her grandparents for two months, but Anita became more worried at this point because Diana's father went back to Houston and did not do anything:

He went back to his alcoholic state that he's in and doesn't worry about it anymore. The grandparents were concerned. They allowed her to start staying with them. They're very old. And my concern was she's still not taking her medication and leaving the house, leaving the door unlocked, she's still up in the mirror talking to herself, and her condition has just worsened. She's regressing very rapidly. I got fearful for them because she's wrecked two cars, then she wants to use the grandfather's vehicle. She got mad at him. I was thinking she would really do something to harm them because she can't have things her way. She wanted a key for the house, and they wouldn't give her a key, and that's why she said she would continue to leave the door open when she leaves the house because they won't give her a key. They had some relative that had to stay for a couple of weeks, and she got into an altercation with them. At this point, she's doing things that's going to cause injury to people. She was putting soap in the tub for people to slip down, and she doesn't eat any food that anybody prepares. The doctor told me this was because of her condition. She thinks people are always going to poison her. She would buy her food, but if she eats out of it and puts it away, she won't eat the leftovers because she'd think someone would do something to it.

Diana stayed at her grandparents' house for two months, and according to Anita, it was a terrorizing two months for the grandparents. Anita kept in touch with Diana because she was still trying to get her to get back to her treatment because at this point she really needed to be 
readmitted. The doctor had told Anita, if Diana became noncompliant at any point, he would help her get Diana readmitted by getting a court order and putting her back in the hospital. However, Diana would become a ward of the State, which meant nobody could sign her out and she would not be able to sign herself out. During this time, Diana's father would not cooperate with Anita on anything. While Diana stayed with her grandparents for two months, Anita tried to communicate with her, but Diana shut all communication down with her because she did not want anybody talking to her about her medication or her condition. During this time, Anita lost touch with Diana except through Facebook updates and friends.

In 2010, Anita heard from a friend of Diana's who called her to say, “I can’t have Diana at my house anymore because she's leaving doors unlocked, she's still talking to herself, she's still doing this." Anita told Diana's friend, "I really need you to call someone. She's not going to answer me." Anita tried other attempts to help Diana, but she would not see Anita and would not voluntarily seek treatment on her own. Through Facebook, Anita learned that Diana had another altercation after going back to school. Because of this altercation, she ended up at a mental health facility in Bogalusa, Louisiana. Anita did not know where the place was until she was at WalMart one day, and Diana called her cell. Because of the altercation, Diana's options were for her to go and seek treatment or they would press charges and send her to jail, so Diana elected to be evaluated. She was only in Bogalusa to be evaluated and called Anita because she needed someone to pick her up after three days. The facility in Bogalusa only gave Diana medications for anxiety to calm her down. Because Diana still did not think anything was wrong, Anita told Diana she could not pick her up. Anita recounted:

I need her to take her meds to pick her up. I had to work, and I can't be a 24-hour caregiver for her. I still needed to work, and if she's going to take her meds or not take her meds and go off somewhere, the minute I go to work, she's going to go off somewhere and I wouldn't know where she is anyway. From the time I actually saw her 
in Baton Rouge, I had gone through a whole lot of traumatic experience because I had never seen her like that. I had never had to deal with anybody who had a mental breakdown or anything. So it was very, very, very taxing on me. I could have been on the verge of having a mental breakdown. It was just so, she had so much potential, it was just heart wrenching to see that. And then, on top of that, not having the support of her parents and getting negative feedback and interjections from them, it was overwhelming for me. I think I lost 30 pounds during the time all this stuff was going on. No sleep, you know, I was being stressed out and not knowing I was stressed out because I was just going through emotions, trying to do this, trying to help going back and forth for visitations, working, going out to New Orleans East to pick up the step-grandmother, meeting in the morning with her and the doctor for those sessions, running out to get the meds, set up appointments. It was a lot.

The last time Anita physically saw Diana was in 2011 when Diana showed up at Anita's workplace. Diana, according to Anita, "came in as if nothing had happened in the past, and she says to me, I need you to help me with my finances, housing, and gas. And I just said, Diana, I can't help you with that. But are you taking your medication? She just politely got up and left. I didn't see her again." Occasionally, Anita received reports that Diana was in Baton Rouge and jumping up all over people's cars and things like that or that Diana traveled to other places including Atlanta, Florida, and Texas. "I think she goes from friend to friend." If Diana sought help, Anita would have been willing to pick her up from Bogalusa: "She has to realize her own need for treatment. That's the only thing that's going to help her." After Diana's release from West Jefferson Behavioral Medical Center, Anita wished there were more resources available to help Diana:

I couldn't watch her 24 hours a day, and that's where the trouble arose. I wish there was something between getting out of the hospital and being independent. Something that helps people get re-allocated on assisted living or something, if they had something like that she could have transitioned to, I think her treatment could have been better. And they didn't have that. We could have really used that.

After Diana visited Anita at her workplace in New Orleans, Anita only received updates about Diana from other family members or through Facebook. In 2018, Anita learned Diana passed away at the age of 30 . Someone had left a message on Anita's cellphone to let her know. In 
addition to Diana's psychiatric diagnoses, she had kidney failure and lupus. Anita said, "She suffered her entire life. She just had a hard life, as far as that." Anita felt a sense of resentment and disappointment towards Diana's other family members, which she recounted:

They didn't do anything. They just covered it up. They ignored it. They thought the medicine wasn't doing anything for her, but when you're on it, you're balanced. The mom never stopped gambling and stuff. All these issues from her childhood came up. She did finish her social work degree. She was functioning but not in a balanced capacity. Because she went into that field, all those things in her childhood surfaced up. She was molested by family members when she was young. She was removed from the house. She never got out of that environment. She had all these other ailments. She was supposed to take dialysis three times a week. She was just not getting the right treatment for her physical or mental ailments.

Diana's mental illness was just one problem out many that plagued her. Her previous

traumas, the environment she grew up in, and other structural factors of inequity made it difficult to seek treatment and recovery.

Anita remembered the first social worker she had met after Diana's initial release from the hospital: "As long as you follow your treatment plan, you can lead a successful and fulfilling life. But she had all those obstacles. She was her own enemy, too." The various paths Anita went through to figure out how to get Diana treatment and medication by calling the coroner's office, jails, and hospitals, demonstrates the common problems caregivers face when trying to get someone in crisis help and the difficulties along this path.

\section{Caregivers and the Therapeutic Process}

Csordas and Kleinman $(1996,8)$ define the therapeutic process as, "all the meaningful activity that mediates procedure and outcome." The therapeutic procedure is the "organized application of techniques with some goal in mind" (Csordas and Kleinman 1996, 8). The therapeutic outcome, "refers to the disposition of participants at a designated end point of the therapeutic process, with respect to both their expressed (high or low) satisfaction and to change (positive or negative) in symptoms, pathology, or functioning" (Csordas and Kleinman 1996, 9). 
In short, procedure refers to the actions that have been taken, and outcome refers to the results obtained in the therapeutic process.

In the case of mental illness, the goal may not be a cure but some form of healing. For individuals diagnosed with chronic mental illnesses, I often heard the term recovery used by mental health professionals and clients. Thus, the desired outcome for individuals with mental illness is recovery, often defined as some form of stability, which caregivers also expressed. Csordas and Kleinman $(1996,10)$ acknowledge that the therapeutic process may also include a, "network of people who may be engaged with varying degrees of responsibility in the decisionmaking process." Csordas and Kleinman $(1996,10)$ use the term therapy management group for this network. While individuals with chronic mental illnesses need to engage in the therapeutic process, I argue that caregivers also need to be engaged in this process.

The stories Anita, Grace, and Debra shared with me illustrate how complex the therapeutic process can be for individuals experiencing psychosis and also for their caregivers. For involuntary commitment, the procedure of navigating the mental healthcare system itself is a process. Many caregivers are surprised to learn that they have to go to the coroner's office to seek involuntary commitment for a family member. This process includes contacting the coroner's office for an Order for Protective Custody (OPC) so that a police officer can take an individual to a treatment facility. A doctor can then execute a Physician's Emergency Certificate (PEC) to detain individuals against their will for 72 hours if the physician determines an individual is a danger to themselves, a danger to others, or is gravely disabled as a result of mental illness or substance use. After those 72 hours pass and if the individual is still detained, Louisiana law requires a second examination by a coroner. ${ }^{25}$ If the individual remains dangerous

\footnotetext{
${ }^{25}$ Louisiana is unique in that it involves the Coroner's Office for involuntary commitment.
} 
or disabled, then the deputy issues a Coroner's Emergency Certificate, which permits individuals to be held against their will for up to 15 days at a treatment facility or until the treatment facility discharges them (Coroner Involuntary Commitment 2018). Entering the treatment facility is just the beginning. Once released from the hospital, medications, support groups, and therapy are also part of the therapeutic process.

Csordas and Kleinman $(1996,11)$ recognize the existence of "broader economic and social regulatory constraints on the structure of a therapeutic system" for the therapeutic process. Anita's story about her daughter Diana and Grace's story about her mother Sandra also illustrate the economic constraints of their situations. Anita lived in Baker, Louisiana and drove two hours one-way to work in New Orleans. Researching what resources were available after Diana was released from the hospital and figuring out how to pay for the medication was a challenge in itself, with the limited free time she did have. Anita also did not have the extended support from Diana's parents. During the period where she visited Diana and tried to get updates when Diana was missing, Anita lost 30 pounds and was on the verge of a breakdown herself. When Anita mentioned wishing there was something to help people become accolated between the hospital and going home, those resources were not available in New Orleans at the time, at least not free ones. The ACT program that Debra mentioned her son participated in was not available until 2008 in Louisiana. Lastly, Grace's advice about sharing the burden with other caregivers was not really an option for Anita. Besides Diana's grandfather and step-grandmother, Anita did not have other caregivers to share the burden with.

The sessions that Anita attended at the hospital, where family members could meet with the psychiatrist were extremely helpful but also unusual. Grace and Debra both mentioned in their experiences to me how they were often excluded from information the doctors provided due 
to the Health Insurance Portability and Accountability Act of 1996 (HIPAA). They used their own strategies to circumvent this; for example, the physicians may not have been able to tell them about the condition of their relative in subsequent hospitalizations, but as caregivers, they could give information to the physicians about the diagnoses and what medications their relatives were taking. Debra shared with me, "The system needs to recognize family members as an important part of the team."

Lastly, several individuals diagnosed with mental illnesses acknowledged the burden put on family members. At Vista, William, a member of the day program often came up to me and said, "Mental illness can be traumatic for family members as well." The staff at Vista shared with me that they encouraged family members to be involved. William's dad, who is retired, often visited Vista and is involved in other ways as a volunteer for fundraisers. However, the staff at Vista also acknowledged that many of the members come from single-parent households, so it is difficult for those family members to visit during the workday or be more involved.

The therapeutic process is not just significant for individuals living with mental illness but is necessary for caregivers as well. Grace, when she was older, joined a support group for family members of people who had bipolar disorder. Grace also shared a book she published with me chronicling her adolescence and relationship with her mother. Debra joined a family support group, which meets monthly and is quite involved with the organization as a volunteer, but even she shared, "There is nothing even in the hospitals for family members. It's important for other family members to find information. It can be very lonely, even today to go through this experience." Anita never had this type of support and could have used it while she was a caregiver for Diana. At the minimum, it could have provided her some closure after Diana's death. 


\section{Conclusion}

This chapter has focused on the challenges caregivers faced when they were seeking treatment for their loved ones. I argue that the caregivers also need to be engaged in the therapeutic process or they will get burnt out themselves. One of the major challenges that confronted Grace Martin and Anita Williams as caregivers was in trying to find help: Grace for her mother Sandra and Anita for her daughter Diana. Grace was able to find help through other family members and create boundaries to maintain a relationship. However, Anita never found the support she needed to get Diana the help she needed, and thus, the caregiver role took a toll on Anita's own health.

Both women, like Tina mentioned in previous chapters, represent the Sojourner Truth Syndrome. Sojourner Truth was an abolitionist preacher who promoted the idea of black freedom; she became an important symbol of both the constraints and activism that characterizes the lives of African American women. Naming a syndrome after her, Mullings suggests, conveys a message "about the interaction of race, class, and gender, as well as the dialectic of oppression, resilience, and resistance" (Mullings 2006, 345-346). The Sojourner Truth Syndrome "offers an interpretive framework designed to provide a broader understanding of why African American women and men die younger and, as compared to whites, have higher rates of morbidity and mortality for most diseases" (Mullings 2006, 346). Incorporating an intersectional approach, it emphasizes "how race, class, and gender operate in the lives of African American women and how this intersectionality interacts to produce health effects" (Mullings 2006, 346).

From a young age, Grace had to call the coroner's office and take care of her younger brother; even though she was the child in the relationship, she was the caregiver for her mother. It was not until she developed boundaries with her mother, found other resources, and received 
help from other family members, that she was able to move on with her own life. As an adult, when she donated one of her kidneys to her mother, she finally felt like the physicians treated both her and her mother holistically, and she wished that type of care and treatment existed when her mother was hospitalized for her mental illness.

In addition, Grace, at the end of our interview, also asked if I had ever gone to a NAMI conference. I had not at that point, and Grace shared with me that she was frustrated by the lack of sessions and research on the black community and other people of color regarding mental health. Without the research, "How do health disparities get addressed?" was the sentiment she shared with me. Grace had participated in several organizations and groups about mental illness and bipolar disorder for caregivers, and even served on the board for one organization, but the work was not what she thought it would be. It also placed an additional burden on her, as a black woman, to do this type of activism work.

Anita's in-depth story illustrates multiple dimensions of the challenges she faced and what was shaping them in trying to take care of her daughter, Diana. Flooded out of her home in New Orleans after Hurricane Katrina, she drove two hours to work one way from her new home in Baker, Louisiana. The distance alone put a strain on her as she was trying to take care of Diana and also limited the type of family support services she could receive. The inconsistent experiences with police officers that she encountered in Baton Rouge reveal the struggles of what caregivers are supposed to do when a loved one is in crisis. In her first encounter, the police told Anita there was nothing to do, but in her second encounter, they told her to go to the coroner's office. Anita's story also exposes how easily those with mental illness can end up in jail instead of a hospital, which was the initial experience for Diana. Unlike Grace, Anita, did have some visiting rights and communication with Diana's doctor when Diana was eventually 
hospitalized. However, these visits were just once a week, and Anita was limited in what she could do. Once Diana was released from the hospital, Anita's stress levels increased dramatically. Anita had to figure out how to continue outpatient treatment and afford medications for Diana on her own, with little help from other family members. She could not watch Diana 24 hours a day, since she was working herself, but Anita also felt like Diana's life was in danger when she was not able to watch her. Anita also had little help from Diana's biological parents in the caregiving process. Describing one parent as an alcoholic and another as a chronic gambler, and growing up in a home that was not fit to be a home, it leads one to examine what the structural conditions were that led Diana's biological parents, both from working class backgrounds, to the state they were in. As Leith Mullings $(2006,346)$ has suggested, "Attention to the historical and contemporary processes by which populations are sorted into hierarchical groups with different degrees of access to the resources of society shifts our analysis to racism rather than race" and "to resource distribution as the larger context that constrains and enables what appears as voluntary lifestyle choices."

Both Grace and Anita, as black women, had to overcome multiple challenges to resources and figure out financial constraints. This was never something that popped up in Debra's narrative. Debra had the resources for her son to see various specialists and try different types of treatment. Lastly, Debra shared that she was not worried about Justin's future. From an upperclass background, Debra has the resources to seek different support groups for herself but also for her son. In addition, Debra also has plans for who will watch over Justin after she and her husband are no longer able to do so and did not seem a bit worried about the future.

In the next chapter, I discuss the institutional circuit and some of the reasons it is difficult to find affordable housing in New Orleans, especially for individuals with chronic mental illness. 


\section{CHAPTER 8}

\section{THE INSTITUTIONAL CIRCUIT}

This chapter focuses on the embodied effects of the housing and homelessness crisis in New Orleans, and why individuals with chronic mental illnesses often move in between supported housing or group homes, jail, hospitals, homeless shelters, and the street, otherwise called "the institutional circuit" (Hopper et al. 1997; Luhrmann 2008; Wiseman 1979). I argue that behavioral health and housing programs can unintentionally create "fault lines of care" (Heckert 2018) and more problems through their interventions, resulting in "iatrogenic effects." Because services are not integrated when an individual leaves a hospital, those with chronic mental illnesses often end up homeless or another part of the institutional circuit. Individuals have to be chronically homeless to qualify for many permanent supportive housing programs. The strict definition of "chronically homeless" poses many challenges for many who are trying to find shelter.

I begin this chapter with the story of Quentin Holmes, an African American man who struggled finding housing. His narrative illustrates the obstacles to finding housing, a job, and any form of stability in his life. I then discuss why and how people like Quentin can get lost in the institutional circuit. Lastly, I examine why affordable housing options in New Orleans are difficult to find. 


\section{Quentin Holmes}

In the summer of 2012, at Genesis House, I met Quentin Holmes, a 32-year-old African American man originally from the Treme neighborhood in New Orleans. After graduating from high school, Quentin worked a variety of jobs from construction work, working at restaurants, and filing paperwork in offices. After a few years, Quentin moved to New York because he wanted to "see what it was like" to live there. However, he did not like New York and returned home after six months. Then in 2008, at the age of 28, Quentin was walking the streets when he realized, "I was talking to myself and then answering myself. I knew I had to go to the hospital." He just happened to be sitting outside a hospital, so he checked himself in and was put in the psychiatric unit. Quentin was diagnosed with schizophrenia.

Quentin did not have any problems discussing his diagnosis with me. He was more ashamed about being arrested. Quentin was part of Mental Health Court in New Orleans, so when I asked him how he ended up in Mental Health Court, he was more ashamed for being incarcerated than having a mental illness. "You won't tell Pastor Frank will you?," Quentin asked me, worried the director of Genesis House would see him in a different light. Pastor Frank has his own history of incarceration, which he openly discussed. 'I don't think he's going to judge you," I replied while also reminding Quentin of confidentiality. In 2009, Quentin was in a car with several other people driving near the French Quarter. New Orleans Police Department (NOPD) officers pulled him over, and according to Quentin, placed cocaine in the cuff of his pants and arrested him. Quentin swore he did not have cocaine, but his public defender told him he would likely get convicted, so he accepted a plea deal. I asked Quentin about the ethnicity of the NOPD officers who arrested him, and he responded, “They were two black cops. They're all equal jackasses to everybody." While Quentin shared with me that he used crack when he was 
younger and spent two and a half years at a state correctional facility from 2004 to 2006 in DeQuincy, Louisiana, he insisted the NOPD officers were "corrupt, corrupt, corrupt" when he was arrested in 2009.

When I later asked a retired New Orleans judge about the likelihood of NOPD officers planting cocaine on someone, the judge responded, "I believe it." While Quentin worried about the hallucinations and delusions caused by his mental illness and feared they would get worse as he got older, his previous convictions and situation with Mental Health Court put more stress on him. A few months after he was arrested in 2009, he was able to join Mental Health Court because of his schizophrenia diagnosis. While mental health courts function differently in various cities, in New Orleans, they essentially run like a probation program within criminal court. If the Mental Health Court case manager deems that mental illness is part of the reason an individual was arrested, the individual has the option to join Mental Health Court. Clients are released from Orleans Parish Prison, meet with their case manager once a week, and attend Mental Health Court twice a month. However, clients are expected to find their own housing. There are several phases of the program, and once participants complete all the phases of Mental Health Court, their charges are dropped. Even though Quentin's arrest was unrelated to his diagnosis, as far as I could tell, he joined the program anyway. As a client in Mental Health Court, Quentin had to show he was taking his medicines, had to take a drug test every week, and updated his case manager about progress on finding and holding a job on a weekly basis.

At Genesis House, Quentin was a house manager. He found this position after joining mental health court. His job basically required him to watch over the other residents who lived in his unit, all of whom were diagnosed with various mental illnesses. As a house manager, Quentin did not get paid. In return for his work, he received a place to live for free and the same food 
clients received at mealtimes. But his obligations at Genesis House were not easy. During the time I was at Genesis House, it was not uncommon for a resident there to have a crisis, and the staff called New Orleans Emergency Medical Services (EMS) at least weekly. Quentin worked six out of seven days a week at Genesis House, so he constantly looked exhausted. His only source of income was shining shoes, a trade he learned from his grandfather. Sometimes he would sit near the entrance of the building where he saw his case manager with his shoe shining kit, ready to shine shoes for lawyers and other professionals who worked in the building. On his days off, Quentin would go to his mother's house uptown, but his job at Genesis House and position in Mental Health Court made him feel "stuck." While he had a place to stay at Genesis House, he did not get paid for the work he did there. Mental Health Court required him to take weekly drug tests, but Quentin had to pay for these tests, and he often did not have the cash to take the tests. In fact, he owed hundreds of dollars for the unpaid drug tests and could go back to Orleans Parish Prison for this debt.

\section{The Institutional Circuit}

The same summer I met Quentin, I observed the staff at Genesis House work alongside outreach workers from NOPD and City Hall to provide housing for homeless individuals. The outreach workers would often go "under the bridge" of Pontchartrain Expressway, ask the homeless questions, and if they wanted housing, the director of Genesis House would take people in a van, staff would conduct intake, and bring them to various housing units that were part of Genesis House. I remembered the staff at Genesis House talking to a young man one week at his encampment under the bridge and bringing him to Genesis House for intake. However, two weeks later, when the Genesis staff returned to the encampment with city employees, I recognized the same man, and asked Pastor Frank and the other staff from 
Genesis House, "Didn’t you guys pick him up last time?" Pastor Frank responded, "We did," and then approached the homeless man to see how he ended up back at the encampment under the bridge. The young man, who was a student at the New Orleans Culinary Institute, said the housing where he was placed by the staff at Genesis house was too far for him to walk from where his classes were, so he left the house where he was placed. Staying in the encampment under the bridge, basically composed of numerous tents, was an "easier option" for him.

Later that day, when the director and all the staff were back at Genesis House, a staff member asked me, "Do you think the homeless choose to stay homeless?" A loaded question, I paused before even thinking of a response. Before I could answer, another staff member responded, "I think they do. Look at the guy we picked up two weeks ago. We took him in, but he ended up back under the bridge." After hearing this statement, Quentin replied with a passionate response: “Sometimes the homeless don't have any other options. I've tried looking for independent housing for years, and I can't get into any programs because of my convictions." Quentin's previous convictions also hurt his prospects of finding stable employment. Even if an employer were to consider him, Quentin shared, "It's frustrating because I have to go see my case manager and take a drug test every week, and these are usually during the middle of a day during working hours. How's that supposed to look to an employer when I have to tell them I can't work certain hours because I have to go take a drug test for Mental Health Court?"

Quentin's predicament was just one of many that made it difficult for him to find his own place to live and a stable job to pay rent, which is why he felt "stuck" at Genesis House. Still, he fared better than many others because he saw his psychiatrist regularly and his symptoms seemed to be manageable. However, when I returned to New Orleans the next 
summer in 2013, Quentin was no longer working at Genesis House, and the staff did not know his whereabouts. Then, as I was walking into Mental Health Court one day a few weeks later, I heard someone call out my name. I turned around and saw Quentin sitting on a bench outside of the courtroom. He had lost a significant amount of weight and had grown a large beard. I am not sure I would have recognized Quentin if he had not said my name. I sat down next to Quentin hoping to catch up. However, he had difficulty concentrating and answering my questions, and I suspected he was either no longer taking his medications or his medications were not working for him anymore. While I was sitting next to Quentin, one of the court staff members approached Quentin and asked, "Quentin, you were doing so well in the program. What happened?" It seemed as if Quentin had missed many of his meetings with his case manager and appearances at Mental Health Court, delaying his progress in the program.

When the Mental Health Court judge arrived, we walked inside. I observed the case manager calling out each client's name and describing that person's progress to the judge. When Quentin's name was called, Bernard, a former staff member at Genesis House went up to the case manager. Bernard now ran his own assisted living program and told the case manager and judge that he would take Quentin into his program. That was the last time I ever saw Quentin. He probably stayed in Bernard's program for a while, but the building Bernard used for his assisted living program was in a state of disrepair. A few years later, when I drove past it, the building was gutted completely, so the individuals who lived there had to find a new place to live. I knew Quentin was an only child, so besides his mother, he really did not have a support system in place. I have no way to know if Quentin is in another 
assisted living program, living on the streets, or if he ever found his own independent place to live.

Quentin's situation is similar to an increasing number of individuals diagnosed with chronic mental illnesses living a nomadic life in New Orleans post-Katrina, where they move in between supported housing or group homes, jail, hospitals, homeless shelters, and the street, otherwise called "the institutional circuit" (Hopper et al. 1997; Luhrmann 2008; Wiseman 1979). In Quentin's case, the assisted living program where he stayed, Genesis House, also contributed to his inability to get into other housing programs. As house manager, this job gave him a place to live and three meals a day, but it also made him "stuck." He was not paid and besides the cash he could get from shining shoes, had little opportunity to earn income and save it. His situation was probably not any better when he stayed in Bernard's housing program, which was modeled after Genesis House, but in a decrepit state to the point where it was demolished a few years later. While being a house manager looked good for Quentin in Mental Health Court as a job, the housing it provided actually prevented him from finding permanent supportive housing, which I explain later in this chapter, since he was not chronically homeless.

\section{Affordable Housing Options in New Orleans}

Part of the problem of finding affordable housing in New Orleans is that there are few options to begin with. After Hurricane Katrina in 2005, much of the public housing managed by the Housing Authority of New Orleans (HANO) was damaged. In late 2007, HANO asked the New Orleans City Council to authorize demolition permits for the city's four largest public housing developments-Lafitte, St. Bernard, B.W. Cooper and C.J. Peete—also known as "the Big Four" (Filosa 2007). In a much-heated city council hearing, city councilmembers unanimously voted for the demolition of the housing projects. The result was a demolition of 
4,500 units of housing to make room for mixed-income neighborhoods. "The Big Four" were where many of my interlocuters native to New Orleans grew up and lived. While 2,987 tenantprotection vouchers were issued to families affected by the demolition of the Big Four (HANO 2018) for mixed-income housing they could use for later, the number of vouchers do not come close to providing housing for all the residents affected by the demolitions and in need of housing post-Katrina. HANO also operates the Housing Choice Voucher Program (HCVP), formerly known as Section 8 , which assists low-income families with rental payments. HANO is currently serving more than 17,000 families on the HCVP, but because it currently has a waiting list of 20,000 additional families, the HCVP waiting list is closed (HANO 2018). Paula, a staff member at Vista, shared with me that HANO used to issue the same amount to individuals regardless of what part of the city they were living in for the HCVP. However, now the vouchers HANO issues are based on zip codes. Someone living in the zip code 70118, a more expensive area of the city that includes Tulane and Loyola Universities, will get an $\$ 850$ voucher, but someone living in New Orleans East will only receive $\$ 650$. According to Paula, this is "flat out discrimination." With the lesser amount given for lower-income areas, most individuals can only find "rinky dinky one-bedroom apartments," and the vouchers barely cover fair market rent.

In another instance of structural inequality in action, an increasing number of developers have been building apartment complexes with Low Income Housing Tax Credits in New Orleans since Hurricane Katrina. The National Housing Preservation Database (NHPD) keeps track of federally assisted rental housing programs across the U.S., with data from the U.S. Department of Housing and Urban Development (HUD) and the U.S. Department of Agriculture (USDA). The database includes housing for ten federally subsidized programs, including Low Income Housing Tax Credit properties (NHPD 2018). Low Income Housing Tax Credit properties 
provide funding for the development costs of low-income housing by allowing investors to take a federal tax credit equal to the percentage of the cost incurred for development of the low-income units in a rental housing project. A proposed development may have a certain percentage of units that are rented to low-income tenants, and these low-income units can exist for 15-year periods or longer. One such development in New Orleans was the American Can apartment building, which had 53 units set aside for low-income and moderate-income tenants in the 268-unit building (Sayre 2016). At the end of 2016, American Can issued eviction notices to its lowincome residents, many of whom had disabilities, because it was converting all of its reducedrent units to market-rate units, doubling the rent from about $\$ 700$ to $\$ 1,300$ in some cases (Sayre 2016). Low-income tenants either had to come up with the extra income or leave American Can. After 15 years, American Can's subsidies expired, so it no longer had to offer the low-income units. While American Can opened in 2001, many similar properties were built after Hurricane Katrina in 2005 and subsidized, and those properties will have expiring subsidies soon, putting more residents at risk for homelessness if the developers remove the low-income units. The City of New Orleans is now only proposing contracting with long-term leases for these types of developments, from 50 to 99 years, according to Tyra Brown, an employee from the City of New Orleans. The example of the American Can apartment complex evictions is just an indication of what is to come for low-income residents in the near future in New Orleans. These types of developments, which only help low-income residents in the short-term but help developers profit in the long-term, are a result of disaster capitalism, "the total collapse of infrastructure and social services" produced by what Naomi Klein refers to as the "perfect conditions of 'schock," in this case Hurricane Katrina (Adams, Van Hattum, and English 2009, 616). 


\section{Navigating Housing Programs}

For individuals diagnosed with chronic mental illnesses, what housing options exist for them? Many of my interlocuters, if they did have income from Supplemental Security Income (SSI) or Social Security Disability Insurance (SSDI), usually only received between \$700 a month, to perhaps $\$ 1,000$ if they also worked part time. With rising rental prices in New Orleans, this amount would hardly cover market-rate rent. Some of my interlocuters lived with family members, so they did not have to worry about paying for housing. Several, like Quentin, lived in an assisted living program, many of which charged around \$500 a month and included three meals a day. And some, if they were lucky, were in a permanent supportive housing (PSH) program. What options exist for individuals who are homeless? To demonstrate the complexity of navigating these programs, I will provide a narrative from Danish, an employee at a community mental health clinic in New Orleans whom I interviewed in May of 2017 and discuss in a previous chapter. One of the most pressing problems Danish shared with me was about the lack of resources for finding affordable housing in New Orleans.

\section{Chronically Homeless}

Danish described a homeless client they ${ }^{26}$ were trying to help who went to UNITY of Greater New Orleans, ${ }^{27}$ which receives funding through the U.S. Housing and Urban Development (HUD), to receive a referral for housing. Almost every housing program in New Orleans will only accept referrals from UNITY. To receive a referral, homeless individuals have to verify their homelessness with a seven-day homeless voucher. The most common way is by

\footnotetext{
${ }^{26}$ Danish identifies as gender non-binary and uses them/they pronouns.

${ }^{27}$ UNITY of Greater New Orleans is a "nonprofit organization leading a collaborative of over 60 agencies providing housing and services to people who are homeless or at risk of homelessness in Orleans and Jefferson Parishes" (UNITY 2019).
} 
receiving a homeless verification voucher from a homeless shelter. The Salvation Army shelter is one of the most common shelters where people stay in New Orleans. The first five nights at the Salvation Army shelter are free; after that, individuals have to pay $\$ 10$ a night. But even with the voucher from the Salvation Army, Danish stated that was not enough for their client. UNITY asked Danish to provide a street intersection where their client sleeps, so outreach workers could "ride by" on a random day to "make sure she's really homeless."

I frequently heard these types of stories about accessing services for housing programs, both from case managers and individuals with mental illness. UNITY often received a bad reputation for not being able to help those on the verge of homelessness, but the organization focuses on housing programs for the chronically homeless. Because UNITY receives funding through the U.S. Housing and Urban Development (HUD), it follows HUD's definition of chronically homeless, which is: "an individual or family that is homeless and resides in a place not meant for human habitation, a safe haven, or in an emergency shelter, and has been homeless and residing in such a place for at least 1 year or on at least four separate occasions in the last 3 years" (HUD 2015). HUD's statutory definition “also requires that the individual or family has a head of household with a diagnosable substance use disorder, serious mental illness, developmental disability, posttraumatic stress disorder, cognitive impairments resulting from a brain injury, or a chronic physical illness or disability" to be eligible for its Continuum of Care program (HUD 2015, 75792). The Continuum of Care (CoC) program is designed to promote community wide commitment to the goal of ending homelessness (HUD Exchange 2018). CoC programs provide funding to nonprofits and state and local governments to find housing for homeless individuals. As the primary $\mathrm{CoC}$ in New Orleans, UNITY contracts with various agencies to provide housing; while UNITY is the mother agency and serves as a gatekeeper in 
New Orleans, the agencies it contracts with are the ones that provide the direct resources to homeless individuals.

Thus, UNITY was not really checking to see if Danish's client was "really homeless" but was chronically homeless. With HUD's strict definition, UNITY has to monitor documentation for an individual's or household's eligibility to meet the criteria of being chronically homeless. Failure to maintain this documentation can require recipients of HUD funds to repay grant funds, thus putting UNITY's programs at risk.

\section{Permanent Supportive Housing}

Those who do meet HUD's definition of chronically homeless are eligible for $\mathrm{CoC}$ permanent supportive housing. The challenge with the term permanent supportive housing is that it is an umbrella term or catch-all phrase for many different types of programs. Figure 9 shows the various forms of permanent supportive housing offered in Louisiana including capital, tenant based housing, and rental assistance-based programs. Brian, a former case manager who focused on finding housing programs for clients at Vista for more than three years, was unfamiliar with the some of the various permanent supportive housing programs in Figure 9, which was presented at a panel entitled, "Integrated Permanent Supportive Housing: How Louisiana Made It Happen" at the 2018 NAMI (National Alliance on Mental Illness) National Convention in New Orleans. 


\section{Louisiana PSH - Braided Funding Model}

Capital

- Low Income Housing Tax Credit (LIHTC)

- Home Investment Partnership Program (HOME)

- Housing Trust Fund (HTF)

- Community Development Block Grant (CDBG)

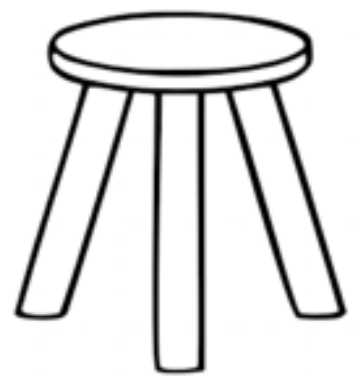

Rental Assistance

- 811 Project Rental Assistance (PRA)

- Project-Based Vouchers (PBV)

- Continuum of Care (CoC) PSH Rental Assistance

Tenancy and Other Supports

- Medicaid State Plan

- Medicaid Waivers

- Ryan White

- Veteran's Affairs

- Community Development Block Grant (CDBG)

Figure 9: Permanent Supportive Housing Model

As a former case manager who focused on finding housing programs for clients, Brian explained the various types of programs available: in rental-based assistance programs, clients pay $30 \%$ of their income, and the lease is in the client's name. Typically, in these circumstances, the case manager will try to get utilities (water, gas, electricity) included. In leasing-based assistance programs, the lease is in the agency's name instead of the client, and the clients still only pay $30 \%$ of their income for rent. Some permanent supportive housing programs are actually not that permanent; they can include safe haven transitional shelters where clients stay for up to 90 days and Rapid Rehousing, which primarily services families but only provides housing for six months. In addition, individuals can also apply for permanent supportive housing through the state of Louisiana. Unlike the CoC programs offered through UNITY, applications for the Louisiana Permanent Supportive Housing program go through the Louisiana Department of Health. Louisiana PSH participants pay $30 \%$ of their monthly income on rent, and to qualify for Louisiana PSH, a person has to: 1) have a significant, long term disability and currently 
receiving Medicaid or Ryan White services ${ }^{28} ; 2$ ) need housing supports offered by the PSH program; and 3) meet low-income requirements, at or below $50 \%$ of area median income (Louisiana Department of Health 2018).

The Louisiana PSH-Braided Funding Model, shown in Figure 9 does work for individuals with disabilities, when one can actually get in. While I was at the NAMI National Convention in 2018, I overheard some local NAMI affiliate members mention comments about the "Integrated Permanent Supportive Housing: How Louisiana Made It Happen" panel: "Why is this in the program booklet? It doesn't work." Much of the panel was about how other states could use federal funds to develop a similar PSH braided model in their own state. The issue is not that PSH does not work. Many of the clients who end up getting housing through the program do stay in it with support services: Louisiana PSH provides pre-tenancy support such as helping clients attain necessary documents to complete the housing application and moving into a unit, assisting clients with developing daily living skills including managing money, medications, and transportation, assisting clients with communicating with the landlord and neighbors, providing individual counseling, and 24 hour emergency services and crisis intervention. Thus, the Louisiana PSH combines housing and tenancy support services for individuals to re-enter or remain in the community.

The challenge with Louisiana PSH is how to become a recipient in the first place. When an audience member at the NAMI National Convention asked the panelists, "How long is the wait time for receiving permanent supportive housing?," the panelists responded that they did not have that data. I received a clearer answer by attending a panel on "Navigating the Housing

\footnotetext{
${ }^{28}$ Medicaid is state-sponsored, unlike Medicare which is federal. Ryan White services are a federal program providing comprehensive HIV medical care, medications, and support services to individuals living with HIV who have low income, are uninsured, and underserved.
} 
Landscape," sponsored by the New Orleans Behavioral Health Council a few months later. According to Michell Brown, the director of the State's PSH program within the Louisiana Department of Health, the waiting list for Louisiana PSH is not based on a first come, first serve basis. It is based on who is more at-risk of being institutionalized again. Thus, someone who might have been number two on the waiting list could be moved further down the list if someone else with a greater risk of being re-institutionalized applies to the program. This is why the panelists at the NAMI National Convention could not answer the question about the wait time for receiving Louisiana PSH. Furthermore, when one actually looks at the application for Louisiana PSH, there are no one-bedroom units available in New Orleans except for the elderly, which Louisiana PSH defines as 55 or older (PSH Program Application 2018). Unless applicants are willing to move to more rural parts of the state, they probably will not find housing through Louisiana PSH.

\section{Short-Term Housing Options}

Permanent Supportive Housing is an option for those who are chronically homeless. What options exist for individuals who have just become homeless? Patty, a 44-year-old African American woman originally from a small town in Mississippi, was a peer support specialist at Vista when I met her. Her story illustrates how she navigated "the institutional circuit" while she was homeless.

Patty moved to Baton Rouge in 2008 for a telemarketing job, and she was doing "pretty good" for a while. However, her mental health started declining rapidly; she had strong anxiety and suicidal thoughts. She eventually recognized she needed help, but the hospitals only provided medication, and Patty recognized she needed additional therapy but did not know where to even start for resources. With her frequent hospitalizations in Baton Rouge, she had lost 
her job and apartment, so during her last hospitalization in Baton Rouge, Patty told the staff to bring her to New Orleans because Baton Rouge only had two homeless shelters for women. She had been living in a group home setting, but the environment in those settings often triggered her PTSD. By the time she got to New Orleans, she had been living on the streets for months, going to several churches and homeless shelters for vouchers. Many times, she could not get into the Salvation Army because of the long lines, or she did not have the $\$ 10$ to get in. Patty went to another homeless shelter located in a central part of the city, but Patty said they "made you profess to Christ." Patty thought about just professing to Christ to get in, but did not feel comfortable doing that, so she hit the streets again. She sometimes stayed in a friend's apartment, stocked up on vouchers from other shelters when she could, and eventually applied for and found housing through UNITY. While waiting for housing, the staff at UNITY signed Patty up for Medicaid. Patty knew she needed medicine from her doctor, but the $\$ 10$ co-pays were not affordable for her. Her doctor told her to "figure out a way to get the money" for the medicine, so she panhandled outside the doctor's office holding up signs saying "need \$10 for copay" to get the medicine she needed. While Patty is grateful for the housing she has now, she shared that there were few options available if one is homeless. Living on the streets for months was a struggle to just survive. Patty shared, “How am I supposed to take my medications if I don't even have a place to put them?"

The temporary homeless shelters are the primary options for individuals who are newly homeless. However, these shelters also have many shortcomings. They often segregate individuals based on gender, so families are often separated. Many do not feel safe with their belongings, and some impose rules on when individuals can enter and have to leave. Michael, and older white man who came to Vista during Drop-In hours for a few weeks one summer, 
approached me and said the homeless shelters sometimes have rules that make it hard to get out of homelessness. He was looking for a job as a security guard, but while he found some shifts, they were at night. He did not have a place to leave his belongings, as the homeless shelter where he was staying had strict rules about taking your belongings with you, and he could not enter the homeless shelter after his shift ended in the middle of the night. Thus, he had to choose between working or staying at the shelter. One day, Michael asked me, "Have you ever heard of the phrase structural violence?" I responded, “I teach about that in my classes!” Michael went on to explain how many of the programs intended to help the homeless create more barriers. He shared, "They prevent you from succeeding. They may be non-profits, but they make a lot of profit from homeless people like me.”

Another demographic which many short-term homeless shelters fail is the transgender community. Brian, a former housing case manager, said transgender individuals are hesitant to utilize homeless shelters, which is why they die more frequently than any other population. For instance, many shelters make transgender individuals stay on the side of the shelter based on their sex, not their gender. If an individual is transitioning male to female, but if they have not transitioned yet or have not changed their name, the shelter will make that individual stay on the male side. They are often ridiculed and beaten up at the shelter. For these reasons, according to Brian, "The trans community does not typically hit the shelter system and often avoid street outreach. They are a tightknit community and stay with their own people." Brian advocated that UNITY and HUD should not hold the transgender community to the same documentation level as everyone else "because they're resisting and resisting for good reasons. Someone fleeing domestic violence isn't forced to prove the domestic violence. They just accept them.” In New Orleans, Woman's Space is the only safe haven that successfully accommodates transgender 
individuals, but it is only an option for women who meet HUD's definition of chronically homeless, so clients have to be homeless for more than a year.

Another option for individuals with chronic mental illnesses is staying at a group home or assisted living program like Genesis House, where Quentin worked. While Genesis House was in a newer building, was clean, and met basic housing codes, many group homes do not provide safe environments. Often, hospitals have a list of these types of programs, and social workers will just give patients phone numbers to call before they are being released. Many of the phone numbers do not work, as the group home may have closed. Others charge rent, so if a client does not at least have minimum income from SSI or SSDI, even these options are unattainable. Even Genesis House, where Quentin worked, only offered the essentials for a basic living environment. As noted earlier, Quentin did not get paid for his work overseeing other residents in his unit as a house manager; he received three meals a day and a roof over his head; in addition, the work was demanding as many of the clients were in psychosis or in crisis, as calls to emergency medical services were frequent, thus putting a toll on Quentin's own well-being. At a New Orleans Behavioral Health Council meeting, another attendee suggested reporting group homes that are not up to code to the state. But she also noted, "It's the hospitals that give out these lists to the patients. Without group homes, where would these people end up other than the streets?"

\section{Changes and Expansion of Medicaid Under the ACA}

In 2016, the State of Louisiana expanded Medicaid under the Affordable Care Act. This helped Louisiana residents qualify for insurance who were not eligible for Medicaid before the expansion and also did not qualify for the tax credits for insurance through the Affordable Care Act. More than 473,900 Louisiana residents signed up for Medicaid as a result of the 
expansion, resulting in the lowest rate of uninsured residents out of any Gulf Coast state by 2018 (Berchick et al. 2018). However, even with the expansion of Medicaid, finding psychiatrists and mental health providers in the community who accept Medicaid has been a challenge for patients. One mental health professional I interviewed shared, "I can probably count the number of psychiatrists who accept Medicaid in New Orleans on my hands." Many psychiatrists do not accept Medicaid because of the low reimbursement rates. Of the psychiatrists who did accept Medicaid, some had to stop taking in more patients after being overwhelmed with an influx of patients after the Medicaid expansion.

Medicaid has also become more complicated for programs that offer community mental health services and other providers. Before Governor Jindal's administration, hospitals and community mental health service providers received Medicaid reimbursements directly from the Louisiana State Department of Health and Hospitals. In 2012, Magellan Health, a for-profit company, entered a contract to manage Medicaid in Louisiana. At the time, the mental health professionals I talked to hated Magellan because of the difficulty of approving requests for services. Lucy, a staff member at Vista shared, "We thought Magellan was awful, but now they seem great," referring to the five managed care organizations that now provide Medicaid in Louisiana. With the five managed care organizations (MCOs), all for-profit, the mental health staff at Vista, where I conducted most of my fieldwork, now see a lot of denied requests for services. Each MCO has different standards, applications, definitions, and requirements, and with the latest cuts to mental health services in Louisiana, the guidelines for providers keep changing with each MCO. The staff at Vista now spend more time trying to get approval for services through the MCOs instead of spending time with clients. When providers contacted the Louisiana Department of Health and Hospitals directly, it was much easier for staff to fill out the 
forms for Medicaid since there was a standard, and according to staff at Vista, "The Medicaid officials were easier to contact, they asked questions but always approved us, and it was a great relationship." However, the privatization of Medicaid is a trend occurring across the U.S.

\section{Criminalization of Mental Health Services}

With the privatization and closure of state hospitals, the waiting list to find psychiatrists and other mental health professionals, the five MCOs denying approval of services, and lack of affordable housing in New Orleans, mental health professionals are seeing more people end up in jail in New Orleans. After Katrina, the largest provider of mental health services in New Orleans was Orleans Parish Prison (OPP) ${ }^{29}$ with 60 cells (Mehmood 2010). Orleans Parish Prison was replaced with the construction and opening of a $\$ 150$ million facility, Orleans Justice Center (OJC) in 2015. Despite the protests of groups like the Orleans Parish Prison Reform Coalition (OPPRC) and mental health professionals, the New Orleans City Council voted for the expansion of OJC in 2017 for Phase III to house individuals with mental illness (OPPRC 2018). OPPRC and partner grassroots organizations in New Orleans are still hoping city officials will retrofit the existing facilities to house individuals until they can be transferred to a hospital instead of building Phase III. In a letter delivered to Mayor LaToya Cantrell and City Councilmembers in February 2019, OPPRC stated (Sade Dumas, personal communication):

While we share a deep concern for the condition of people in the jail with acute mental illness, Phase III is an inappropriate way to care for people with severe psychological disorders or psychiatric disorders, who do not belong in jail. Providing constitutional conditions in the existing jail can be achieved through a smart retrofit of Phase II facilities to safely house people until they can be transferred to a hospital. City money used to operate a mental health jail is money that could be spent on mental health treatment in the community, to provide care for people so they never enter the criminal justice system, and to care for them when they are released.

\footnotetext{
${ }^{29}$ Despite the name, OPP operated as a hybrid jail-prison. Even though the new building is called OJC, many locals still refer to it as OPP.
} 
Since 2013, both the Orleans Parish Sheriff's Office (OPSO), which runs OJC (Orleans Parish Jail Monitors 2014), and the New Orleans Police Department (NOPD) have been under federal consent decree (Consent Decree Monitors 2019) with the Department of Justice for constitutional violations. While NOPD has made some strides by requiring new recruits to undergo Crisis Intervention Team (CIT) training to help officers respond to and deescalate mental health crises, OJC is still plagued by many problems from inappropriate mental healthcare for inmates, injuries, and deaths (OPPRC 2018).

\section{Conclusion: Fault Lines of Care}

The criteria that permanent supportive housing programs require and the limitations that short-term housing shelters place on clients are resonant with "fault lines of care" (Heckert 2018). Heckert uses the phrase "fault lines of care" to describe how in the geological sense, certain stressors, such as the movement of magma, can create enough pressure to generate new fault lines or weaken existing ones $(2018,8)$. The "fault lines of society are equally complex. The health effects of poverty, gender inequality, and racial inequality are often obvious. Less obvious are the ways that health interventions with good intentions can create rifts" (Heckert $2018,8)$. The requirements that many short-term homeless shelters and group homes place on the homeless often put more stressors on the same populations they are meant to help; while hospital social workers seem to be doing a service for patients who are being released from psychiatric units and entering a group home, without checking on the conditions of the group homes patients are entering, health and housing workers may be doing more harm than good. Quentin stayed at a group home that put a roof over his head, but because his living situation was considered "habitable," he did not qualify for permanent supportive housing. At the same time, the requirements of Mental Health Court added extra burdens for him; while Quentin sought 
employment, the weekly drug tests and appointments with his case manager added barriers for employment. Much of the income Quentin did make from shoe-shining went to public transportation just to meet his case manager.

Furthermore, while permanent supportive housing programs do work for many individuals, they only work if a client can get into one. Susan, a peer support specialist at Vista, received most of her income from SSDI, but her income was a little higher than most of my interlocuters because of her work as a peer support specialist and managing Drop-In at Vista. However, her position at Drop-In was cut in 2017 after just three days' notice; the Drop-In program was funded through Jefferson Parish Human Services Authority (JPHSA), the local government entity which provides behavioral health services through the state of Louisiana. Because of state budget cuts, JPHSA ended its contract with Vista, eliminating the Drop-In program. Susan, however, was living in a leasing-based permanent supportive housing program, which is based on one's income. Initially, she was terrified about how to pay all of her bills, but then I asked her, "Isn't your apartment based on your income level?" She had completely forgotten about this as her income had been stable for a while, so the next day, she talked to her housing manager, and her next month's rent was reduced to reflect $30 \%$ of her income. The housing program Susan lives in worked the way it is supposed to, but it is rare for other individuals to find a space there. Because the only time a unit is available in Susan's building is when a resident moves away to another city or state or when a resident dies, the director of the program does not even keep a waiting list. Instead, if a space becomes available, the program opens up an application for potential tenants. The lack of available units in these types of housing programs are reflective of most permanent supportive housing programs, as many applications just say "not available" for most units in the New Orleans area. 
Lastly, my research shows the lived effects of a lack of low-barrier homeless shelters in New Orleans. The city opened a new low-barrier shelter with 100 beds in September of 2018; because it is a low-barrier shelter, the facility is not supposed to have an entrance fee, minimum stay, or sobriety requirement; in addition, "there are no religious expectations or forced morning departures that other overnight shelters require," and access is 24-7 (Sayre 2018a). However, one week after opening, homeless individuals were reporting being denied entry because the lowbarrier shelter is at full capacity, illustrating the need for similar facilities in New Orleans. Without an integrated system where psychiatric patients have a place to go other than the streets when released from hospitals, they will continue navigating the institutional circuit. As Brian, the case manager and housing advocate, shared with me, what ends up happening is a homeless individual or someone on the verge of homelessness will contact 15 to 20 different agencies looking for a place to stay: "The agencies should be doing this work for the individuals instead." With better integrated services when someone comes out of a hospital or jail, housing and healthcare workers can prevent the homeless population from falling within the fault lines of care. 


\section{CHAPTER 9}

\section{CONCLUSION}

One day while I was at Vista during Drop-In hours, I was looking at a quilted blanket that hung on the back wall of the room. The blanket had different squares, made by Vista day program members with their names on it, and each square had a visual of the goals of the member who made it, similar to a vision board. One of the squares had a car on it; others had fruits and vegetables, suggesting a goal of a healthier diet. I recognized a few of the names on the quilt, but most were unfamiliar to me. I then asked Susan, a peer support specialist who was running Drop-In, who some of the people with unfamiliar names were while we were playing a game of Rummikub. Susan responded, "That person is no longer with us." I asked about the next person's name on the quilt: "What about her?" Susan responded, "She passed away." Some were no longer members of Vista or had moved away, but I was surprised by how many individuals who had made the quilt had died. I then asked, "Is the blanket old?" "It's actually not that old. It was maybe made a short while before you started coming here," Susan responded. Susan then asked me, "Did you go the NAMI State Conference last year?" Susan referenced the previous year's National Alliance on Mental Illness (NAMI) state conference in New Orleans. I told Susan, "Yes, I did." Susan shared, "Well, I don't know if you were at this session, but there was a doctor who gave a talk about mortality. And he said people like me with serious mental illnesses die, on average, 20 years before everyone else." At this point, Michelle, another peer support specialist who was working during Drop-In hours, interjected: "I hate it when you bring 
that up. I don't want to be reminded about my own mortality." Susan then replied, "Well, it's true. We die before the rest of the population."

I did not attend the specific session Susan described at the NAMI State Conference, but the statistic she shared was one I heard frequently from various mental health professionals. In addition, my interlocuters were often reminded about and discussed death when a member at Vista passed away. Susan, Michelle, and other members of Vista would often discuss why individuals with chronic mental illnesses die before the general population; they theorized past traumas, side effects and long-term consequences from the psychiatric medicines they took, poverty, or homelessness.

This "mortality gap" has been noted since the 1930s, when "Benjamin Malzberg, a New York epidemiologist, published a study showing that people with mental illness died, on average, 14 to 18 years earlier than otherwise similar people in the general population" (Rosenbaum 2016, 1585). This mortality gap still exists and may have widened, with some studies suggesting it ranges from 13 to 30 years, is due to mostly medical conditions instead of "unnatural causes" such as accidents or suicide, and is pervasive across the globe (Rosenbaum 2016, 1585). Rosenbaum $(2016,1585)$ writes about the possible reasons why this mortality gap may exist; it could be from certain behaviors more common among people with chronic mental illnesses such as physical inactivity, substance use, and smoking, thus increasing the risk for chronic diseases. In addition, some common psychiatric medications often cause obesity and diabetes, contributing to the burden of heart disease (Rosenbaum 2016, 1585).

Some clinicians have argued for better "integrated care" to confront this mortality gap, addressing both the physical and psychiatric ailments for individuals with severe mental illnesses (Rosenbaum 2016). I propose that stakeholders provide better "integrated advocacy" to address 
the most common challenges individuals with chronic mental illnesses face; that is, address this mortality gap using synergistic activism. Before discussing what I mean by synergistic activism, I will describe the most common syndemic phenomena that affected my interlocuters.

\section{Syndemics in New Orleans}

Syndemics theory is an "explanatory framework for the analysis of disease interactions, including their origins in disease clustering, dynamics of interaction, stages of disease enhancement, and the social conditions that facilitate these processes" (Singer 2009, 227). Introduced by Merrill Singer in the 1990s, the term syndemics was coined "as a new theoretical perspective to understand the synergistic interaction of coexisting diseases and how biological and environmental factors that worsen the complex outcomes of those diseases" in some populations (Hart and Horton 2017, 888). The syndemics concept has three key features: it involves "the clustering of two or more diseases within a population; the biological social, and psychological interaction of those diseases; and the large-scale social forces that precipitate disease clustering in the first place” (Mendenhall 2017, 889). Unlike comorbidities, understanding the effects of social inequities and unjust exercises of power is key to understanding syndemics.

In New Orleans, among my interlocuters, mental illness and substance use co-existed for some, but not all of my research participants. Among older individuals, alcoholism was the main concern my interlocuters faced, but opioid use was also on the rise and becoming a problem in local emergency rooms. For those who did not have substance use issues, weight gain, diabetes, and high blood pressure were prevalent in addition to the symptoms arising from psychiatric ailments. The combination of these ailments itself can explain the mortality gap. 
In addition, the stigma attached to mental illness adds another layer of complexity to seeking mental health services. Many of my interlocuters could not work because of their disabilities. When people from the community would ask them what they did for a living, some would respond that they were disabled. However, unless one is clearly in psychosis, mental illness is not a visible disability like many other physical disabilities, so my interlocuters felt an added shame. At Vista, individuals with mental illness did not feel judged since they were with their peers, but outside of Vista, the lack of understanding about mental illness added stigma and judgements towards individuals with chronic mental illnesses, especially for my black interlocuters.

Because most of my interlocuters received income from SSI or SSDI, they had extremely limited incomes. Some lived with family members or had some form of permanent supportive housing, but many had experienced homelessness, which also impacted their mental health. Furthermore, amongst African American men I interviewed, many had previously been incarcerated. This impacted the types of jobs and housing they could find, often limiting them if they had felony convictions. Some of my interlocuters came to New Orleans after Hurricane Katrina in 2005; it was actually easier for them to receive Permanent Supportive Housing because they were new to the area. However, for those from New Orleans, some endured trauma during and after Hurricane Katrina and had never received appropriate trauma-informed care. Many of the mental health professionals I interviewed understood the deleterious effects stemming from the combination of mental illness, substance use, and physical ailments including diabetes and high blood pressure. In addition, many understood how poverty, incarceration, and stigma about mental illness also impacted how individuals received or accessed mental health services. However, the lapses where mental health professionals could really help individuals 
with chronic mental illnesses often occurred due to constraints from the organization where they worked. For instance, one agency could provide psychosocial rehabilitation services but did not have resources for affordable housing available for those who needed it. Another agency had case managers who knew how to find permanent supportive housing for its clients, but the agency did not have experience with substance use and how to treat clients with substance use issues.

At the macro level, state budget cuts also affect mental health services. Both Susan and Michelle lost their jobs when the contract with Jefferson Parish Human Services Authority ended. With recent budget cuts from the state, funding for many Medicaid programs decreased. By 2018, after I stopped conducting fieldwork, the state budget cuts and the impacts on community mental health programs became more obvious. Vista had to close down its day program two days out of the five-day week. As Lucy, one of the staff members, disclosed to me, this did affect members. While Vista held medicine for members, it does not handle them; members organize their own medicines into their pill boxes to take home. On the two days Vista was now closed for clients (the building remained open for staff), the staff noticed that some members were forgetting to take their medicine. The staff had to be more creative by calling members and asking if they had taken their medicine and doing more fieldwork where they went out to members' homes to check in on them.

Lucy also revealed other patterns of discrimination that impacted members. For instance, the preauthorization for services were getting denied more often for members in the day program. In addition, the budget cuts meant longer waiting lists for hospital beds; Lucy spent the previous year working with one member who was in crisis but kept being triaged for 72 hours at UMC but would then be released even though she was clearly suicidal. With the member's 
brother, Lucy kept contacting the Coroner's Office to get this member committed since she was a danger to herself. After a while, Lucy just started calling another private hospital where she knew the social workers, and when she knew a member of Vista was at UMC, she would pull all the connections she had to get that individual transferred to the private hospital. However, Lucy did not know how much or if the member was being charged for treatment at the private hospital. In addition, Lucy revealed discriminatory policies from the city and state. Some of the members had discounted rates to use public transportation; many did not though. Lucy disclosed that the Regional Transit Authority (RTA), which operates public transportation in New Orleans, no longer counted mental illness as a disability. The difference between paying 40 cents for a oneway fare on the streetcar or bus vs. $\$ 1.25$ is significant for those with limited incomes to begin with. The RTA found a loophole legally where they do not have to count mental illness as a disability, so Vista staff try to get members the lower fare through a physical disability if members have one. Furthermore, food stamps are being denied more frequently. Lucy disclosed that the letters for members will often be dated before the postmark stamp on the envelope, and the letters say something to the effect that because a client missed his/her appointment, s/he would lose access to food stamps. Lucy called the food stamp office and pointed out that the letter was dated before the postmark date; with these schemes, clients missed appointments they did not know about.

Lastly, for those trying to get SSI/SSDI, the case managers I interviewed shared that judges do not often view mental illness as a disability. I hardly met anyone who would qualify on the first try and some spend years waiting for SSI/SSDI. I gave Robin a ride home one day because the weather was horrible; before driving her home, another client at Drop-In was frustrated about his case and whether he would ever get benefits. I asked Robin if she had that 
problem. She replied, "No. But I showed up to my hearing in a wheelchair with a broken hip and a bunch of other broken bones, so that probably made a difference." Robin had attempted suicide in 2012 after jumping out of a window, which is how she broke so many of her bones. She is the only person I know to have received disability benefits on the first try.

With discriminatory policies on so many levels coming from city and state agencies, this medical discrimination feeds into structural discrimination. Susan, who is on Medicare, still works at her job as a cashier at the grocery store. At one point, she mentioned to me, "This is the most stigma-free place I have ever worked." "More than Vista?," I asked. "Well, I don't have to worry about budget cuts at the grocery store." Susan explained how many of the cashiers are actually part-time workers because they also have disabilities, so the managers know they cannot schedule them with too many hours. She also thought her secondary diagnosis of OCD helped her pack the grocery bags well. I complained about my king cake being placed upside down in a bag one day and consequently being ruined. Susan responded, "If you were in my line, I wouldn't make that mistake. I may not be the quickest, but my OCD makes me finicky about placing things correctly." I asked Susan, "Do you tell others about your diagnoses?” After pausing for a second, her response was, "I am not my illness!"

This sentiment was one I heard frequently. Other members at Vista would say something to the effect that it does not matter what you go to a hospital for, you somehow end up in the psychiatric unit. Susan initially had no reason to tell anyone about her disability. At Vista, she ended up in the emergency room one Saturday while she was working at Drop-In. Having experienced a stroke before, she thought she was having the same symptoms. It turned out that she had vertigo, and that was what was making her dizzy. But she also disclosed, "I did not want 
to tell the emergency room doctor about my mental illness because they love saying how everything is psychosomatic. I hate that word."

At the grocery store where Susan works now, she did have to disclose her diagnosis eventually. The co-payment for her Latuda prescription, which she took for her bipolar disorder, was no longer affordable under Medicare. Susan's doctor at Central City switched her to another medicine where she could afford the co-payments, but Susan had no idea how the change in medicine would affect her. "I had to tell some of the other employees, if you notice a change in my behavior, please let me know." If Medicare actually covered the costs of Susan's medications, Susan would not have been placed in that predicament in the first place. If city and state policies did not keep cutting funds for mental health services, Susan would not have to worry so much about her health. Even so, Susan had an advantage over others with a car giving her access to places more than my other interlocuters, her positionality as a white woman, and being able to have a part-time job.

\section{Stigma Syndemics}

My research contributes to the theoretical debates about stigma by using the framework of stigma syndemics. By using this framework, it adds to the political and historical dimensions Tyler and Slater (2018) call for in analyzing stigma. In examining how individuals with chronic mental illnesses navigated the mental healthcare system in New Orleans, my white interlocuters often had more resources and help from their family members. Robin, for example, often relied on her dad who is a physician when her prescription was delayed by her pharmacy. The delay in getting prescriptions filled was something my black interlocuters often faced as well from the

same pharmacy, but they did not have the agency or resources to speed the process. Susan, while she utilized Central City for her psychiatrist, like many of my other interlocuters, was better off 
than my black interlocuters because she had extra income from her part-time job. For many of my black interlocuters, a part-time job was something they wanted but were often prevented from getting. Quentin's previous felony conviction prevented him from finding a job and receiving stable housing. His participation in Mental Health Court created additional burdens for him.

When I asked my interlocuters, "What does recovery mean to you?," the responses also showed a racial difference, as mentioned in Chapter 3. My white interlocuters viewed recovery as a process or journey, knowing their mental illness is not something that will be cured, but understanding to take things day-by-day. In contrast, my black interlocuters, viewed recovery as following orders, staying out of the hospital, and listening to their doctor. Somehow, if they did get rehospitalized, it was their own fault. Given that six out of the 10 black men I had interviewed had been in jail or prison, the notion of "following orders" is not surprising. Even though they had a list of medications and took those medications, when I asked my black interlocuters what the medications were for during the illness and life history interviews, they did not know. This was a sharp contrast from my white interlocuters who could name each medication they took, the dosage, and what the medication was for.

The difference in caregivers, described in Chapter 7, is also blatant. Debra Green, the 69year-old white woman who described her son's illness was one of the few people I interviewed who had the resources and access to get various types of treatment for her son. In contrast, Anita Williams, the 48-year-old African American woman did not have the time, money, or resources to find a stable place for her daughter Diana to live after she was released from the hospital.

When Charity Hospital existed, despite its problems as Jordan mentioned in Chapter 6, it at least did not cost patients, serving as the safety-net hospital for the region. Replaced with 
University Medical Center (UMC) in 2015, which operates as a public-private partnership, the mental health professionals I interviewed at Vista were unsure if members who were hospitalized there would be billed or if their insurance would cover medical costs. Even though Louisiana expanded Medicaid under the Affordable Care Act, the reimbursement rates are so low that many providers do not accept Medicaid. According to an article by The Times-Picayune, one father who sought treatment for his son at UMC for the psychiatric services he received there ended up with a bill for more than $\$ 50,000$ (The Times-Picayune Editorial Board 2018).

\section{Intersectionality and Mental Illness}

Leith Mullings (2005a, 685) urges anthropologists to "name racism and the forces that reproduce it" by confronting "forthrightly the extent to which structural racism is pervasively embedded in our social system." Anthropologists have "the potential to uncover the systemic and dynamic nature of racism and to identify the subterranean mechanisms through which racial hegemony is both perpetuated and deconstructed" (Mullings 2005a, 685). Thus, I discuss race, gender, class, and other axes of identity throughout this dissertation as a response to point out how uneven services are for my black interlocuters, but also to address levels of racism they experienced. My contributions to medical anthropology here come through the framework of examining intersectionality with relation to mental illness. With exceptions such as Jonathan Metzl's book The Protest Psychosis: How Schizophrenia Became a Black Disease (2009) and Emily Martin's article, "Moods and Representations of Social Inequality," in the Gender, Race, Class, \& Health: Intersectional Approaches volume (Schulz and Mullings 2006), few anthropologists have looked closely at the relationship between mental illness, health disparities, and intersectionality. Both of the works above focus on a specific diagnosis: schizophrenia in Metzl's book and bipolar disorder in Martin's article. The purpose of my research was not to 
examine a specific diagnosis, but to examine how intersectionality played out in how individuals sought services, the types of treatment they received, and the health disparities that existed. Race itself is not a risk factor for disease; the effects of systemic racism, however, did create health disparities amongst my research population.

My black interlocuters were more likely to be imprisoned, affecting their ability to get employment or find housing. They have never really received trauma-informed care even though they have experienced various traumas. The city policy from the Regional Transit authority to not count mental illness as a disability hurts this population more, as they depend on public transportation. Their experiences at public behavioral health clinics, like Jordan's, illustrate the racism they have experienced in the past and how many are still distrustful of the mental healthcare system. The black caregivers I interviewed had fewer resources and access to services for their loved ones. Finally, the additional budget cuts by the state mentioned above disproportionately affect the African American community. All of these challenges and constraints affect the health and well-being of individuals with chronic mental illness. As Leith Mullings (2005a, 685) argues, “anthropologists must address the issue of public engagement and praxis. No matter how well we research racism, it will remain largely irrelevant unless we are able to get our analyses out of the academy and into public discourse." How can mental health professionals and other stakeholders work to navigate the challenges communities of color encounter? I propose synergistic activism as a way to address these challenges.

\section{Synergistic Activism}

Following Cone and Martin (2003), Merrill Singer uses the term synergistic enlightenment as the "recognition of the value of taking interdisciplinary approaches and overcoming barriers erected by discipline-centric attitudes” (2009, 227). Synergistic 
enlightenment suggests the cooperation of professionals with training from various disciplines (e.g. anthropology, sociology, public health, psychiatry). I use the term synergistic activism to include individuals who many not necessarily be professionals or trained in a specific discipline to overcome barriers. In the mental health world, especially in New Orleans, individuals who live with chronic mental illnesses may identify as peer support specialists and offer a type of support to other individuals diagnosed with psychiatric disorders in a way mental health professionals and other specialists cannot; in addition, other populations, without specialized training, can play an important role in navigating the mental healthcare system, and these can include family members of individuals with chronic mental illnesses and community health workers.

I use the term activism specifically, instead of enlightenment, because much of grassroots organizing work does not come from working in silos; it is the most effective when coalition building is done to confront issues that affect marginalized communities in activism work, especially in new modes of community that forces people to think as a collective instead of individual terms (Davis 2016, 49). For those who do community organizing work at the grass roots level, they are aware that it is easier for the oppressor to defeat each group off one by one; however, as a coalition, each group is much stronger. Thus, synergistic activism is coalition building to address the most pressing problems of a syndemic phenomenon through integrated activism and advocacy. Amongst those with chronic mental illnesses, these include addressing homelessness, substance use, and incarceration. Because individuals with chronic mental illnesses often face many of these problems, in addition to living with their mental illness, communities can best address these problems at the local level through coalition building. This coalition building can happen at churches where mental health is actually discussed, amongst 
caregivers who are trying to figure out how to get treatment for their loved ones, amongst housing advocates who are dealing with a rising homeless population, amongst prison reform advocates, and other entities who are affected by mental illness in one way or another.

Synergistic activism is different from Community Based-Participatory Research (CBPR), which is the "systematic approach for engaging specially defined groups of people in a process of inquiry and social change" (Roberts 2013, ix) in the sense that much CBPR has already been completed, especially in New Orleans. However, CBPR can lay the foundation for synergistic activism, focusing on activism and advocacy that still needs to take place through coalition building in the community.

In the immediate years after Hurricane Katrina, mental health professionals did come together under the Behavioral Health Action Network (BHAN), a subset of the Louisiana Public Health Institute (LPHI), to assess and monitor psychiatric system needs following Hurricane Katrina. Some of the outcomes of BHAN was the creation of more community based mental health services such as assertive community treatment (ACT) programs and the passage of Nicola's Law, which introduced assisted outpatient treatment (AOT) in Louisiana. While ACT programs have existed in other cities for decades (Estroff 1981), the first ACT program did not exist in New Orleans until after Hurricane Katrina. The creation of these community programs was a step in the right direction, but BHAN disintegrated when its funding from Baptism Community Ministries ended in 2010. Even so, much of its focus only examined psychiatric services. For true synergistic activism, stakeholders need to address the syndemics that affect individuals with chronic mental illnesses; this means looking beyond psychiatric services.

With fewer inpatient psychiatric beds due to disaster capitalism and the neoliberalization of public social services, and fewer affordable housing options, the local jail has now become the 
de facto establishment for individuals with chronic mental illnesses. Formerly called Orleans Parish Prison, the newly built jail is now called Orleans Justice Center, which opened in 2015. In 2017, the New Orleans City Council voted to expand more beds for "mental health" in Orleans Justice Center, so the local jail is now the largest "provider" of mental health services in New Orleans (Orleans Parish Prison Reform Coalition 2018). This combination of fewer affordable housing options and resulting criminalization of mental illness has led to an increasing number of individuals diagnosed with chronic mental illnesses living a nomadic life in New Orleans postKatrina, where they move in between supported housing, jail, hospitals, homeless shelters, and the street, otherwise called "the institutional circuit" (Hopper et al. 1997; Luhrmann 2008). The combination of these forces is more likely to negatively affect the health of the African American community, who are poorer and have fewer resources in New Orleans.

To truly address the syndemics of psychiatric illness, substance use, and physical health problems, mental health stakeholders in New Orleans recognized the need to also focus on housing concerns and the criminal justice system to address the "institutional circuit." One specific example of synergistic activism is when American Can Apartments announced it would evict its low-income tenants, many of whom had disabilities in 2017. The apartment complex was part of low-income tax credit development, where it had a certain number of units for individuals with low-income and received tax credits in return. However, when the complex was bought by new owners, the affordable housing unit tenants had to pay market rate rent or leave. Because of the media coverage received when low-income tenants announced they were being evicted from American Can, community partners from various workgroups of the New Orleans Behavioral Health Council stepped in, including Southeast Louisiana Legal Services and the Louisiana Department of Health, to see if tenants could stay longer or receive permanent 
supportive housing vouchers. The short term solution was for low-income tenants to stay a few months longer in the building. However, they were eventually evicted. Workers from legal services and Permanent Supportive Housing sought to find other housing options for the tenants long-term, but it remains unclear whether that happened. However, when community partners from a coalition work together, the activism work and outcomes are more effective.

\section{Advocacy}

At a panel sponsored by the New Orleans Behavioral Health Council in 2018, a woman from the audience brought up the fact that there are often few advocates for mental health compared to other programs at the state capitol when state legislators revisit the budget each

year. With the way Louisiana's state constitution is structured, when a budget deficit occurs, the areas that are unprotected are higher education and healthcare. Within healthcare, behavioral health services are often the first to face cuts. The woman in the audience who discussed the need for more advocates shared that hundreds of people showed up to the state capitol building to support services affecting people with developmental disabilities, while only five people showed up advocating for mental health services. The New Orleans Behavioral Health Council already has a structure with dozens of community partners in each of its workgroups; if each of those community partners maintained a coalition to advocate for mental health services at the state capitol when the state budget is revisited each year, instead of just those who work in the mental health fields and are already stretched thin, then synergistic activism at its best would take place. With community partners that focus on all the needs of the psychiatric population, not just those that work in mental health fields, the syndemic problems that plague this community may finally be addressed through integrated advocacy. For instance, after Nicola Cotton's death in 2008, state legislators passed Nicola's Law, based on Kendra's Law that exists in New York. 
Nicola's law calls for assisted outpatient treatment (AOT) courts, where a judge would oversee mental health treatment in civil court (The Times-Picayune Editorial Board 2018), for individuals who otherwise get lost in the institutional circuit. However, ever since Nicola's Law was passed in 2008, an assisted outpatient treatment court has not existed in Louisiana. With integrated advocacy, the establishment of AOT courts can exist with steady funding. In the short term, advocates can fight budget cuts that mental health programs seem to face each year in Louisiana. In the long term, the mortality gap that Susan described may actually be reduced. 


\section{APPENDIX A \\ Internalized Stigma of Mental Illness (ISMI) Scale}

(Ritsher, Otilingam, and Grajales 2003)

The instructions for the instrument are as follows: "We are going to use the term 'mental illness' in the rest of this questionnaire, but please think of it as whatever you feel is the best term for it. For each question, please mark whether you strongly disagree (1), disagree (2), agree (3) or strongly agree (4).'”

1

Strongly Disagree

Agree
2

Disagree
3

Agree
4

Strongly

\section{Alienation}

I feel out of place in the world because I have a mental illness.

Having a mental illness has spoiled my life.

People without mental illness could not possibly understand me.

I am embarrassed or ashamed that I have a mental illness.

I am disappointed in myself for having a mental illness.

I feel inferior to others who don't have a mental illness.

\section{Stereotype Endorsement}

Stereotypes about the mentally ill apply to me.

People can tell that I have a mental illness by the way I look.

Mentally ill people tend to be violent.

Because I have a mental illness, I need others to make most decisions for me.

People with mental illness cannot live a good, rewarding life.

Mentally ill people shouldn't get married.

I can't contribute anything to society because I have a mental illness.

\section{Discrimination Experience}

People discriminate against me because I have a mental illness.

Others think that I can't achieve much in life because I have a mental illness.

People ignore me or take me less seriously just because I have a mental illness.

illness.

People often patronize me, or treat me like a child, just because I have a mental

Social Withdrawal

Nobody would be interested in getting close to me because I have a mental illness. illness.

I don't talk about myself much because I don't want to burden others with my mental

I don't socialize as much as I used to because my mental illness might make me look 
or behave 'weird'.

Negative stereotypes about mental illness keep me isolated from the 'normal' World.

I stay away from social situations in order to protect my family or friends from

embarrassment. inadequate.

Being around people who don't have a mental illness makes me feel out of place or

I avoid getting close to people who don't have a mental illness to avoid rejection.

Stigma Resistance (reverse-coded items)

I feel comfortable being seen in public with an obviously mentally ill person.

In general, I am able to live life the way I want to.

I can have a good, fulfilling life, despite my mental illness.

People with mental illness make important contributions to society.

Living with mental illness has made me a tough survivor.

\section{Perceived Devaluation and Discrimination Scale}

(Link 1987, 111)

Note: All items are answered using a 6-point strongly agree (1) to strongly disagree (6) format. In items followed by an (R), the scoring is reversed.

Items in Devaluation-Discrimination Measure

$\begin{array}{llllll}1 & 2 & 3 & 4 & 5 & 6\end{array}$

Strongly Agree $\quad$ Strongly Disagree

1. Most people would willingly accept a former mental patient as a close friend.

2. Most people believe that a person who has been in a mental hospital is just as intelligent as the average person.

3. Most people believe that a former mental patient is just as trustworthy as the average citizen.

4. Most people would accept a fully recovered former mental patient as a teacher of young children in a public school.

5. Most people feel that entering a mental hospital is a sign of personal failure (R).

6. Most people would not hire a former mental patient to take care of their children, even if he or she had been well for some time (R).

7. Most people think less of a person who has been in a mental hospital (R).

8. Most employers will hire a former mental patient if he or she is qualified for the job. 
9. Most employers will pass over the application of a former mental patient in favor of another applicant $(\mathrm{R})$.

10. Most people in my community would treat a former mental patient just as they would treat anyone.

11. Most young women would be reluctant to date a man who has been hospitalized for a serious mental disorder $(\mathrm{R})$.

12. Once they know a person was in a mental hospital, most people will take his opinions less seriously (R). 


\begin{abstract}
APPENDIX B initial illness narratives I conducted:

- What do you call this problem?

- What do you believe is the cause of this problem?

- What course do you expect it to take? How serious is it?

- What do you think this problem does inside your body?

- How does it affect your body and your mind?

- What do you most fear about this condition?

- What do you most fear about the treatment?
\end{abstract}

Questions for the Explanatory Models Approach (Kleinman and Benson 2006, 1674) for the 


\section{APPENDIX C}

\section{Questions for the McGill Illness Narrative Interview (MINI)}

Danielle Groleau, Allan Young, \& Laurence J. Kirmayer. 2006. "The McGill Illness

Narrative Interview (MINI): An Interview Schedule to Elicit Meanings and Modes of Reasoning Related to Experience.” Transcultural Psychiatry 43 (4): 671-691.

\section{Section 1. INITIAL ILLNESS NARRATIVE}

1. When did you experience your health problem or difficulties (HP) for the first time? [Substitute respondent's terms for 'HP' in this and subsequent questions.] [Let the narrative go on as long as possible, with only simple prompting by asking, 'What happened then? And then?']

2. We would like to know more about your experience. Could you tell us when you realized you had this (HP)?

3. Can you tell us what happened when you had your (HP)?

4. Did something else happen? [Repeat as needed to draw out contiguous experiences and events.]

5. If you went to see a helper or healer of any kind, tell us about your visit and what happened afterwards.

6. If you went to see a doctor, tell us about your visit to the doctor/hospitalization and about what happened afterwards.

6.1 Did you have any tests or treatments for your (HP)? [The relevance of this question depends on the type of health problem.]

\section{Section 2. PROTOTYPE NARRATIVE}

7. In the past, have you ever had a health problem that you consider similar to your current (HP)? [If answer to \#7 is Yes, then ask Q.8]

8. In what way is that past health problem similar to or different from your current (HP)?

9. Did a person in your family ever experience a health problem similar to yours? [If answer to \#9 is Yes, then ask Q.10]

10. In what ways do you consider your (HP) to be similar to or different from this other person's health problem?

11. Did a person in your social environment (friends or work) experience a health problem similar to yours? [If answer to \#11 is Yes, then ask Q.12] 
12. In what ways do you consider your (HP) to be similar to or different from this other person's health problem?

13. Have you ever seen, read or heard on television, radio, in a magazine, a book or on the Internet of a person who had the same health problem as you? [If answer to \#13 is Yes, then ask Q.14]

14. In what ways is that person's problem similar to or different from yours?

\section{Section 3. EXPLANATORY MODEL NARRATIVE}

15. Do you have another term or expression that describes your (HP)?

16. According to you, what caused your (HP)? [List primary cause(s).]

16.1 Are there any other causes that you think played a role? [List secondary causes.]

17. Why did your (HP) start when it did?

18. What happened inside your body that could explain your (HP)?

19. Is there something happening in your family, at work or in your social life that could explain your health problem? [If answer to \#19 is Yes, then ask Q.20]

20. Can you tell me how that explains your health problem?

21. Have you considered that you might have [INTRODUCE POPULAR SYMPTOM OR

ILLNESS LABEL]?

22. What does [POPULAR LABEL] mean to you?

23. What usually happens to people who have [POPULAR LABEL]?

24. What is the best treatment for people who have [POPULAR LABEL]?

25. How do other people react to someone who has [POPULAR LABEL]?

26. Who do you know who has had [POPULAR LABEL]?

27. In what ways is your (HP) similar to or different from that person's health problem? 28. Is your (HP) somehow linked or related to specific events that occurred in your life? 29. Can you tell me more about those events and how they are linked to your (HP)?

\section{Section 4. SERVICES AND RESPONSE TO TREATMENT}

30. During your visit to the doctor (healer) for your HP, what did your doctor (healer) tell you that your problem was?

31. Did your doctor (healer) give you any treatment, medicine or recommendations to follow? [List all]

32. How are you dealing with each of these recommendations? [Repeat $Q .33$ to $Q .36$ as needed for every recommendation, medicine and treatment listed.]

33. Are you able to follow that treatment (or recommendation or medicine)?

34. What made that treatment work well?

35 . What made that treatment difficult to follow or work poorly?

36. What treatments did you expect to receive for your (HP) that you did not receive? 37 . What other therapy, treatment, help or care have you sought out?

38. What other therapy, treatment, help or care would you like to receive? 


\section{Section 5. IMPACT ON LIFE}

39. How has your (HP) changed the way you live?

40. How has your (HP) changed the way you feel or think about yourself?

41. How has your (HP) changed the way you look at life in general?

42. How has your (HP) changed the way that others look at you?

43. What has helped you through this period in your life?

44. How have your family or friends helped you through this difficult period of your life?

45. How has your spiritual life, faith or religious practice helped you go through this difficult period of your life?

46. Is there anything else you would like to add? 


\section{APPENDIX D}

\section{Sample Instrument for Evaluating Decisional Capacity}

1. What is the purpose of the study that was just described to you?

\begin{tabular}{|l|l|l|l|}
\hline Response (Study dependent) & Score: & 0 & 1
\end{tabular}

2. What makes you want to consider participating in this study?

Response (Partly Study dependent) Score: 1001

3. Do you have to be in this study if you don't want to participate? Response $(1=$ No $)$ Score: 10 0 1

4. Can you withdraw from this study at any time? Response $(1=Y e s)$ Score: 001

5. Please describe one thing that will happen to people who decide to be in this study. Response (1=interviewed) Score: $10 \mid 1$

6. Please describe one risk or discomfort you may experience if you participate in this study. \begin{tabular}{|l|l|l|l|}
\hline Response (1=breach of confidentiality or distress from questions) & Score: & 0 & 1
\end{tabular}

7. Please describe one way that people might benefit if they participate in this study. Response (partly study dependent) Score: 1001

8. Is it possible that being in this study won't have any direct benefit to you? Response $(1=$ Yes $)$ Score: 1001

9. Where can you find the phone numbers of the people to contact if you have questions? Response ( 1 = In the consent form) Score: 0011

Table 8: Sample Instrument for Evaluating Decisional Capacity

This instrument is modified from the UCSD Human Research Protections Program (2012) Decisional Capacity Assessment Instrument Samples. 


\section{BIBLIOGRAPHY}

Adams, Vincanne. 2013. Markets of Sorrow, Labors of Faith: New Orleans in the Wake of Katrina. Durham: Duke University Press.

Adams, Vincanne, Taslim Van Hattum, and Diana English. 2009. "Chronic Disaster Syndrome: Displacement, Disaster Capitalism, and the Eviction of the Poor from New Orleans." American Ethnologist 36 (4): 615-636.

Alexander, Michelle. 2010. The New Jim Crow: Mass Incarceration in the Age of Colorblindness. New York: The New Press.

Anand, Sudhir, and Kara Hanson. 1997. "Disability-Adjusted Life Years: A Critical Review." Journal of Health Economics 16 (6): 685-702.

APA (American Psychiatric Association). 2013. The Diagnostic and Statistical Manual of Mental Disorders: DSM-5. Arlington, VA: American Psychiatric Publishing.

Arcury, Thomas, and Sara Quandt. 1999. "Participant Recruitment for Qualitative Research: A Site-Based Approach to Community Research in Complex Societies." Human Organization 58 (2): 128-133.

Baker, Lee D. 1998. From Savage to Negro: Anthropology and the Construction of Race, 18961954. Berkeley: University of California Press.

Barrett, Robert J. 1996. The Psychiatric Team and the Social Definition of Schizophrenia: An Anthropological Study of Person and Illness. Cambridge: Cambridge University Press.

Becker, Anne E. 2007. "Culture and Eating Disorders Classification." International Journal of Eating Disorders 40: S111-S116.

Benedict, Ruth. 1942. Race and Racism. London: George Routledge \& Sons.

Benedict, Ruth 1982. Race: Science and Politics. Revised edition. Westport: Greenwood Press. First Published 1940.

Benedict, Ruth and Margaret Mead. 1959. "Race Prejudice in the United States." In An Anthropologist at Work: Writings of Ruth Benedict, 358-360. Boston: Houghton Mifflin Company. 
Berchick, Edward R., Emily Hood, and Jessica C. Barnett. 2018. "Health Insurance Coverage in the United States: 2017 Current Population Reports." Accessed February 22, 2019. https://www.census.gov/content/dam/Census/library/publications/2018/demo/p60264.pdf

Bernard, H. Russell. 2011. Research Methods in Anthropology: Qualitative and Quantitative Approaches, Fifth edition. Lanham: AltaMira Press.

Bhavsar, Vishal and Dinesh Bhugra. 2018. "Violence Towards People with Mental Illness: Assessment, Risk Factors, and Management." Psychiatry and Clinical Neurosciences 72: 811-820. doi:10.1111/pcn.12775

Boas, Franz. 1940. Race, Language, and Culture. New York: The Free Press.

Brereton, Elinor J. 2018. Psychotropic Medications and Children: Perceptions of Mental Health Professionals. Master's thesis, University of Denver. ProQuest (10825046).

Brodwin, Paul. 2013 Everyday Ethics: Voices from the Front Line of Community Psychiatry. Berkeley: University of California Press.

Brohan, Elaine, Mike Slade, Sarah Clement, and Graham Thornicroft. 2010. "Experiences of Mental Illness Stigma, Prejudice, and Discrimination: A Review of Measures.” BMC Health Services Research 10 (80): 1-11.

Burton, Dawn. 2009. "'Reading' Whiteness in Consumer Research.” Consumption Markets and Culture 12 (2): 171-201.

Calderón-Abbo, José. 2008. “The Long Road Home: Rebuilding Public Inpatient Psychiatric Services in Post-Katrina New Orleans.” Psychiatric Services 59 (3): 304-309.

Carpenter-Song, Elizabeth. 2011. "Recognition in Clinical Relationships." In Shattering Culture: American Medicine Responds to Cultural Diversity, edited by Mary-Jo DelVecchio Good, Sarah S. Willen, Seth Donal Hannah, Ken Vickery, and Lawrence Taeseng Park, 168-183. New York: Russell Sage Foundation.

Carter, Rebecca Louise. 2014. "Valued Lives in Violent Places: Black Urban Placemaking at a Civil Rights Memorial in New Orleans.” City \& Society 26 (2): 239-261.

Carter, Rebecca Louise. 2018. "Life-in-Death: Raising Dead Sons in New Orleans.” Ethnos 83 (4): 683-705.

Census FactFinder. 2017. “Community Facts.” Accessed January 19, 2019. https://factfinder.census.gov/faces/nav/jsf/pages/community_facts.xhtml 
Chen, Jun Mian. 2017. “The Contentious Field of Whiteness Studies." Journal for Social Thought 2 (1): 15-27.

Clark, Carrie, Catherine C. Classen, Anne Fourt, and Maithili Shetty. 2015. "Understanding Trauma and Trauma-Informed Care: The Basics." In Treating the Trauma Survivor: An Essential Guide to Trauma-Informed Care, 5-10. New York: Routledge.

Collins, Patricia Hill. 2000. Black Feminist Thought: Knowledge, Consciousness, and the Politics of Empowerment. New York: Routledge.

Cone, Richard and Emily Martin. 2003. "Corporal Flows: The Immune System, Global Economies of Food, and New Implications for Health." In Social and Cultural Lives of Immune Systems, edited by J. Wilce Jr., 232-266. New York: Routledge.

Consent Decree Monitors. 2019. "Consent Decree Monitor: New Orleans, Louisiana." Accessed February 23, 2019. http://consentdecreemonitor.com/

Coroner Involuntary Commitment. 2018. "Mental Health.” Accessed September 13, 2018. http://neworleanscoroner.com/mental-health/

Corrigan, Patrick W. and Amy C. Watson. 2002. "The Paradox of Self-Stigma and Mental Illness." Clinical Psychology: Science and Practice 9 (1): 35-53.

Crenshaw, Kimberlé. 1989. "Demarginalizing the Intersection of Race and Sex: A Black Feminist Critique of Antidiscrimination Doctrine, Feminist Theory and Antiracist Politics." University of Chicago Legal Forum, 139: 57-80.

Crocker, J., B. Major, and C. Steele. 1998. "Social Stigma." In Handbook of Social Psychology, edited by D.S. Fiske, D. Gilbert, and G. Lindzey, 504-553. Boston: McGraw-Hill.

Csordas, Thomas J., and Arthur Kleinman. 1996. “The Therapeutic Process.” In Medical Anthropology: Contemporary Theory and Method, Revised Edition, edited by Carolyn F. Sargent and Thomas M. Johnson, 3-20. Westport: Praeger.

Cure Stigma. 2018. "Cure Stigma Quiz." National Alliance on Mental Illness website. Accessed July 5, 2018. https://www.curestigma.org/

Davis, Angela Y. 1981. Women, Race, and Class. New York: Random House.

Davis, Angela Y. 2016. Freedom is a Constant Struggle: Ferguson, Palestine, and the Foundations of a Movement, edited by Frank Barat. Chicago: Haymarket Books.

DeBerry, Jarvis. 2015. "Mental Illness Can Push Even the Brightest People into Homelessness." nola.com website, July 14. Accessed July 30, 2018. https://www.nola.com/opinions/2015/07/homeless_mentally_ill.html 
DeBerry, Jarvis. 2015. "How Easy Is It for People of Color to Get Mental Health Treatment in New Orleans?" nola.com website, July 21. Accessed July 30, 2018. https://www.nola.com/health/index.ssf/2015/07/mental_health_new_orleans.html

Desjarlais, Robert. 1997. Shelter Blues: Sanity and Selfhood Among the Homeless. Philadelphia: University of Pennsylvania Press.

Desjarlais, Robert, Leon Eisenberg, Byron Good, and Arthur Kleinman, eds. 1995. World Mental Health: Problems and Priorities in Low-Income Countries. Oxford: Oxford University Press.

DiAngelo, Robin. 2018. White Fragility: Why It's so Hard for White People to Talk about Racism. Boston: Beacon Press.

Eaton, Leslie. 2008. “Officer's Slaying Leaves New Orleans Asking Why.” The New York Times website, January 31. Accessed February 24, 2019.

https://www.nytimes.com/2008/01/31/us/31shooting.html

Estroff, Sue E. 1981. Making It Crazy: An Ethnography of Psychiatric Clients in an American Community. Berkeley: University of California Press.

Fanon, Frantz. 1991. Black Skins, White Masks. Boston: Grove Press.

Filosa, Gwen. 2007. "Live Updates on Demolition Vote from Council Chambers." The TimesPicayune website, December 19. Accessed August 22, 2018. https://www.nola.com/news/index.ssf/2007/12/city_hall_girds_for_public hou.html

Filosa, Gwen. 2010. "Man Who Killed New Orleans Police Officer Nicola Cotton Ruled 'Incompetent,' Will Not Stand Trial." The Times-Picayune website, September 29. Accessed February 24, 2019. https://www.nola.com/crime/2010/09/man_who_killed_new_orleans_pol.html

Finley, Erin P. 2011. Fields of Combat: Understanding PTSD Among Veterans of Iraq and Afghanistan. Ithaca: Cornell University Press.

Foucault, Michel. 1988. Madness and Civilization: A History of Insanity in the Age of Reason. Translated by Richard Howard. New York: Vintage Books. First Published 1965.

Glustrom, Alexander, dir. 2014. Big Charity: The Death of America's Oldest Hospital. New Orleans. DVD.

Goffman, Erving. 1963. Stigma: Notes on the Management of Spoiled Identity. Englewood Cliffs: Prentice-Hall.

Gotham, Kevin Fox and Miriam Greenberg. 2008. "From 9/11 to 8/29: Post-Disaster Recovery and Rebuilding in New York and New Orleans. Social Forces 87 (2): 1041-1062. 
Gould, Stephen Jay. 1981. "American Polygeny and Craniometry before Darwin.” In The Mismeasure of Man, 30-72. New York: Norton.

Gravlee, Clarence C., and Elizabeth Sweet. 2008. "Race, Ethnicity, and Racism in Medical Anthropology, 1977-2002.” Medical Anthropology Quarterly 22 (1): 27-51.

Groleau, Danielle, Allan Young, A., and Laurence J. Kirmayer. 2006. "The McGill Illness Narrative Interview (MINI): An Interview Schedule to Elicit Meanings and Modes of Reasoning Related to Experience." Transcultural Psychiatry 43 (4): 671-691.

Guarnaccia, Peter. 2009. "Methodological Challenges in Research on the Determinants of Minority Mental Health and Wellness." In Determinants of Minority Mental Health, edited by Sana Loue and Martha Sajatovic, 365-386. New York: Springer.

Hannah, Seth Donal. 2011. "Clinical Care in Environments of Hyperdiversity." In Shattering Culture: American Medicine Responds to Cultural Diversity, edited by Mary-Jo DelVecchio Good, Sarah S. Willen, Seth Donal Hannah, Ken Vickery, and Lawrence Taeseng Park, 35-69. New York: Russell Sage Foundation.

HANO (Housing Authority of New Orleans). 2018. "Housing Choice Voucher Program." Accessed August 22, 2018. http://www.hano.org/housing/hcvp.aspx

Harrison, Faye V. 1995. "The Persistent Power of 'Race' in the Cultural and Political Economy of Racism." Annual Review of Anthropology 24: 47-74.

Harrison, Faye V. 1999. "Introduction: Expanding the Discourse on 'Race."' American Anthropologist 100 (3): 609-631.

Hellebuyck, Michele, Madeline Halpern, Theresa Nguyen, and Danielle Fritze. 2018. "The State of Mental Health in America." Mental Health America, Inc. Accessed April 13, 2019. http://www.mentalhealthamerica.net/issues/mental-health-america-printed-reports

Heckert, Carina. 2018. Fault Lines of Care: Gender, HIV, and Global Health in Bolivia. New Brunswick: Rutgers University Press.

Hopper, Kim, John Jost, Terry Hay, Susan Welber, and Gary Haugland. 1997. "Homelessness, Severe Mental Illness, and the Institutional Circuit." Psychiatric Services 48 (5): 659665.

HUD (Department of Housing and Urban Development). 2015. "Homeless Emergency Assistance and Rapid Transition to Housing: Defining 'Chronically Homeless." Federal Register 80 (233): 75791-75792. Accessed August 20, 2018: https://www.gpo.gov/fdsys/pkg/FR-2015-12-04/pdf/2015-30473.pdf

HUD Exchange. 2018. “Continuum of Care (CoC) Program.” Accessed August 22, 2018. https:/www.hudexchange.info/programs/coc/ 
Insel, Thomas. 2013. "Post by Former NIMH Director Thomas Insel: Transforming Diagnosis." NIMH website, April 29. Accessed April 14, 2019. https://www.nimh.nih.gov/about/directors/thomas-insel/blog/2013/transformingdiagnosis.shtml

JPHSA (Jefferson Parish Human Services Authority). 2019. "Jefferson Parish Human Services Authority." Accessed February 22, 2019. https://www.jphsa.org/

Kleinman, Arthur. 1988. The Illness Narratives: Suffering, Healing, and the Human Condition. New York: Basic Books.

Kleinman, Arthur, and Peter Benson. 2006. "Anthropology in the Clinic: The Problem of Cultural Competency and How to Fix It." PLoS Medicine 3 (10): e294.

Kohrt, Brandon A. and Emily Mendenhall. 2015. "Introduction: Anthropological Perspectives on Global Mental Health.” In Global Mental Health: Anthropological Perspectives, edited by Brandon A. Kohrt and Emily Mendenhall, 13-17. Walnut Creek: Left Coast Press, Inc.

Kohrt, Brandon A, Emily Mendenhall, and Peter J. Brown. 2015. "Historical Background: Medical Anthropology and Global Mental Health.” In Global Mental Health: Anthropological Perspectives, edited by Brandon A. Kohrt and Emily Mendenhall, 1935. Walnut Creek: Left Coast Press, Inc.

LeBel, Thomas P. 2008. "Perceptions of and Responses to Stigma." Sociology Compass 2 (2): 409-432.

Leibing, Annette and Lawrence Cohen, eds. 2006. Thinking About Dementia: Culture, Loss, and the Anthropology of Senility. New Brunswick: Rutgers University Press.

Lester, Rebecca J. 2013. "Lessons from the Borderline: Anthropology, Psychiatry, and the Risks of Being Human." Feminism \& Psychology 23 (1): 70-77.

Lévi-Strauss, Claude. 1963. “The Sorcerer and His Magic.” In Structural Anthropology, Vol. 1, Translated by Claire Jacobson. New York: Basic Books.

Link, Bruce G. 1987. "Understanding Labeling Effects in the Area of Mental Disorders: An Assessment of the Effects of Expectations of Rejection. American Sociological Review 52 (1): 96-112.

LLAC. 2018. "Our History: Louisiana Language Access Coalition.” Accessed July 3, 2018. https://lalanguageaccesslatinoforum.wordpress.com/about/ 
Louisiana Department of Health. 2010. "DHH Secretary, Advocacy Groups, Human Service Leaders Celebrate Mental Health Transformation: New Mental Health Care Clinics Opened in New Orleans." Office of Behavioral Health website, March 11. Accessed April 13, 2019. http://ldh.la.gov/index.cfm/newsroom/detail/245

Louisiana Department of Health. 2018. "Permanent Supportive Housing (PSH)." Accessed August 22, 2018. http://ldh.la.gov/index.cfm/page/1732

Louisiana State Legislature. n.d. "RS 28:53.” Accessed April 13, 2019. http://legis.la.gov/Legis/Law.aspx?d=85245

Lovell, Anne M. 2011. "Debating Life After Disaster: Charity Hospital Babies and Bioscientific Futures in Post-Katrina New Orleans.” Medical Anthropology Quarterly 25 (2): 254-277.

Lovell, Anne M. 2014. "Reformers, Preservationists, Patients and Planners: Embodied Histories and Charitable Populism in the Post-Disaster Controversy over a Public Hospital.” In Hurricane Katrina in Transatlantic Perspective, edited by Romain Huret and Randy Sparks, 100-120. Baton Rouge: LSU Press.

LSBSWE (Louisiana State Board of Social Work Examiners). 2018. "Licensee Info." Accessed August 1, 2018. https://www.labswe.org/

Luhrmann, Tanya Marie. 2000. Of Two Minds: The Growing Disorder in American Psychiatry. New York: Alfred A. Knopf.

Luhrmann, Tanya Marie. 2008. “The Street Will Drive You Crazy”: Why Homeless Psychotic Women in the Institutional Circuit in the United States Often Say No to Offers of Help." American Journal of Psychiatry 165 (1): 15-20.

Martin, Emily. 2006. "Moods and Representations of Social Inequality." In Gender, Race, Class and Health: Intersectional Approaches, edited by Amy Schulz and Leith Mullings, 6088. San Francisco: Jossey-Bass.

Martin, Emily. 2007. Bipolar Expeditions: Mania and Depression in American Culture. Princeton: Princeton University Press.

Martin, Marilyn. 2002. Saving Our Last Nerve: The Black Woman's Path to Mental Health. Roscoe: Hilton Publishing.

McCall, Leslie. 2005. "The Complexity of Intersectionality.” Signs 30 (3): 1771-1800. 
McCoy, Terrence. 2015. "The Homeless Man Who Went to Harvard Law with John Roberts." The Washington Post website, July 13. Accessed July 30, 2018. https://www.washingtonpost.com/local/social-issues/the-homeless-man-who-graduatedfrom-harvard-law-school-with-chief-justice-john-roberts/2015/07/13/63257b5c-20ca11e5-bf41c23f5d3face1_story.html?postshare $=2511436851494187 \&$ utm term $=.944 \mathrm{~b} 25 \mathrm{cfc} 4 \mathrm{ec}$

Mehmood, Saira A. 2010. "An Assessment of Inpatient Psychiatric Beds in the New Orleans Metropolitan Area." Report prepared for the City of New Orleans.

Mehmood, Saira A. 2018. "The Fallacy of Equating Gun Violence with Mental Illness.” Anthropology News website, June 25, 2018. DOI: 10.1111/AN.892

Mehmood, Saira A. forthcoming. "Using Ethnographic Methods to Determine Capacity to Consent amongst Individuals Diagnosed with Chronic Mental Illnesses." In Research Involving Participants with Cognitive Disabilities and Differences: Ethics, Autonomy, Inclusion, and Innovation, edited by Ariel Cascio and Eric Racine. Oxford: Oxford University Press.

Mendenhall, Emily. 2012. Syndemic Suffering: Social Suffering, Depression, and Diabetes Among Mexican Immigrant Women. Walnut Creek: Left Coast Press Inc.

Mendenhall, Emily. 2017. "Syndemics: A New Path for Global Health Research." The Lancet. 389 (10072): 889-891.

Merriam, Sharan B., Juanita Johnson-Bailey, Ming-Yeh Lee, Youngwha Kee, Gabo Ntseane, and Mazanah Muhamad. 2001. "Power and Positionality: Negotiating Insider/Outsider Status Within and Across Cultures." International Journal of Lifelong Education 20 (5): 405416.

Metzl, Jonathan M. 2009. The Protest Psychosis: How Schizophrenia Became a Black Disease. Boston: Beacon Press.

MHA (Mental Health America). 2019. “Who We Are.” Accessed April 14, 2019. https://www.mentalhealthamerica.net/who-we-are

MHSD. 2019a. Metropolitan Human Services District “About Us.” Accessed February 22, 2019. https://www.mhsdla.org/about-us/

MHSD. 2019b. Metropolitan Human Services District "Contact Us.” Accessed February 22, 2019. https://www.mhsdla.org/contact-us/

Mohanty, Chandra Talpade. 1991. "Introduction." In Third World Women and the Politics of Feminism, edited by Chandra Talpade Mohanty, Ann Russo, and Lourdes Torres, 1-47. Bloomington: Indiana University Press. 
Moller, Jan. 2009. "Louisiana Has Budget Surplus after All.” The Times-Picayune website, October 17. Accessed May 7, 2019. https://www.nola.com/politics/2009/10/louisiana_has_budget_surplus_a.html

Mowbray, Carol, Lisa Lewandowski, Mark Holter, and Deborah Bybee. 2006. "The Clubhouse as an Empowering Setting." Health and Social Work 31 (3): 167-79.

Mukhopadhyay, Carol C. and Yolanda T. Moses. 1997. "Reestablishing 'Race' in Anthropological Discourse.” American Anthropologist 99 (3): 517-533.

Mullings, Leith. 2002. "The Sojourner Syndrome: Race, Class, and Gender in Health and Illness." Voices 6 (1): 32-36.

Mullings, Leith. 2005a. "Interrogating Racism: Toward an Antiracist Anthropology." Annual Review of Anthropology 34: 667-693.

Mullings, Leith. 2005b. "Resistance and Resilience: The Sojourner Syndrome and the Social Context of Reproduction in Central Harlem.” Transforming Anthropology 13 (2): 79-91.

Mullings, Leith. 2006. "Resistance and Resilience: The Sojourner Syndrome and the Social Context of Reproduction in Central Harlem." In Gender, Race, Class and Health: Intersectional Approaches, edited by Amy Schulz and Leith Mullings, 345-370. San Francisco: Jossey-Bass.

Mullings, Leith and Amy Schulz. 2006. "Intersectionality and Health: An Introduction." In Gender, Race, Class and Health: Intersectional Approaches, edited by Amy Schulz and Leith Mullings, 3-20. San Francisco: Jossey-Bass.

Myers, Neely Laurenzo. 2015. Recovery's Edge: An Ethnography of Mental Health Care and Moral Agency. Nashville: Vanderbilt University Press.

NAMI (National Alliance on Mental Illness). 2018. "Bebe Moore Campbell National Minority Mental Health Awareness Month.” Accessed July 30, 2018. https://www.nami.org/GetInvolved/Awareness-Events/Minority-Mental-Health-Awareness-Month/Learn-AboutMinority-Mental-Health-Month

NAMI (National Alliance on Mental Illness). 2019. “About NAMI.” Accessed April 14, 2019. https://www.nami.org/About-NAMI

NHPD (National Housing Preservation Database). 2018. "About the Database." Accessed September 10, 2018. https://preservationdatabase.org/about-the-database/

NOBHC (New Orleans Behavioral Health Council). 2018. "Behavioral Health Council." Accessed August 1, 2018. https://www.nola.gov/health-department/behavioralhealth/behavioral-health-council/ 
OBH (Office of Behavioral Health). 2018a. "About the Office of Behavioral Health.” Accessed August 1, 2018. http://ldh.la.gov/index.cfm/page/94

OBH (Office of Behavioral Health). 2018b. "Mental Health Services." Accessed August 1, 2018. http://ldh.la.gov/index.cfm/page/97

O'Nell, Theresa DeLeane. 1996. Disciplined Hearts: History, Identity, and Depression in an American Indian Community. Berkeley: University of California Press.

OPPRC (Orleans Parish Prison Reform Coalition). 2018. "No Jail Expansion: 1,438 Bed Cap." Accessed August 1, 2018. https://opprcnola.org/bedcap/

Ortner, Sherry B. 1998. "Identities: The Hidden Life of Class." Journal of Anthropological Research 54 (1): 1-17.

Politico. 2016. "2016 Louisiana Presidential Election Results." Politico website, December 13. Accessed April 14, 2019. https://www.politico.com/2016election/results/map/president/louisiana/

PSH Program Application. 2018. "Permanent Supportive Housing (PSH) Program Application." Accessed August 22, 2018. http://ldh.la.gov/assets/docs/OAAS/PSH/PSHApplication.pdf

Rabaka, Reiland. 2010. Africana Critical Theory: Reconstructing the Black Radical Tradition, from W. E. B. Du Bois and C. L. R. James to Frantz Fanon and Amilcar Cabral. Lanham: Lexington Books.

Ritsher, Jennifer Boyd, Poorni G. Otilingam, and Monica Grajales. 2003. "Internalized Stigma of Mental Illness: Psychometric Properties of a New Measure.” Psychiatry Research 121 (1): 31-49.

Rhodes, Lorna A. 1991. Emptying Beds: The Work of an Emergency Psychiatric Unit. Berkeley: University of California Press.

Roberts, Laura Weiss. 2013. Community-Based Participatory Research for Improved Mental Healthcare: A Manual for Clinicians and Researchers. New York: Springer.

Robinson, Cedric J. 2000. Black Marxism: The Making of the Black Radical Tradition. $2^{\text {nd }}$ Edition. Chapel Hill: The University of North Carolina Press.

Rosenbaum, Lisa. 2016. "Closing the Mortality Gap-Mental Illness and Medical Care." The New England Journal of Medicine 375 (16): 1585-1589.

Sacks, Karen Brodkin. 1989. “Toward a Unified Theory of Class, Race, and Gender.” American Ethnologist 16(3): 534-550. 
Sayre, Katherine. 2016. "Low-Income Housing Advocates Demand Stop to American Can Evictions." nola.com website, December 22. Accessed August 22, 2018. https://www.nola.com/business/index.ssf/2016/12/housing_advocates_demand_a_sto.htm 1

Sayre, Katherine. 2018a. "New Shelter to Open for New Orleans' Homeless, but Advocates Want More Services." nola.com website, March 22. Accessed August 22, 2018. https://expo.nola.com/erry-2018/03/76c8c6c4b0/new_homeless_shelter_to_open_d.html

Sayre, Katherine. 2018b. "Louisiana's Mental Health Care System Is Broken. Here's How We Got Here." nola.com website, September 12. Accessed December 10, 2018. https://expo.nola.com/news/erry-2018/09/75833429e32870/louisianas-mental-healthcare.html

Schulz, Amy J. and Leith Mullings, editors. 2006. Gender, Race, Class, and Health: Intersectional Approaches. San Francisco: Jossey-Boss.

Singer, Merrill. 2009. Introduction to Syndemics: A Critical Systems Approach to Public and Community Health. San Francisco: Jossey-Bass.

Singer, Merrill, Ostrach, Baylor and Shir Lerman. 2017. "Introduction.” In Stigma Syndemics: New Directions in Biosocial Health, edited by Bayla Ostrach, Shir Lerman, and Merrill Singer, vii-xii. Lanham: Lexington Books.

Smedley, Audrey. 1998. “'Race' and the Construction of Human Identity.” American Anthropologist 100 (3): 690-702.

Smith-Morris, Carolyn, ed. 2016. Diagnostic Controversy: Cultural Perspectives on Competing Knowledge in Healthcare. New York: Routledge.

Solórzano, Daniel G. and Tara J. Yosso. 2002. "Critical Race Methodology: Counter-Storytelling as an Analytical Framework for Education Research." 8 (1): 23-44.

Sussman, Robert W. 1999. "Preface in Contemporary Issues Forum: Race and Racism." American Anthropologist 100 (3): 607-608.

The Times-Picayune Editorial Board. 2018. "Louisiana Is Failing Families Dealing with Mental Illness. nola.com website, September 16. Accessed April 15, 2019. https://www.nola.com/opinions/2018/09/fragile_state_mental_health.html

Tyler, Imogen, and Tom Slater. 2018. "Rethinking the Sociology of Stigma." The Sociological Review Monographs 66 (4): 721-743.

UCSD Human Research Protections Program. n.d. "Decision Making Capacity Guidelines." Accessed June 6, 2012: http://irb.ucsd.edu/decisional.shtml 
UMC (University Medical Center). 2019. “Adult Inpatient Services.” Accessed April 25, 2019: https://www.umcno.org/programs-services/behavioral-health-services/adult-inpatientservices/

UNITY. 2019. "Unity of Greater New Orleans: Mission.” Accessed April 3, 2019. https://unitygno.org/about-us/mission-history/

U.S. Department of Labor. n.d. "Voluntary Self-Identification of Disability." Accessed September 12, 2018. https://www.dol.gov/ofccp/regs/compliance/sec503/Self ID_Forms/VoluntarySelfID_CC-305_ENG_JRF_QA_508c.pdf

VAYLA. 2018. "VAYLA New Orleans: Mission Statement”. Accessed July 13, 2018. https://www.vayla-no.org/about.html

Willen, Sarah S. 2011. "Clinician-Patient Matching." In Shattering Culture: American Medicine Responds to Cultural Diversity, edited by Mary-Jo DelVecchio Good, Sarah S. Willen, Seth Donal Hannah, Ken Vickery, and Lawrence Taeseng Park, 112-130. New York: Russell Sage Foundation.

Wiseman, Jacqueline P. 1970. Stations of the Lost: The Treatment of Skid Row Alcoholics. Englewood Cliffs: Prentice-Hall.

Yang, Lawrence Hsin, Arthur Kleinman, Bruce Link, Jo C. Phelan, Sing Lee, and Bryon Good. 2007. "Culture and Stigma: Adding Moral Experience to Stigma Theory." Social Science and Medicine 64 (7): 1524-1535. 